\title{
Anti-AIDS agents 86. Synthesis and anti-HIV evaluation of 2',3'- seco-3'-nor DCP and DCK analogues
}

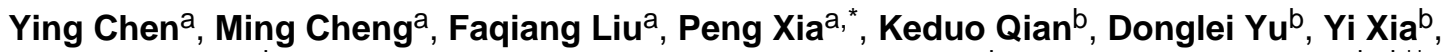 \\ Zheng-Yu Yang ${ }^{b}$, Chin-Ho Chen ${ }^{c}$, Susan L. Morris-Natschke ${ }^{b}$, and Kuo-Hsiung Lee ${ }^{b, d,{ }^{* *}}$ \\ aDepartment of Medicinal Chemistry, School of Pharmacy, Fudan University, Shanghai 201203, \\ China

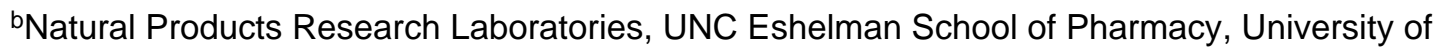 \\ North Carolina, Chapel Hill, NC 27599-7568, USA \\ 'Duke University Medical Center, Durham, NC 27710, USA \\ ${ }^{\mathrm{d} C h i n e s e ~ M e d i c i n e ~ R e s e a r c h ~ a n d ~ D e v e l o p m e n t ~ C e n t e r, ~ C h i n a ~ M e d i c a l ~ U n i v e r s i t y ~ a n d ~ H o s p i t a l, ~}$ \\ Taichung, Taiwan
}

\begin{abstract}
In a continuing study of novel anti-HIV agents with drug-like structures and properties, $301^{\prime}-O-$, $1^{\prime}$-S $S$-, 4'-O- and 4'-substituted-2',3'-seco-3'-nor DCP and DCK analogues (8-37) were designed and synthesized. All newly synthesized seco-compounds were screened against HIV-1 $1_{\mathrm{NL} 4-3}$ and a multiple reverse transcriptase (RT) inhibitor-resistant (RTMDR) strain in the TZM-bl cell line, using seco-DCK (7) and 2-ethyl-DCP (4) as controls. Several compounds $(\mathbf{1 4}, \mathbf{1 8}, \mathbf{1 9}, \mathbf{2 2 - 2 4}$, and 32) exhibited potent anti-HIV activity with $\mathrm{EC}_{50}$ values ranging from 0.93 to $1.93 \mu \mathrm{M}$ and

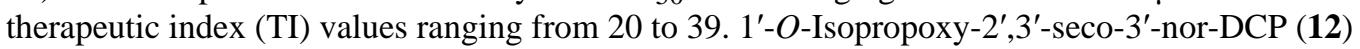
showed the greatest potency among the newly synthesized compounds with $\mathrm{EC}_{50}$ values of 0.47 and $0.88 \mu \mathrm{M}$, and TI of 96 and 51, respectively, against HIV-1 $1_{\mathrm{NL} 4-3}$ and RTMDR strains. The seco-compounds exhibited better chemical stability in acidic conditions compared with DCP and DCK compounds. Overall, the results suggested that seco-DCP analogues with simplified structures may be more favorable for development as novel anti-HIV candidates.
\end{abstract}

\section{Keywords \\ 2', 3'-Seco-3'-nor-DCPs; Anti-HIV activity; Structure-activity relationship (SAR)}

\section{Introduction}

Acquired immunodeficiency syndrome (AIDS), one of the most devastating diseases currently affecting mankind, is caused by infection with the human immunodeficiency virus (HIV). Although there are over 30 clinically used drugs [1], the fast emergence of drug resistance and toxicity problems due to long-term use and drug-drug interactions have

(c) 2011 Elsevier Masson SAS. All rights reserved.

"Corresponding author. Tel.: +86 21 51980116. pxia@fudan.edu.cn (P. Xia). ${ }^{* *}$ Corresponding author. Tel.: +1 919962 0066; fax: +1 919966 3893.khlee@unc.edu (K.H. Lee).

Publisher's Disclaimer: This is a PDF file of an unedited manuscript that has been accepted for publication. As a service to our customers we are providing this early version of the manuscript. The manuscript will undergo copyediting, typesetting, and review of the resulting proof before it is published in its final citable form. Please note that during the production process errors may be discovered which could affect the content, and all legal disclaimers that apply to the journal pertain. 
limited their long-term drug effectiveness. Therefore, studies aimed at the discovery of new anti-viral agents with novel structures or targets are still needed.

In our prior research, $3^{\prime} R, 4^{\prime} R$-di- $O$-(-)-camphanoyl-(+)-cis-khellactone (DCK, 1) and 4methyl-DCK (2) exhibited high potency against HIV-1 replication in H9 lymphocytes (Figure 1) [2,3]. Subsequently, diverse DCK analogues were designed and synthesized by modifications of DCK, particularly different coumarin substituents, ring isomers, and bioisosteric replacements [4-10]. Most of the new compounds showed promising in vitro inhibitory activity in anti-HIV replication assays, and a preliminary structure-activity relationship (SAR) was established. However, the problems of poor water solubility, low bioavailability and reduced potency against multiple reverse transcriptase (RT) inhibitorresistant (RTMDR) strains have obstructed the further development of DCKs. Subsequently, $4 H$-chromone-4-one (DCP, 3) derivatives, which are positional isomers of DCK, were designed and synthesized [11, 12]. Among them, 2-ethyl DCP (4), 5-methyl-2-ethyl DCP (5), and 2,5-dimethyl DCP (6) not only exhibited high activity against wild-type HIV isolates, but also retained potency against RTMDR-1 (Figure 1).

These favorable results led us to investigate whether the integrity of the tricyclic system (ring-A, -B and -C) was essential for the anti-HIV activity. While ring-A opened DCK analogues did not exhibit antiviral activity, ring-C opened DCK analogues (seco-DCKs) were active. In fact, compared with $\mathbf{2}$, seco-DCK analogue $\mathbf{7}$ showed better anti-HIV activity and increased sensitivity against RTMDR in anti-HIV replication assays using HIV-1 ${ }_{\text {IIIB }}$ in MT- 2 cell lines, as well as HIV-1 $1_{\mathrm{NL} 4-3}$ and RTMDR in MT-4 lymphocytes [13]. The secoDCKs have a simplified skeleton, fewer hydrogen-bond acceptors and lower $\log \mathrm{P}$ values, resulting in increased water solubility and better pharmacokinetic properties compared with DCKs. Our success with seco-DCKs prompted us to make corresponding modifications on DCP analogues in our search for new desirable anti-HIV inhibitors with better drug-like properties and inhibitory activity against RTMDR. Herein, we report the design, synthesis, biological evaluation and chemical stability of novel 2', $3^{\prime}$-seco-3'-nor DCP (8-31, 33-37) and DCK (32) analogues (Figures 2-4).

\section{Design}

Previous research suggested that a 4'-camphanoyl moiety is preferred for anti-HIV activity of DCK/DCP analogues. Therefore, in our current study, we first retained the 4'-camphanoyl ester substitution, while focusing on diverse substituents at the $1^{\prime}-O$ position of the new ringC opened seco-DCP products. Eight 2',3'-seco-3'-nor-2-ethyl DCP analogues (8-15) with different aliphatic groups, such as methyl, ethyl, isopropyl, isobutyl, and 2- $\alpha$-bromoethyl, at the $1^{\prime}-O$ position were synthesized. Aromatic and heterocyclic moieties, which were not introduced at the $1^{\prime}-O$ position in our prior seco-DCK study, were also incorporated to examine the effects of 1 '- $O$-aryl rings with electron-donating or -withdrawing groups and 1 '$O$-heterocyclic substituents on the antiviral replication activity of new compounds (16-28). In addition, because an ether bond usually has better chemical stability than an ester bond, the 4'-camphanoyl ester [-O $(\mathrm{C}=\mathrm{O})$ - linkage] was replaced with a 4'-camphanol ether [-O$\mathrm{CH}_{2}$ - linkage] with the aim of slowing down possible metabolism at this position. Accordingly, three 4'-camphanol ethers of 2',3'-seco-3'-nor-2-ethyl-DCPs (29-31) were generated. Prior research on bioisosteric replacement showed that some 1-thia and/or 1'-thia DCKs exhibited comparable or better activity against HIV replication compared with 1-oxa and/or 1'-oxa DCKs. Consequently, we synthesized 1'-thia-2',3'-seco-3'-nor-4-methyl-DCK (32) and 1'-thia-2', $3^{\prime}$-seco-3'-nor-2-ethyl-DCP (33) to verify if seco-series showed a similar trend. Finally, we replaced the $4^{\prime}-O$-camphanoyl ester with piperidinyl oxalamide moieties, and synthesized four 4'-(N'-substituted piperidin-1-yl)-2',3'-seco-3'-nor DCP analogues (34- 
37). All new compounds were evaluated in an antiviral replication assay against wild-type virus, and 15 compounds were also assayed against RTMDR virus.

\section{Chemistry}

Scheme 1 shows the synthesis of 1'-O-alkyl-2',3'-seco-3'-nor DCPs (8-15). Commercially available 2,4-dihydroxy-3-methylacetophenone (38) was selectively protected as the 4methoxymethyl (MOM) ether (39), followed by condensation with ethyl propionate to afford 40, which was further reacted with concentrated hydrochloric acid in $\mathrm{EtOH}$ to provide bicyclic compound $\mathbf{4 1}$. Four 7-alkoxy ethers (42a-d) were synthesized by alkylation of $\mathbf{4 1}$ with corresponding bromides, and subsequent treatment with $N$-bromosuccinimide provided 8-bromomethylmonobromides (43a-d) and 2- $\alpha$-bromoethyl-8-bromomethyldibromides $(\mathbf{4 4} \mathbf{e}-\mathbf{h})$. A mixture of the mono- and di-bromides was first heated at reflux in a solution of $\mathrm{NaOAc} / \mathrm{Ac}_{2} \mathrm{O}$ and then hydrolyzed with $2 \mathrm{~N} \mathrm{HCl}$ in $\mathrm{EtOH}$ to produce 8-hydroxymethyl compounds (45a-d) and 2- $\alpha$-bromoethyl-8-hydroxymethyl compounds $(\mathbf{4 6} \mathbf{e}-\mathbf{h})$, respectively. Subsequently, the desired esters $8-\mathbf{1 5}$ were prepared by esterification of $\mathbf{4 5 a}-\mathbf{d}$ and $46 \mathbf{e}-\mathbf{h}$ with camphanoyl chloride in DMAP and $\mathrm{CH}_{2} \mathrm{Cl}_{2}$ at room temperature.

The synthesis of 1'-O-aryl or -heterocyclic substituted 2',3'-seco-3'-nor-2-ethyl-DCPs (1628) is depicted in Scheme 2. To avoid the reaction of the 7-OH group of $\mathbf{4 1}$ with NBS, the MOM ether $\mathbf{4 7}$ was prepared and subsequently brominated with NBS to yield the 8bromomethyl compound $\mathbf{4 8}$, which was then treated as described above to afford 49. Thirteen 7-aromatic and -heterocyclic substituted ethers $(\mathbf{5 0 a}-\mathbf{m})$ were prepared by alkylation of 49 with corresponding bromides in DMF in the presence of $\mathrm{K}_{2} \mathrm{CO}_{3}$ at room temperature. Compounds 50a-m were then converted into the target compounds (16-28) by acylation with camphanoyl chloride.

As shown in Scheme 3, etherification of 7-alkyloxy-8-bromomethyl-2-ethyl-4H-chromen-4ones $(\mathbf{4 3 a}-\mathbf{c})$ with camphanol in toluene in presence of $\mathrm{NaH}$ afforded the three respective $4{ }^{\prime}$ camphanol ether 2',3'-seco-3'-nor-2-ethyl-DCPs (29-31). Four 4'-( $\mathrm{N}^{\prime}$-substituted piperidin-1-yl)-2', $3^{\prime}$-seco-3'-nor DCP analogues (34-37) were obtained from the amidation of $\mathbf{4 3 b}$ with the corresponding $\mathrm{N}^{\prime}$-substituted piperidine in THF in presence of DMAP at room temperature.

The syntheses of 1'-thia-2',3'-seco-3'-nor-4-methyl-DCK (32) and 1'-thia-2',3'-seco-3'-nor-2ethyl-DCP (33) are depicted in Schemes 4 and 5, respectively. For 33, the mono-acetylation of commercially available resorcinol $(\mathbf{6 0})$ in an HOAc solution containing zinc chloride gave 61. 2-Ethyl-7-hydroxy-4H-chromen-4-one (64) was then obtained from 61 via three steps, $4-\mathrm{OH}$ protection with $\mathrm{MOMCl}(\mathbf{6 2})$, condensation with ethyl propionate $(\mathbf{6 3})$, and ring-A closure. Compounds 52 (Scheme 4) and 65 (Scheme 5) were obtained by Duff formylation of 51 and $\mathbf{6 4}$, respectively, with hexamethylenamine in acetic acid solution. Because hydrogen bonding between the 7-hydroxy and 8-formyl groups could possibly interfere with the conversion of the 7-OH to 7-SH, the 8-formyl moiety in $\mathbf{5 2}$ and $\mathbf{6 5}$ was first protected as a cyclic acetal in intermediates 53 and $\mathbf{6 6}$ by reaction with ethylene glycol in the presence of $p$-toluenesulfonic acid in benzene under reflux-dehydration conditions. Subsequently, the 7-hydroxy compounds (53 and 66) were converted to the 7-mercapto compounds (56 and 69) in three steps, acylation with dimethylthiocarbamoyl chloride (54 and 67), Newman-Kwart rearrangement (55 and 68), and basic hydrolysis. The alkylation of 56 and 69 with isopropyl bromide yielded 57 and 70. Finally, target compounds 32 and 33 were prepared from $\mathbf{5 7}$ and $\mathbf{7 0}$ by the following reaction sequence, deprotection of the 8acetal in $1 \mathrm{~N} \mathrm{HCl}$, reduction of $\mathbf{5 8}$ and $\mathbf{7 1}$ with $\mathrm{NaBH}_{4}$ in $\mathrm{MeOH}$, and esterification of $\mathbf{6 0}$ and 72 with camphanoyl chloride. 


\section{Results and discussion}

All 30 newly synthesized seco-DCK and DCP analogues (8-37) were evaluated for in vitro suppression of $\mathrm{HIV}-1_{\mathrm{NL4}-3}$ replication in a single cycle infection assay using the TZM-bl cell line with both 2-ethyl-DCP (4) and seco-DCK (7) as positive controls. Moreover, compounds 8-15, 29-31, and 34-37 were also screened for antiviral activity against HIV-1 RTMDR. The data are summarized in Tables 1 and 2.

As shown in Table 1, compounds 8-15 exhibited varying degrees of potency against wildtype HIV-1 $1_{\mathrm{NL} 4-3}$. Based on the size of the alkyl group at the $1^{\prime}-O$ position, the rank order of antiviral activity was methyl < ethyl < isobutyl < isopropyl. 1'- $O$-Isopropyl substituted $\mathbf{1 2}$ showed the best antiviral activity against both HIV-1 $1_{\text {NL4-3 }}$ and RTMDR with $\mathrm{EC}_{50}$ values of 0.47 and $0.88 \mu \mathrm{M}$, and TI of 96 and 51, respectively, which were generally comparable or better, particularly against RTMDR, than those of prior hits 7 (EC 500.5 and $1.89 \mu \mathrm{M}$; TI 34.54 and 9.13 , respectively) and $4\left(\mathrm{EC}_{50} 0.12\right.$ and $0.20 \mu \mathrm{M}$, TI 118.75 and 71.25 , respectively). Compounds 12 and $\mathbf{1 4}$ (1'-O-isobutyl-2',3'-seco-3'-nor-2-ethyl-DCP) had comparable anti-RTMDR potencies ( $\mathrm{EC}_{50} 0.88$ and $0.94 \mu \mathrm{M}$, respectively), which were two-fold better than that of $\mathbf{7}$. Compounds with a bromine on the 2-ethyl group $(\mathbf{9}, \mathbf{1 1}, \mathbf{1 3}$, and 15) exhibited much lower anti-HIV activity compared with the corresponding nonbrominated compounds $(\mathbf{8}, \mathbf{1 0}, \mathbf{1 2}$, and $\mathbf{1 4})$. This finding suggested that a $2-\alpha$-bromoethyl group was unfavorable. Overall, the results suggested that the size of an isopropyl group at the $1^{\prime}-O$ position was more suitable to fit within the binding pocket of wild-type virus, while both isopropyl and isobutyl may fit into the slightly changed binding pocket of the RTMDR strain, due to possible mutations near the interaction site.

The three novel 4'-camphanol ether seco-DCP analogues (29-31) exhibited better inhibition

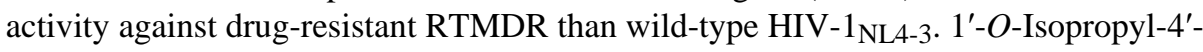
camphanol ether 31 exhibited the best potency against RTMDR (EC $\mathrm{E}_{50} 1.49 \mu \mathrm{M}$, TI 31.45). However, the 4'-camphanol ether compounds (29-31) were less potent than their corresponding 4 '-camphanoyl ester analogues $(\mathbf{8}, \mathbf{1 0}, \mathbf{1 2}$, respectively). The four compounds (34-37) with a piperidinyl group rather than a camphanoyl ester or camphanol ether at the 4'-position showed decreased or completely abolished inhibitory activity against HIV, further confirming our prior finding that a 4'-camphanoyl group is very important for enhanced anti-HIV activity in the DCK/DCP series.

The anti-HIV-1 $1_{\mathrm{NL} 4-3}$ results for $1^{\prime}-O$-aryl and -heterocyclic 2 ', 3'-seco-3'-nor-2-ethyl- DCPs (16-28) and $1^{\prime}$-thia compounds (32 and 33) are shown in Table 2. Among these analogues, 1'-O-3-methoxycarbonylbenzyl-2',3'-seco-3'-nor-2-ethyl-DCP (23) $\left(\mathrm{EC}_{50} 0.93 \mu \mathrm{M}\right.$, TI $39.20)$ and the positive control (7) $\left(\mathrm{EC}_{50} 0.5 \mu \mathrm{M}\right.$, TI 34.54) exhibited comparable potency. 1'-O-Pyrid-3-yl-methyl, -pyrid-4-yl-methyl, 1'-O-3-cyanobenzyl, 1'-O-3-methoxybenzyl, and $1^{\prime}-O-3$-methylbenzyl analogues $(\mathbf{1 8}, \mathbf{1 9}, \mathbf{2 1}, \mathbf{2 2}$, and $\mathbf{2 4}$, respectively) also showed moderate anti-HIV inhibitory activity with $\mathrm{EC}_{50}$ values ranging from 1.26 to $2.41 \mu \mathrm{M}$. The significantly reduced potency of $\mathbf{1 7}$, which contains a 1'-O-pyrid-2-yl-methyl substituent, compared with 18 and 19 suggested that a nitrogen atom at the 2-position of the aromatic ring is detrimental to the antiviral activity. Compounds 25 and 26 with $1^{\prime}-O-3,5-$ dimethoxybenzyl and 1'-O-3-trifluoromethoxybenzyl substituents exhibited very weak antiHIV activity, while compounds 16, 20, 27, and 28 with $1^{\prime}-O-\gamma$-butyrolactone, $1^{\prime}-O-3-$ trifluoromethylbenzyl, 1'-O-2-bromo-5-methoxybenzyl, and 1'-O-2-nitro-4,5dimethoxybenzyl substituents lost all activity. These results indicated that the $1^{\prime}-O$ substituents have a significant impact on the analogues' antiviral activity. The $1^{\prime}-O$ position in the seco-compounds, which corresponds to the 2'-postion of DCK and DCP analogues, should be interacting with the viral binding target, as consistent with our previous study in the DCK series. Finally, compound 32 (1'-thia-seco-DCK) showed moderate antiviral 
activity ( $\mathrm{EC}_{50} 1.53 \mu \mathrm{M}$, TI 21.32), while $\mathbf{3 3}$ (1'-thia-seco-DCP) was more active ( $\mathrm{EC}_{50} 0.56$ $\mu \mathrm{M}$, TI 11.25). Comparing the sulfur compounds with their oxygen counterparts, 32 was less potent than 12, while 33 was equipotent with $\mathbf{7 .}$

Chemically, the seco-DCK/DCP analogues have lower molecular weights and should have reduced spatial strain, because they contain only one rather than two adjacent, extremely bulky cis-3',4'-camphanoyl esters as found in the DCK and DCP series. Hypothetically, these changes could improve the chemical stability of the molecules and their drug-like properties. Consequently, the chemical stability of 4-Me-DCK (2), seco-DCK (7), 1'-thiaseco-DCK (32), 2-ethyl-DCP (4), and seco-DCP (12) were tested under acidic conditions with HPLC monitoring. The preliminary results are listed in Table 3 . The results showed that, after 30 min, only $64 \%$ of compound $\mathbf{2}$ was detectable, while $77 \%$ of $\mathbf{7}$ and $96 \%$ of $\mathbf{3 2}$ were intact. Compound 12, which exhibited the greatest antiviral activity among the newly synthesized seco-DCK/DCP analogues, also showed the best chemical stability in this study (100\% intact after $30 \mathrm{~min})$. Overall, the seco-series of compounds showed good stability in acidic conditions, indicating that they should remain stable in the stomach via oral administration.

\section{Conclusions}

In conclusion, most of the new 2', $3^{\prime}$-seco-3'-nor-2-ethyl-DCP analogues showed potent to moderate anti-HIV activity, and compounds $\mathbf{1 2}$ and $\mathbf{1 4}$ also showed promising activity against RTMDR. In addition, the chemical stability of seco-DCKs and seco-DCPs was improved in comparison with DCK and DCP analogues. Preliminary SAR conclusions were as follows, a) integrity of the ring-C is not essential for DCK and DCP analogues, and aliphatic alkyl substituents at 1 '- $O$-position are better than aryl or heterocyclic groups, with isopropyl substitution being the most favorable for anti-HIV potency; b) converting the 4'camphanoyl ester into a camphanol ether resulted in some potency decrease, but compounds remained more selective against RTMDR; c) 4'-camphanoyl is the most preferred moiety for anti-HIV activity of DCK and DCP analogues; and d) sulfur rather than oxygen at the 1'position led to similar or slightly reduced anti-HIV activity.

\section{Experimental}

Melting points were measured with a Fisher Johns melting apparatus without correction. The proton nuclear magnetic resonance $\left({ }^{1} \mathrm{H}\right.$ NMR) spectra were measured on a Bruker-DPX 400 MHz spectrometer and $300 \mathrm{MHz}$ Varian Gemini 2000 spectrometer using TMS as internal standard. The solvent used was $\mathrm{CDCl}_{3}$ unless indicated. Mass spectra were measured with HP5973N analytical mass spectrometers. High resolution mass spectra (HRMS) were measured on a Shimadzu LCMSIT-TOF with ESI interface. HPLC purity determinations were conducted using a Shimadzu LCMS-2010 with a Grace Alltima 2.1× $150 \mathrm{~mm}$ HP C18 $3 \mu \mathrm{M}$ column and Shimadzu SPD-M20A detector at $254 \mathrm{~nm}$ wavelength. HPLC purity analyses were determined by using two different solvent conditions. The first was $70 \%$ $\mathrm{MeCN}$ as solvent $\mathrm{A}$ and $30 \% \mathrm{H}_{2} \mathrm{O}$ as solvent $\mathrm{B}$ with $0.2 \mathrm{~mL} / \mathrm{min}$ flow rate; the second was $70 \% \mathrm{MeOH}$ as solvent $\mathrm{A}$ and $30 \% \mathrm{H}_{2} \mathrm{O}$ as solvent B with $0.1 \mathrm{~mL} / \mathrm{min}$ flow rate. The HPLC model was an isocratic system. All target compounds had purity greater than $95 \%$. Commercially available silica gel $\mathrm{H}$ was used for column chromatography. Thin-layer chromatography (TLC) was performed on PLC silica gel 60 F254 plates.

\subsection{Synthesis of 1'-alkoxy-seco-DCPs (8-15)}

\subsubsection{1-(2-Hydroxy-4-(methoxymethoxy)-3-methylphenyl)ethanone (39)-}

Chloromethyl methyl ether $(9.14 \mathrm{~mL}, 120 \mathrm{mmol})$ was added dropwise into a mixture of $\mathbf{3 8}$ $(10.0 \mathrm{~g}, 60.2 \mathrm{mmol})$ and potassium carbonate $(20.8 \mathrm{~g}, 150 \mathrm{mmol})$ in anhydrous acetone $(60$ 
$\mathrm{mL}$ ) in an ice-bath. The reaction mixture was then allowed to warm to room temperature and stirred for $1.5 \mathrm{~h}$. The mixture was then filtered, and the filtrate was dissolved in brine and extracted with EtOAc $(35 \mathrm{~mL})$. The organic layer was dried in vacuo to provide $39(13.9 \mathrm{~g})$ as brown oil: $91 \%$ yield. ${ }^{1} \mathrm{H}$ NMR $\delta: 2.14\left(3 \mathrm{H}, \mathrm{s}, 3-\mathrm{CH}_{3}\right), 2.56\left(3 \mathrm{H}, \mathrm{s}, 1-\mathrm{COCH}_{3}\right), 3.50(3 \mathrm{H}$, $\left.\mathrm{s}, 4-\mathrm{OCH}_{2} \mathrm{OCH}_{3}\right), 5.27\left(2 \mathrm{H}, \mathrm{s}, 4-\mathrm{OCH}_{2} \mathrm{OCH}_{3}\right), 6.65(1 \mathrm{H}, \mathrm{d}, J=8.7 \mathrm{~Hz}, 6-\mathrm{H}), 7.57(1 \mathrm{H}, \mathrm{d}, J$ $=8.7 \mathrm{~Hz}, 5-\mathrm{H}), 12.80(1 \mathrm{H}, \mathrm{s}, 2-\mathrm{OH})$. ESI-MS $m / z 209\left(\mathrm{M}^{+}-1\right)$.

6.1.2. 2-Ethyl-7-hydroxy-8-methyl-4H-chromen-4-one (41)—Sodium hydride (60\% in mineral oil, $9.52 \mathrm{~g} / 15.9 \mathrm{~g}, 397 \mathrm{mmol})$ was added slowly to a mixture of $\mathbf{3 9}(13.9 \mathrm{mg}, 66.1$ $\mathrm{mmol}$ ) and ethyl propionate $(19.0 \mathrm{~mL}, 165 \mathrm{mmol})$ in absolute THF under nitrogen. Then, the mixture was warmed to reflux temperature for $2 \mathrm{~h}$, cooled and neutralized to $\mathrm{pH} 8$ with $37 \%$ $\mathrm{HCl}(25 \mathrm{~mL})$. Water $(60 \mathrm{~mL})$ was added and the mixture was extracted with EtOAc $(4 \times 30$ $\mathrm{mL}$ ). The organic layer was collected and evaporated in vacuo to yield $\mathbf{4 0}$ as dark oil. This crude product and $37 \% \mathrm{HCl}(3 \mathrm{~mL})$ were dissolved in $\mathrm{EtOH}(60 \mathrm{~mL})$ and refluxed for 45 $\mathrm{min}$ to give 41, which was used in the next reaction without further purification. $\mathrm{mp} 223-$ $224{ }^{\circ} \mathrm{C} .{ }^{1} \mathrm{H}$ NMR (DMSO, $\left.\delta\right): 1.23\left(3 \mathrm{H}, \mathrm{t}, J=7.2 \mathrm{~Hz}, 2-\mathrm{CH}_{2} \mathrm{CH}_{3}\right), 2.20\left(3 \mathrm{H}, \mathrm{s}, 8-\mathrm{CH}_{3}\right)$, $2.65\left(2 \mathrm{H}, \mathrm{q}, J=7.2 \mathrm{~Hz}, 2-\mathrm{CH}_{2} \mathrm{CH}_{3}\right), 6.06(1 \mathrm{H}, \mathrm{s}, 3-\mathrm{H}), 6.98(1 \mathrm{H}, \mathrm{d}, J=8.7 \mathrm{~Hz}, 6-\mathrm{H}), 7.68$ $(1 \mathrm{H}, \mathrm{d}, J=8.7 \mathrm{~Hz}, 5-\mathrm{H})$. ESI-MS $m / z 203\left(\mathrm{M}^{+}-1\right)$.

6.1.3. Synthesis of 2-ethyl-7-alkoxychromones (42a-d)-A mixture of 41 (1 equiv), $\mathrm{K}_{2} \mathrm{CO}_{3}$ (3 equiv), and halogenated compounds (2 equiv) in DMF ( $5 \mathrm{~mL}$ ) was stirred for $45 \mathrm{~min}$ at room temperature. After filtering the mixture and removing the solvent in vacuo, the residue was purified by column chromatography (eluent: hexane/EtOAc 95:5) to afford the desired compounds (42a-d) as white solids in $73-82 \%$ yields.

6.1.3.1. 2-Ethyl-7-methoxy-8-methyl-4H-chromen-4-one (42a): $75 \%$ yield, mp 104-106 ${ }^{\circ} \mathrm{C} .{ }^{1} \mathrm{H}$ NMR $\delta: 1.32\left(3 \mathrm{H}, \mathrm{t}, J=7.5 \mathrm{~Hz}, 2-\mathrm{CH}_{2} \mathrm{CH}_{3}\right), 2.30\left(3 \mathrm{H}, \mathrm{s}, 8-\mathrm{CH}_{3}\right), 2.68(2 \mathrm{H}, \mathrm{q}, J=$ $\left.7.5 \mathrm{~Hz}, 2-\mathrm{CH}_{2} \mathrm{CH}_{3}\right), 3.95\left(3 \mathrm{H}, \mathrm{s}, 7-\mathrm{OCH}_{3}\right), 6.11(1 \mathrm{H}, \mathrm{s}, 3-\mathrm{H}), 6.96(1 \mathrm{H}, \mathrm{d}, J=9.0 \mathrm{~Hz}, 6-\mathrm{H})$, $8.10(1 \mathrm{H}, \mathrm{d}, J=9.0 \mathrm{~Hz}, 5-\mathrm{H})$. ESI-MS $m / z 219\left(\mathrm{M}^{+}+1\right)$.

6.1.3.2. 7-Ethoxy-2-ethyl-8-methyl-4H-chromen-4-one (42b): 73\% yield, mp 85-87 ${ }^{\circ} \mathrm{C} .{ }^{1} \mathrm{H}$ NMR $\delta: 1.33\left(3 \mathrm{H}, \mathrm{t}, J=7.5 \mathrm{~Hz}, 2-\mathrm{CH}_{2} \mathrm{CH}_{3}\right), 1.48\left(3 \mathrm{H}, \mathrm{t}, J=7.2 \mathrm{~Hz}, 7-\mathrm{OCH}_{2} \mathrm{CH}_{3}\right)$, $2.31\left(3 \mathrm{H}, \mathrm{s}, 8-\mathrm{CH}_{3}\right), 2.68\left(2 \mathrm{H}, \mathrm{q}, J=7.5 \mathrm{~Hz}, 2-\mathrm{CH}_{2} \mathrm{CH}_{3}\right), 4.17(2 \mathrm{H}, \mathrm{q}, J=7.2 \mathrm{~Hz}, 7-$ $\left.\mathrm{OCH}_{2} \mathrm{CH}_{3}\right), 6.11(1 \mathrm{H}, \mathrm{s}, 3-\mathrm{H}), 6.93(1 \mathrm{H}, \mathrm{d}, J=9.0 \mathrm{~Hz}, 6-\mathrm{H}), 8.01(1 \mathrm{H}, \mathrm{d}, J=9.0 \mathrm{~Hz}, 5-\mathrm{H})$. ESI-MS $m / z 233\left(\mathrm{M}^{+}+1\right)$.

6.1.3.3. 2-Ethyl-7-isopropoxy-8-methyl-4H-chromen-4-one (42c): $79 \%$ yield, mp 99-101 ${ }^{\circ} \mathrm{C} .{ }^{1} \mathrm{H}$ NMR $\delta: 1.33\left(3 \mathrm{H}, \mathrm{t}, J=6.9 \mathrm{~Hz}, 2-\mathrm{CH}_{2} \mathrm{CH}_{3}\right), 1.38(6 \mathrm{H}, \mathrm{d}, J=6.0 \mathrm{~Hz}, 7-$ $\left.\mathrm{OCH}\left(\mathrm{CH}_{3}\right)_{2}\right), 2.29\left(3 \mathrm{H}, \mathrm{s}, 8-\mathrm{CH}_{3}\right), 2.68\left(2 \mathrm{H}, \mathrm{J}=6.9 \mathrm{~Hz}, 2-\mathrm{CH}_{2} \mathrm{CH}_{3}\right), 4.70(1 \mathrm{H}, \mathrm{m}, J=6.0$ $\left.\mathrm{Hz}, 7-\mathrm{OCH}\left(\mathrm{CH}_{3}\right)_{2}\right), 6.11(1 \mathrm{H}, \mathrm{s}, 3-\mathrm{H}), 6.95(1 \mathrm{H}, \mathrm{d}, J=9.0 \mathrm{~Hz}, 6-\mathrm{H}), 8.01(1 \mathrm{H}, \mathrm{d}, J=9.0$ $\mathrm{Hz}, 5-\mathrm{H})$. ESI-MS $m / z 247\left(\mathrm{M}^{+}+1\right)$.

6.1.3.4. 2-Ethyl-7-isobutoxy-8-methyl-4H-chromen-4-one (42d): $82 \%$ yield, mp 61-62 ${ }^{\circ} \mathrm{C} .{ }^{1} \mathrm{H}$ NMR $\delta: 1.07\left(6 \mathrm{H}, \mathrm{d}, J=6.6 \mathrm{~Hz}, 7-\mathrm{OCH}_{2} \mathrm{CH}\left(\mathrm{CH}_{3}\right)_{2}\right), 1.33(3 \mathrm{H}, \mathrm{t}, J=7.2 \mathrm{~Hz}, 2-$ $\left.\mathrm{CH}_{2} \mathrm{CH}_{3}\right), 2.16\left(1 \mathrm{H}, \mathrm{m}, \mathrm{J}=6.6 \mathrm{~Hz}, 7-\mathrm{OCH}_{2} \mathrm{CH}\left(\mathrm{CH}_{3}\right)_{2}\right), 2.32\left(3 \mathrm{H}, \mathrm{s}, 8-\mathrm{CH}_{3}\right), 2.68(2 \mathrm{H}, J=$ $\left.7.2 \mathrm{~Hz}, 2-\mathrm{CH}_{2} \mathrm{CH}_{3}\right), 3.86\left(2 \mathrm{H}, \mathrm{d}, \mathrm{J}=6.6 \mathrm{~Hz}, 7-\mathrm{OCH}_{2} \mathrm{CH}\left(\mathrm{CH}_{3}\right)_{2}\right), 6.11(1 \mathrm{H}, \mathrm{s}, 3-\mathrm{H})$, $6.93(1 \mathrm{H}, \mathrm{d}, J=9.0 \mathrm{~Hz}, 6-\mathrm{H}), 8.01(1 \mathrm{H}, \mathrm{d}, J=9.0 \mathrm{~Hz}, 5-\mathrm{H})$. ESI-MS $m / z 261\left(\mathrm{M}^{+}+1\right)$.

6.1.4. Synthesis of bromides (43a-d and $44 e-h)-A$ mixture of $42 a-d$ ( 1 equiv) and NBS (1.2 equiv) in $\mathrm{CCl}_{4}$ was refluxed for $16 \mathrm{~h}$. After filtration and removal of the solvent, the residue was purified by column chromatography with a gradient eluent of $\mathrm{CH}_{2} \mathrm{Cl}_{2}$ / 
$\mathrm{MeOH} 40: 1$ to 30:1 to afford pure 43a-d and $\mathbf{4 4 e - h}$ in yields of $40-78 \%$ and $11-15 \%$, respectively.

6.1.4.1. 8-(Bromomethyl)-2-ethyl-7-methoxy-4H-chromen-4-one (43a): $40 \%$ yield (starting with $300 \mathrm{mg}$ of 42a): $\mathrm{mp} 162-164{ }^{\circ} \mathrm{C} .{ }^{1} \mathrm{H}$ NMR $\delta: 1.36(3 \mathrm{H}, \mathrm{t}, J=7.5 \mathrm{~Hz}, 2$ $\left.\mathrm{CH}_{2} \mathrm{CH}_{3}\right), 2.72\left(2 \mathrm{H}, \mathrm{q}, J=7.5 \mathrm{~Hz}, 2-\mathrm{CH}_{2} \mathrm{CH}_{3}\right), 4.03\left(3 \mathrm{H}, \mathrm{s}, 7-\mathrm{OCH}_{3}\right), 4.78(2 \mathrm{H}, \mathrm{s}, 8-$ $\left.\mathrm{CH}_{2} \mathrm{Br}\right), 6.15(1 \mathrm{H}, \mathrm{s}, 3-\mathrm{H}), 6.99(1 \mathrm{H}, \mathrm{d}, J=9.0 \mathrm{~Hz}, 6-\mathrm{H}), 8.16(1 \mathrm{H}, \mathrm{d}, J=9.0 \mathrm{~Hz}, 5-\mathrm{H})$. ESI-MS m/z $297\left(\mathrm{M}^{+}+1\right)$.

6.1.4.2. 8-(Bromomethyl)-7-ethoxy-2-ethyl-4H-chromen-4-one (43b): $58 \%$ yield (starting with $880 \mathrm{mg}$ of 42b): $\mathrm{mp} 114-116{ }^{\circ} \mathrm{C} .{ }^{1} \mathrm{H}$ NMR $\delta: 1.36\left(3 \mathrm{H}, \mathrm{t}, J=7.8 \mathrm{~Hz}, 2-\mathrm{CH}_{2} \mathrm{CH}_{3}\right), 1.52$ $\left(3 \mathrm{H}, \mathrm{t}, J=6.9 \mathrm{~Hz}, 7-\mathrm{OCH}_{2} \mathrm{CH}_{3}\right), 2.72\left(2 \mathrm{H}, \mathrm{q}, J=7.8 \mathrm{~Hz}, 2-\mathrm{CH}_{2} \mathrm{CH}_{3}\right), 4.25(2 \mathrm{H}, \mathrm{q}, J=6.9$ $\left.\mathrm{Hz}, 7-\mathrm{OCH}_{2} \mathrm{CH}_{3}\right), 4.79\left(2 \mathrm{H}, \mathrm{s}, 8-\mathrm{CH}_{2} \mathrm{Br}\right), 6.14(1 \mathrm{H}, \mathrm{s}, 3-\mathrm{H}), 6.96(1 \mathrm{H}, \mathrm{d}, J=9.0 \mathrm{~Hz}, 6-\mathrm{H})$, $8.13(1 \mathrm{H}, \mathrm{d}, J=9.0 \mathrm{~Hz}, 5-\mathrm{H})$. ESI-MS $m / z 311\left(\mathrm{M}^{+}+1\right)$.

6.1.4.3. 8-(Bromomethyl)-2-ethyl-7-isopropoxy-4H-chromen-4-one (43c): $45 \%$ yield (starting with $1.2 \mathrm{~g}$ of $42 \mathrm{c}$ ): $\mathrm{mp} 66-68{ }^{\circ} \mathrm{C} .{ }^{1} \mathrm{H} \mathrm{NMR} \delta: 1.36\left(3 \mathrm{H}, \mathrm{t}, J=7.8 \mathrm{~Hz}, 2-\mathrm{CH}_{2} \mathrm{CH}_{3}\right)$, $1.44\left(6 \mathrm{H}, \mathrm{d}, J=6.0 \mathrm{~Hz}, 7-\mathrm{OCH}\left(\mathrm{CH}_{3}\right)_{2}\right), 2.71\left(2 \mathrm{H}, \mathrm{q}, J=7.8 \mathrm{~Hz}, 2-\mathrm{CH}_{2} \mathrm{CH}_{3}\right), 4.72-4.81$ $\left(3 \mathrm{H}, \mathrm{m}, J=6.0 \mathrm{~Hz}, 7-\mathrm{OCH}\left(\mathrm{CH}_{3}\right)_{2} \& 8-\mathrm{CH}_{2} \mathrm{Br}\right), 6.14(1 \mathrm{H}, \mathrm{s}, 3-\mathrm{H}), 6.96(1 \mathrm{H}, \mathrm{d}, J=9.0 \mathrm{~Hz}$, $6-\mathrm{H}), 8.12(1 \mathrm{H}, \mathrm{d}, J=9.0 \mathrm{~Hz}, 5-\mathrm{H})$. ESI-MS $m / z 325\left(\mathrm{M}^{+}+1\right)$.

6.1.4.4. 8-(Bromomethyl)-2-ethyl-7-isobutoxy-4H-chromen-4-one (43d): $78 \%$ yield (starting with $200 \mathrm{mg}$ of $\mathbf{4 2 d}$ ): $\mathrm{mp} 91-93^{\circ} \mathrm{C} .{ }^{1} \mathrm{H}$ NMR $\delta: 1.25(6 \mathrm{H}, \mathrm{d}, J=6.6 \mathrm{~Hz}, 7$ $\left.\mathrm{OCH}_{2} \mathrm{CH}\left(\mathrm{CH}_{3}\right)_{2}\right), 1.50\left(3 \mathrm{H}, \mathrm{t}, J=7.5 \mathrm{~Hz}, 2-\mathrm{CH}_{2} \mathrm{CH}_{3}\right), 2.35(1 \mathrm{H}, \mathrm{m}, J=6.6 \mathrm{~Hz}, 7-$ $\left.\mathrm{OCH}_{2} \mathrm{CH}\left(\mathrm{CH}_{3}\right)_{2}\right), 2.85\left(2 \mathrm{H}, J=7.5 \mathrm{~Hz}, 2-\mathrm{CH}_{2} \mathrm{CH}_{3}\right), 4.07(2 \mathrm{H}, \mathrm{d}, J=6.6 \mathrm{~Hz}, 7-$ $\left.\mathrm{OCH}_{2} \mathrm{CH}\left(\mathrm{CH}_{3}\right)_{2}\right), 4.93\left(2 \mathrm{H}, \mathrm{s}, 8-\mathrm{CH}_{2} \mathrm{Br}\right), 6.28(1 \mathrm{H}, \mathrm{s}, 3-\mathrm{H}), 7.09(1 \mathrm{H}, \mathrm{d}, J=9.0 \mathrm{~Hz}, 6-\mathrm{H})$, $8.27(1 \mathrm{H}, \mathrm{d}, J=9.0 \mathrm{~Hz}, 5-\mathrm{H})$. ESI-MS $m / z 339\left(\mathrm{M}^{+}+1\right)$.

6.1.4.5. 2-(1-Bromoethyl)-8-(bromomethyl)-7-methoxy-4H-chromen-4-one (44e): $14 \%$ yield (starting with $300 \mathrm{mg}$ of 42a): $\mathrm{mp} 153-156^{\circ} \mathrm{C} .{ }^{1} \mathrm{H}$ NMR $\delta: 2.09(3 \mathrm{H}, \mathrm{d}, J=7.2 \mathrm{~Hz}, 2-$ $\left.\mathrm{CHBr} \mathrm{CH}_{3}\right), 4.04\left(3 \mathrm{H}, \mathrm{s}, 7-\mathrm{OCH}_{3}\right), 4.81\left(2 \mathrm{H}, \mathrm{s}, 8-\mathrm{CH}_{2} \mathrm{Br}\right), 4.94(1 \mathrm{H}, \mathrm{q}, J=7.2 \mathrm{~Hz}, 2-$ $\left.\mathrm{CHBrCH}_{3}\right), 6.33(1 \mathrm{H}, \mathrm{s}, 3-\mathrm{H}), 7.02(1 \mathrm{H}, \mathrm{d}, J=9.0 \mathrm{~Hz}, 6-\mathrm{H}), 8.16(1 \mathrm{H}, \mathrm{d}, J=9.0 \mathrm{~Hz}, 5-\mathrm{H})$. ESI-MS $m / z 377$ (100).

6.1.4.6. 2-(1-Bromoethyl)-8-(bromomethyl)-7-ethoxy-4H-chromen-4-one (44f): $15 \%$ yield (starting with $880 \mathrm{mg}$ of $\mathbf{4 2 b}$ ): $\mathrm{mp} 138-140{ }^{\circ} \mathrm{C} .{ }^{1} \mathrm{H} \mathrm{NMR} \delta: 1.53(3 \mathrm{H}, \mathrm{t}, J=6.9 \mathrm{~Hz}, 7$ $\left.\mathrm{OCH}_{2} \mathrm{CH}_{3}\right), 2.09\left(3 \mathrm{H}, \mathrm{d}, J=7.2 \mathrm{~Hz}, 2-\mathrm{CHBrCH}_{3}\right), 4.26\left(2 \mathrm{H}, \mathrm{q}, J=6.9 \mathrm{~Hz}, 7-\mathrm{OCH}_{2} \mathrm{CH}_{3}\right)$, $4.82\left(2 \mathrm{H}, \mathrm{s}, 8-\mathrm{CH}_{2} \mathrm{Br}\right), 4.95\left(1 \mathrm{H}, \mathrm{q}, J=7.2 \mathrm{~Hz}, 2-\mathrm{CHBrCH}_{3}\right), 6.33(1 \mathrm{H}, \mathrm{s}, 3-\mathrm{H}), 6.99(1 \mathrm{H}$, d, $J=9.0 \mathrm{~Hz}, 6-\mathrm{H}), 8.12(1 \mathrm{H}, \mathrm{d}, J=9.0 \mathrm{~Hz}, 5-\mathrm{H})$. ESI-MS $m / z .384(100)$.

6.1.4.7. 2-(1-Bromoethyl)-8-(bromomethyl)-7-isopropoxy-4H-chromen-4-one (44g): $15 \%$ yield (starting with $1.2 \mathrm{~g}$ of $\mathbf{4 2 c}$ ): $\mathrm{mp} 95-97{ }^{\circ} \mathrm{C} .{ }^{1} \mathrm{H}$ NMR $\delta: 1.45(6 \mathrm{H}, \mathrm{d}, J=6.0 \mathrm{~Hz}, 7-$ $\left.\mathrm{OCH}\left(\mathrm{CH}_{3}\right)_{2}\right), 2.85\left(3 \mathrm{H}, \mathrm{d}, \mathrm{J}=6.9 \mathrm{~Hz}, 2-\mathrm{CHBrCH}_{3}\right), 4.80(3 \mathrm{H}, \mathrm{m}, J=6.0 \mathrm{~Hz}, 7-$

$\left.\mathrm{OCH}\left(\mathrm{CH}_{3}\right)_{2} \& 8-\mathrm{CH}_{2} \mathrm{Br}\right), 4.94\left(1 \mathrm{H}, \mathrm{q}, J=6.9 \mathrm{~Hz}, 2-\mathrm{CHBrCH}_{3}\right), 6.32(1 \mathrm{H}, \mathrm{s}, 3-\mathrm{H}), 7.00$ $(1 \mathrm{H}, \mathrm{d}, J=9.0 \mathrm{~Hz}, 6-\mathrm{H}), 8.12(1 \mathrm{H}, \mathrm{d}, J=9.0 \mathrm{~Hz}, 5-\mathrm{H})$. ESI-MS $m / z 405(100)$.

6.1.4.8. 2-(1-Bromoethyl)-8-(bromomethyl)-7-isobutoxy-4H-chromen-4-one (44h): $11 \%$ yield (starting with $200 \mathrm{mg}$ of $\mathbf{4 2 d}$ ): $\mathrm{mp} 108-109^{\circ} \mathrm{C} .{ }^{1} \mathrm{H}$ NMR $\delta: 1.11(6 \mathrm{H}, \mathrm{d}, J=6.6 \mathrm{~Hz}$, 7$\left.\mathrm{OCH}_{2} \mathrm{CH}\left(\mathrm{CH}_{3}\right)_{2}\right), 2.09\left(3 \mathrm{H}, \mathrm{d}, J=6.9 \mathrm{~Hz}, 2-\mathrm{CHBrCH}_{3}\right), 2.22(1 \mathrm{H}, \mathrm{m}, J=6.6 \mathrm{~Hz}, 7-$ $\left.\mathrm{OCH}_{2} \mathrm{CH}\left(\mathrm{CH}_{3}\right)_{2}\right), 3.95\left(2 \mathrm{H}, \mathrm{d}, J=6.6 \mathrm{~Hz}, 7-\mathrm{OCH}_{2} \mathrm{CH}\left(\mathrm{CH}_{3}\right)_{2}\right), 4.83\left(2 \mathrm{H}, \mathrm{s}, 8-\mathrm{CH}_{2} \mathrm{Br}\right), 4.94$ $\left(1 \mathrm{H}, J=6.9 \mathrm{~Hz}, 2-\mathrm{CHBrCH}_{3}\right), 6.33(1 \mathrm{H}, \mathrm{s}, 3-\mathrm{H}), 7.0(1 \mathrm{H}, \mathrm{d}, J=9.0 \mathrm{~Hz}, 6-\mathrm{H}), 8.12(1 \mathrm{H}, \mathrm{d}$, $J=9.0 \mathrm{~Hz}, 5-\mathrm{H})$. ESI-MS $\mathrm{m} / z 412(100)$. 
6.1.5. Synthesis of 8-hydroxymethyl compounds (45a-d and 46e-h)-A mixture of the above bromides [43a-d or 44e-h (1 equiv)] and NaOAc (10 equiv) in acetic anhydride $(5 \mathrm{~mL})$ was refluxed for $2 \mathrm{~h}$ and progress was monitored by $\mathrm{TLC}\left(\mathrm{CH}_{2} \mathrm{Cl}_{2} / \mathrm{MeOH}\right.$ 20:1). After removal of solvent in vacuo, $\mathrm{EtOH}(5 \mathrm{~mL})$ and $2 \mathrm{~N} \mathrm{HCl}(2 \mathrm{~mL})$ were added, and the mixture refluxed for $2 \mathrm{~h}$. After the solvent was removed in vacuo, the crude product was purified by column chromatography (eluent: $\mathrm{CH}_{2} \mathrm{Cl}_{2} / \mathrm{MeOH}$ 99:1) to give $\mathbf{4 5 a}-\mathbf{d}$ and $\mathbf{4 6 e}-\mathbf{h}$.

6.1.5.1. 2-EthyYl-8-(hydroxymethyl)-7-methoxy-4H-chromen-4-one (45a): $87 \%$ yield (starting with $300 \mathrm{mg}$ of 43a): $\mathrm{mp} 139-140{ }^{\circ} \mathrm{C} .{ }^{1} \mathrm{H}$ NMR $\delta: 1.32(3 \mathrm{H}, \mathrm{t}, J=7.5 \mathrm{~Hz}, 2-$ $\left.\mathrm{CH}_{2} \mathrm{CH}_{3}\right), 2.34\left(1 \mathrm{H}, \mathrm{s}, 8-\mathrm{CH}_{2} \mathrm{OH}\right), 2.69\left(2 \mathrm{H}, \mathrm{q}, \mathrm{J}=7.5 \mathrm{~Hz}, 2-\mathrm{CH}_{2} \mathrm{CH}_{3}\right), 4.01(3 \mathrm{H}, \mathrm{s}, 7-$ $\left.\mathrm{OCH}_{3}\right), 4.97\left(2 \mathrm{H}, \mathrm{s}, 8-\mathrm{CH}_{2} \mathrm{OH}\right), 6.13(1 \mathrm{H}, \mathrm{s}, 3-\mathrm{H}), 7.02(1 \mathrm{H}, \mathrm{d}, J=9.0 \mathrm{~Hz}, 6-\mathrm{H}), 8.17(1 \mathrm{H}$, d, $J=9.0 \mathrm{~Hz}, 5-\mathrm{H})$. ESI-MS m/z $235\left(\mathrm{M}^{+}+1\right)$.

6.1.5.2. 7-Ethoxy-2-ethyl-8-(hydroxymethyl)-4H-chromen-4-one (45b): $42 \%$ yield (starting with $140 \mathrm{mg}$ of 43b): $\mathrm{mp} 100-102{ }^{\circ} \mathrm{C} .{ }^{1} \mathrm{H}$ NMR $\delta: 1.32(3 \mathrm{H}, \mathrm{t}, J=7.2 \mathrm{~Hz}, 2$ $\left.\mathrm{CH}_{2} \mathrm{CH}_{3}\right), 1.51\left(3 \mathrm{H}, \mathrm{t}, \mathrm{J}=6.9 \mathrm{~Hz}, 7-\mathrm{OCH}_{2} \mathrm{CH}_{3}\right), 2.44\left(1 \mathrm{H}, \mathrm{s}, 8-\mathrm{CH}_{2} \mathrm{OH}\right), 2.68(2 \mathrm{H}, \mathrm{q}, J=$ $\left.7.2 \mathrm{~Hz}, 2-\mathrm{CH}_{2} \mathrm{CH}_{3}\right), 4.24\left(2 \mathrm{H}, \mathrm{q}, \mathrm{J}=6.9 \mathrm{~Hz}, 7-\mathrm{OCH}_{2} \mathrm{CH}_{3}\right), 4.98\left(2 \mathrm{H}, \mathrm{s}, 8-\mathrm{CH}_{2} \mathrm{OH}\right), 6.12$ $(1 \mathrm{H}, \mathrm{s}, 3-\mathrm{H}), 7.0(1 \mathrm{H}, \mathrm{d}, J=9.0 \mathrm{~Hz}, 6-\mathrm{H}), 8.13(1 \mathrm{H}, \mathrm{d}, J=9.0 \mathrm{~Hz}, 5-\mathrm{H})$. ESI-MS $m / z 249$ $\left(\mathrm{M}^{+}+1\right)$.

6.1.5.3. 2-Ethyl-8-(hydroxymethyl)-7-isopropoxy-4H-chromen-4-one (45c): $35 \%$ yield (starting with $120 \mathrm{mg}$ of 43c): $\mathrm{mp} 114-116{ }^{\circ} \mathrm{C} .{ }^{1} \mathrm{H}$ NMR $\delta: 1.32(3 \mathrm{H}, \mathrm{t}, J=6.9 \mathrm{~Hz}, 2$ $\left.\mathrm{CH}_{2} \mathrm{CH}_{3}\right), 1.43\left(6 \mathrm{H}, \mathrm{d}, \mathrm{J}=6.0 \mathrm{~Hz}, 7-\mathrm{OCH}\left(\mathrm{CH}_{3}\right)_{2}\right), 2.48\left(1 \mathrm{H}, \mathrm{t}, J=6.4 \mathrm{~Hz}, 8-\mathrm{CH}_{2} \mathrm{OH}\right), 2.68$ $\left(2 \mathrm{H}, \mathrm{q}, J=6.9 \mathrm{~Hz}, 2-\mathrm{CH}_{2} \mathrm{CH}_{3}\right), 4.78\left(1 \mathrm{H}, \mathrm{m}, J=6.0 \mathrm{~Hz}, 7-\mathrm{OCH}\left(\mathrm{CH}_{3}\right)_{2}\right), 4.96(2 \mathrm{H}, \mathrm{d}, J=$ $\left.6.4 \mathrm{~Hz}, 8-\mathrm{CH}_{2} \mathrm{OH}\right), 6.12(1 \mathrm{H}, \mathrm{s}, 3-\mathrm{H}), 7.0(1 \mathrm{H}, \mathrm{d}, J=9.3 \mathrm{~Hz}, 6-\mathrm{H}), 8.12(1 \mathrm{H}, \mathrm{d}, J=9.3 \mathrm{~Hz}$, 5-H). ESI-MS $m / z 263\left(\mathrm{M}^{+}+1\right)$.

6.1.5.4. 2-Ethyl-8-(hydroxymethyl)-7-isobutoxy-4H-chromen-4-one (45d): $58 \%$ yield (starting with $200 \mathrm{mg}$ of $\mathbf{4 3 d})$ : $\mathrm{mp} 120-122^{\circ} \mathrm{C} .{ }^{1} \mathrm{H}$ NMR $\delta: 1.08(6 \mathrm{H}, \mathrm{d}, J=6.6 \mathrm{~Hz}, 7-$ $\left.\mathrm{OCH}_{2} \mathrm{CH}\left(\mathrm{CH}_{3}\right)_{2}\right), 1.32\left(3 \mathrm{H}, \mathrm{t}, J=7.2 \mathrm{~Hz}, 2-\mathrm{CH}_{2} \mathrm{CH}_{3}\right), 2.19(1 \mathrm{H}, \mathrm{m}, J=6.6 \mathrm{~Hz}, 7-$

$\left.\mathrm{OCH}_{2} \mathrm{CH}\left(\mathrm{CH}_{3}\right)_{2}\right), 2.35\left(1 \mathrm{H}, \mathrm{s}, 8-\mathrm{CH}_{2} \mathrm{OH}\right), 2.68\left(2 \mathrm{H}, J=7.2 \mathrm{~Hz}, 2-\mathrm{CH}_{2} \mathrm{CH}_{3}\right), 3.93(2 \mathrm{H}, \mathrm{d}, J$ $\left.=6.6 \mathrm{~Hz}, 7-\mathrm{OCH}_{2} \mathrm{CH}\left(\mathrm{CH}_{3}\right)_{2}\right), 4.98\left(2 \mathrm{H}, \mathrm{s}, 8-\mathrm{CH}_{2} \mathrm{OH}\right), 6.13(1 \mathrm{H}, \mathrm{s}, 3-\mathrm{H}), 6.99(1 \mathrm{H}, \mathrm{d}, J=$ $9.0 \mathrm{~Hz}, 6-\mathrm{H}), 8.13(1 \mathrm{H}, \mathrm{d}, J=9.0 \mathrm{~Hz}, 5-\mathrm{H})$. ESI-MS $m / z 277\left(\mathrm{M}^{+}+1\right)$.

6.1.5.5. 2-(1-Bromoethyl)-8-(hydroxymethyl)-7-methoxy-4H-chromen-4-one (46e): $38 \%$ yield (starting with $100 \mathrm{mg}$ of $\mathbf{4 4 e})$ : colorless oil. ${ }^{1} \mathrm{H}$ NMR $\delta: 1.97(3 \mathrm{H}, \mathrm{d}, J=6.9 \mathrm{~Hz}, 2$ $\left.\mathrm{CHBrCH}_{3}\right), 2.37\left(1 \mathrm{H}, \mathrm{s}, 8-\mathrm{CH}_{2} \mathrm{OH}\right), 4.01\left(3 \mathrm{H}, \mathrm{s}, 7-\mathrm{OCH}_{3}\right), 4.90(1 \mathrm{H}, \mathrm{q}, J=6.9 \mathrm{~Hz}, 2-$ $\left.\mathrm{CHBrCH}_{3}\right), 5.01\left(2 \mathrm{H}, \mathrm{s}, 8-\mathrm{CH}_{2} \mathrm{OH}\right), 6.33(1 \mathrm{H}, \mathrm{s}, 3-\mathrm{H}), 7.05(1 \mathrm{H}, \mathrm{d}, \mathrm{J}=9.0 \mathrm{~Hz}, 6-\mathrm{H}), 8.16$ $(1 \mathrm{H}, \mathrm{d}, J=9.0 \mathrm{~Hz}, 5-\mathrm{H})$. ESI-MS $m / z 313\left(\mathrm{M}^{+}+1\right)$.

6.1.5.6. 2-(1-Bromoethyl)-7-ethoxy-8-(hydroxymethyl)-4H-chromen-4-one (46f): $34 \%$ yield (starting with $90 \mathrm{mg}$ of 44f): colorless oil. ${ }^{1} \mathrm{H}$ NMR $\delta: 1.50(3 \mathrm{H}, \mathrm{t}, J=7.2 \mathrm{~Hz}, 7$ $\left.\mathrm{OCH}_{2} \mathrm{CH}_{3}\right), 1.97\left(3 \mathrm{H}, \mathrm{d}, J=6.9 \mathrm{~Hz}, 2-\mathrm{CHBrCH}_{3}\right), 2.27\left(1 \mathrm{H}, \mathrm{s}, 8-\mathrm{CH}_{2} \mathrm{OH}\right), 4.25(2 \mathrm{H}, \mathrm{q}, J=$ $\left.7.2 \mathrm{~Hz}, 7-\mathrm{OCH}_{2} \mathrm{CH}_{3}\right), 4.95\left(1 \mathrm{H}, \mathrm{q}, \mathrm{J}=6.9 \mathrm{~Hz}, 2-\mathrm{CHBrCH}_{3}\right), 5.01\left(2 \mathrm{H}, \mathrm{s}, 8-\mathrm{CH}_{2} \mathrm{OH}\right), 6.33$ $(1 \mathrm{H}, \mathrm{s}, 3-\mathrm{H}), 7.02(1 \mathrm{H}, \mathrm{d}, J=8.7 \mathrm{~Hz}, 6-\mathrm{H}), 8.14(1 \mathrm{H}, \mathrm{d}, J=8.7 \mathrm{~Hz}, 5-\mathrm{H})$. ESI-MS $m / z 327$ $\left(\mathrm{M}^{+}+1\right)$.

6.1.5.7. 2-(1-Bromoethyl)-8-(hydroxymethyl)-7-isopropoxy-4H-chromen-4-one (46g): $24 \%$ yield (starting with $120 \mathrm{mg}$ of $\mathbf{4 4 g}$ ): $\mathrm{mp} 63-65{ }^{\circ} \mathrm{C} .{ }^{1} \mathrm{H}$ NMR $\delta: 1.39(6 \mathrm{H}, \mathrm{d}, J=6.0 \mathrm{~Hz}$, $\left.7-\mathrm{OCH}\left(\mathrm{CH}_{3}\right)_{2}\right), 1.97\left(3 \mathrm{H}, \mathrm{d}, \mathrm{J}=6.9 \mathrm{~Hz}, 2-\mathrm{CHBrCH}_{3}\right), 2.47\left(1 \mathrm{H}, \mathrm{s}, 8-\mathrm{CH}_{2} \mathrm{OH}\right), 4.80(1 \mathrm{H}$, $\left.\mathrm{m}, J=6.0 \mathrm{~Hz}, 7-\mathrm{OCH}\left(\mathrm{CH}_{3}\right)_{2}\right), 4.91\left(1 \mathrm{H}, \mathrm{q}, J=6.9 \mathrm{~Hz}, 2-\mathrm{CHBrCH}_{3}\right), 4.99(2 \mathrm{H}, \mathrm{s}, 8-$ 
$\left.\mathrm{CH}_{2} \mathrm{OH}\right), 6.33(1 \mathrm{H}, \mathrm{s}, 3-\mathrm{H}), 7.02(1 \mathrm{H}, \mathrm{d}, J=9.3 \mathrm{~Hz}, 6-\mathrm{H}), 8.12(1 \mathrm{H}, \mathrm{d}, J=9.3 \mathrm{~Hz}, 5-\mathrm{H})$. ESI-MS $m / z 341\left(\mathrm{M}^{+}+1\right)$.

6.1.5.8. 2-(1-Bromoethyl)-8-(hydroxymethyl)-7-isobutoxy-4H-chromen-4-one (46h): $14 \%$ yield (starting with $200 \mathrm{mg}$ of $\mathbf{4 4 h}$ ): $\mathrm{mp} 116-118^{\circ} \mathrm{C} .{ }^{1} \mathrm{H}$ NMR $\delta: 1.07(6 \mathrm{H}, \mathrm{d}, J=6.6$ $\left.\mathrm{Hz}, 7-\mathrm{OCH}_{2} \mathrm{CH}\left(\mathrm{CH}_{3}\right)_{2}\right), 1.58\left(3 \mathrm{H}, \mathrm{d}, J=6.6 \mathrm{~Hz}, 2-\mathrm{CHBrCH}_{3}\right), 2.18(1 \mathrm{H}, \mathrm{m}, J=6.6 \mathrm{~Hz}, 7-$ $\left.\mathrm{OCH}_{2} \mathrm{CH}\left(\mathrm{CH}_{3}\right)_{2}\right), 3.10\left(1 \mathrm{H}, \mathrm{s}, 8-\mathrm{CH}_{2} \mathrm{OH}\right), 3.93\left(2 \mathrm{H}, \mathrm{d}, \mathrm{J}=6.6 \mathrm{~Hz}, 7-\mathrm{OCH}_{2} \mathrm{CH}\left(\mathrm{CH}_{3}\right)_{2}\right), 4.70$ $\left(1 \mathrm{H}, \mathrm{q}, J=6.6 \mathrm{~Hz}, 2-\mathrm{CHBrCH}_{3}\right), 5.49\left(2 \mathrm{H}, \mathrm{s}, J=15.3 \mathrm{~Hz}, 8-\mathrm{CH}_{2} \mathrm{OH}\right), 6.34(1 \mathrm{H}, \mathrm{s}, 3-\mathrm{H}), 7.0$ $(1 \mathrm{H}, \mathrm{d}, J=9.0 \mathrm{~Hz}, 6-\mathrm{H}), 8.17(1 \mathrm{H}, \mathrm{d}, J=9.0 \mathrm{~Hz}, 5-\mathrm{H})$. ESI-MS $m / z 355\left(\mathrm{M}^{+}+1\right)$.

6.1.6. Synthesis of 1'-alkoxy-seco-DCPs (8-15)-The substituted 8hydroxymethylchromone (45a-d or 46e-h, 1 equiv), $S$-(-)-camphanic chloride (2.5 equiv), and DMAP (6 equiv) were stirred in $\mathrm{CH}_{2} \mathrm{Cl}_{2}(3 \mathrm{~mL})$ for $1 \mathrm{~h}$ at room temperature, monitored by TLC $\left(\mathrm{CH}_{2} \mathrm{Cl}_{2} / \mathrm{MeOH} 20: 1\right)$. At completion, the mixture was concentrated and the residue was purified by column chromatography with an eluent of hexane/EtOAc 3:1 to afford eight target compounds (8-15).

6.1.6.1. 4'-((-)-Camphanoyloxymethyl)-2-ethyl-7-methoxy-4H-chromen-4-one (8): $78 \%$ yield (starting with $32 \mathrm{mg}$ of 45a): $\mathrm{mp} 164-165{ }^{\circ} \mathrm{C} .{ }^{1} \mathrm{H}$ NMR $\delta 0.92,1.00,1.10(9 \mathrm{H}, \mathrm{s}$, camphanoyl- $\left.\mathrm{CH}_{3} \times 3\right), 1.31\left(3 \mathrm{H}, \mathrm{t}, J=7.8 \mathrm{~Hz}, 2-\mathrm{CH}_{2} \mathrm{CH}_{3}\right), 1.61-2.46(4 \mathrm{H}, \mathrm{m}$, camphanoyl$\left.\mathrm{CH}_{2} \times 2\right), 2.66\left(2 \mathrm{H}, \mathrm{q}, J=7.8 \mathrm{~Hz}, 2-\mathrm{CH}_{2} \mathrm{CH}_{3}\right), 3.97\left(3 \mathrm{H}, \mathrm{s}, 7-\mathrm{OCH}_{3}\right), 5.54(2 \mathrm{H}, \mathrm{t}, J=11.4$ $\left.\mathrm{Hz}, 4^{\prime}-\mathrm{CH}_{2} \mathrm{O}-\right), 6.14(1 \mathrm{H}, \mathrm{s}, 3-\mathrm{H}), 7.02(1 \mathrm{H}, \mathrm{d}, J=9.0 \mathrm{~Hz}, 6-\mathrm{H}), 8.22(1 \mathrm{H}, \mathrm{d}, J=9.0 \mathrm{~Hz}, 5-$ H). ESI-MS $m / z 415\left(\mathrm{M}^{+}+1\right)$.

6.1.6.2. 2-(1-Bromoethyl)-4'-((-)-camphanoyloxymethyl)-7-methoxy-4H-chromen-4one (9): $77 \%$ yield (starting with $33 \mathrm{mg}$ of 46e): $\mathrm{mp} 211-213{ }^{\circ} \mathrm{C} .{ }^{1} \mathrm{H}$ NMR $\delta 0.92,1.01$, $1.09\left(9 \mathrm{H}, \mathrm{s}\right.$, camphanoyl- $\left.\mathrm{CH}_{3} \times 3\right), 1.62-2.43\left(4 \mathrm{H}, \mathrm{m}\right.$, camphanoyl- $\left.\mathrm{CH}_{2} \times 2\right), 1.88(3 \mathrm{H}, \mathrm{d}, J$ $\left.=6.9 \mathrm{~Hz}, 2-\mathrm{CHBrCH}_{3}\right), 3.99\left(3 \mathrm{H}, \mathrm{s}, 7-\mathrm{OCH}_{3}\right), 4.84\left(1 \mathrm{H}, \mathrm{q}, J=6.9 \mathrm{~Hz}, 2-\mathrm{CHBrCH}_{3}\right), 5.57$ $\left(2 \mathrm{H}, \mathrm{m}, 4^{\prime}-\mathrm{CH}_{2} \mathrm{O}-\right), 6.36(1 \mathrm{H}, \mathrm{s}, 3-\mathrm{H}), 7.05(1 \mathrm{H}, \mathrm{d}, J=9.0 \mathrm{~Hz}, 6-\mathrm{H}), 8.23(1 \mathrm{H}, \mathrm{d}, J=9.0$ $\mathrm{Hz}, 5-\mathrm{H})$. ESI-MS $m / z 493\left(\mathrm{M}^{+}+1\right)$.

6.1.6.3. 4'-((-)-Camphanoyloxymethyl)-7-ethoxy-2-ethyl-4H-chromen-4-one (10): $77 \%$ yield (starting with $24 \mathrm{mg}$ of $\mathbf{4 5 b})$ : $\mathrm{mp} 117-118{ }^{\circ} \mathrm{C} .{ }^{1} \mathrm{H}$ NMR $\delta 0.93,1.01,1.10(9 \mathrm{H}, \mathrm{s}$, camphanoyl- $\left.\mathrm{CH}_{3} \times 3\right), 1.31\left(3 \mathrm{H}, \mathrm{t}, J=7.5 \mathrm{~Hz}, 2-\mathrm{CH}_{2} \mathrm{CH}_{3}\right), 1.46(3 \mathrm{H}, \mathrm{t}, J=6.9 \mathrm{~Hz}, 7-$ $\left.\mathrm{OCH}_{2} \mathrm{CH}_{3}\right), 1.64-2.46\left(4 \mathrm{H}, \mathrm{m}\right.$, camphanoyl- $\left.\mathrm{CH}_{2} \times 2\right), 2.66\left(2 \mathrm{H}, \mathrm{q}, J=7.5 \mathrm{~Hz}, 2-\mathrm{CH}_{2} \mathrm{CH}_{3}\right)$, $4.21\left(2 \mathrm{H}, \mathrm{q}, J=6.9 \mathrm{~Hz}, 7-\mathrm{OCH}_{2} \mathrm{CH}_{3}\right), 5.54\left(2 \mathrm{H}, \mathrm{t}, J=11.4 \mathrm{~Hz}, 4^{\prime}-\mathrm{CH}_{2} \mathrm{O}-\right), 6.14(1 \mathrm{H}, \mathrm{s}, 3-$ H), $6.99(1 \mathrm{H}, \mathrm{d}, J=9.0 \mathrm{~Hz}, 6-\mathrm{H}), 8.20(1 \mathrm{H}, \mathrm{d}, J=9.0 \mathrm{~Hz}, 5-\mathrm{H})$. ESI-MS $m / z 429\left(\mathrm{M}^{+}+1\right)$.

6.1.6.4. 2-(1-Bromoethyl)-4'-((-)-camphanoyloxymethyl)-7-ethoxy-4H-chromen-4-one (11): $58 \%$ yield (starting with $19 \mathrm{mg}$ of $\mathbf{4 6 f}$ ): $\mathrm{mp} 151-152{ }^{\circ} \mathrm{C} .{ }^{1} \mathrm{H}$ NMR $\delta 0.93,1.02,1.09$ $\left(9 \mathrm{H}, \mathrm{s}\right.$, camphanoyl- $\left.\mathrm{CH}_{3} \times 3\right), 1.47\left(3 \mathrm{H}, \mathrm{t}, J=6.9 \mathrm{~Hz}, 7-\mathrm{OCH}_{2} \mathrm{CH}_{3}\right), 1.62-2.43(7 \mathrm{H}, \mathrm{m}$, camphanoyl- $\mathrm{CH}_{2} \times 2$ and 2- $\left.\mathrm{CHBrCH}_{3}\right), 4.23\left(2 \mathrm{H}, \mathrm{q}, J=6.9 \mathrm{~Hz}, 7-\mathrm{OCH}_{2} \mathrm{CH}_{3}\right), 4.88(1 \mathrm{H}, \mathrm{q}$, $\left.2-\mathrm{CHBrCH}_{3}\right), 5.58\left(2 \mathrm{H}, \mathrm{m}, 4^{\prime}-\mathrm{CH}_{2} \mathrm{O}-\right), 6.35(1 \mathrm{H}, \mathrm{d}, J=8.4 \mathrm{~Hz}, 3-\mathrm{H}), 7.02(1 \mathrm{H}, \mathrm{d}, J=9.0$ $\mathrm{Hz}, 6-\mathrm{H}), 8.20(1 \mathrm{H}, \mathrm{d}, J=9.0 \mathrm{~Hz}, 5-\mathrm{H})$. ESI-MS $m / z, 507\left(\mathrm{M}^{+}+1\right)$.

6.1.6.5. 4'-((-)-Camphanoyloxymethyl)-2-ethyl-7-isopropoxy-4H-chromen-4-one (12): $70 \%$ yield (starting with $38 \mathrm{mg}$ of $\mathbf{4 5 c}$ ): $\mathrm{mp} 168-169^{\circ} \mathrm{C} .{ }^{1} \mathrm{H}$ NMR $\delta 0.94,1.01,1.10(9 \mathrm{H}, \mathrm{s}$, camphanoyl- $\left.\mathrm{CH}_{3} \times 3\right), 1.30\left(3 \mathrm{H}, \mathrm{t}, J=7.2 \mathrm{~Hz}, 2-\mathrm{CH}_{2} \mathrm{CH}_{3}\right), 1.39(6 \mathrm{H}, \mathrm{d}, J=6.0 \mathrm{~Hz}, 7-$ $\left.\mathrm{OCH}\left(\mathrm{CH}_{3}\right)_{2}\right), 1.63-2.45\left(4 \mathrm{H}, \mathrm{m}\right.$, camphanoyl- $\left.\mathrm{CH}_{2} \times 2\right), 2.66(2 \mathrm{H}, \mathrm{q}, J=7.2 \mathrm{~Hz}, 2-$ $\left.\mathrm{CH}_{2} \mathrm{CH}_{3}\right), 4.76\left(2 \mathrm{H}, \mathrm{m}, J=6.0 \mathrm{~Hz}, 7-\mathrm{OCH}\left(\mathrm{CH}_{3}\right)_{2}\right), 5.53\left(2 \mathrm{H}, \mathrm{t}, J=11.4 \mathrm{~Hz}, 4^{\prime}-\mathrm{CH}_{2} \mathrm{O}-\right)$, $6.14(1 \mathrm{H}, \mathrm{s}, 3-\mathrm{H}), 7.0(1 \mathrm{H}, \mathrm{d}, J=9.0 \mathrm{~Hz}, 6-\mathrm{H}), 8.20(1 \mathrm{H}, \mathrm{d}, J=9.0 \mathrm{~Hz}, 5-\mathrm{H})$. ESI-MS $m / z$ $443\left(\mathrm{M}^{+}+1\right)$. 
6.1.6.6. 2-(1-Bromoethyl)-4'-((-)-camphanoyloxymethyl)-7-isopropoxy-4H-chromen-4one (13): $92 \%$ yield (starting with $40 \mathrm{mg}$ of $\mathbf{4 6 g}$ ): $\mathrm{mp} 50-52{ }^{\circ} \mathrm{C} .{ }^{1} \mathrm{H}$ NMR $\delta 0.94,1.01,1.09$ (9H, s, camphanoyl- $\left.\mathrm{CH}_{3} \times 3\right), 1.40\left(6 \mathrm{H}, \mathrm{d}, J=6.0 \mathrm{~Hz}, 7-\mathrm{OCH}\left(\mathrm{CH}_{3}\right)_{2}\right), 1.62-2.43(7 \mathrm{H}, \mathrm{m}$, camphanoyl- $\mathrm{CH}_{2} \times 2$ and $\left.2-\mathrm{CHBrCH}_{3}\right), 4.78\left(1 \mathrm{H}, \mathrm{m}, J=6.0 \mathrm{~Hz}, 7-\mathrm{OCH}\left(\mathrm{CH}_{3}\right)_{2}\right), 4.88(1 \mathrm{H}$, $\left.\mathrm{m}, 2-\mathrm{CHBrCH}_{3}\right), 5.55\left(2 \mathrm{H}, \mathrm{m}, 4^{\prime}-\mathrm{CH}_{2} \mathrm{O}-\right), 6.33(1 \mathrm{H}, \mathrm{d}, J=7.5 \mathrm{~Hz}, 3-\mathrm{H}), 7.02(1 \mathrm{H}, \mathrm{d}, J=$ $9.0 \mathrm{~Hz}, 6-\mathrm{H}), 8.20(1 \mathrm{H}, \mathrm{d}, J=9.0 \mathrm{~Hz}, 5-\mathrm{H})$. ESI-MS $m / z 521\left(\mathrm{M}^{+}+1\right)$.

6.1.6.7. 4'-((-)-Camphanoyoxymethyl)-2-ethyl-7-isobutoxy-4H-chromen-4-one (14): $85 \%$ yield (starting with $30 \mathrm{mg}$ of $\mathbf{4 5 d}$ ): $\mathrm{mp} 161-162{ }^{\circ} \mathrm{C} .{ }^{1} \mathrm{H}$ NMR $\delta 0.92,0.99,1.04(9 \mathrm{H}, \mathrm{s}$, camphanoyl- $\left.\mathrm{CH}_{3} \times 3\right), 1.07\left(6 \mathrm{H}, \mathrm{d}, J=6.9 \mathrm{~Hz}, 7-\mathrm{OCH}_{2} \mathrm{CH}\left(\mathrm{CH}_{3}\right)_{2}\right), 1.31(3 \mathrm{H}, \mathrm{t}, J=7.5 \mathrm{~Hz}$, 2- $\left.\mathrm{CH}_{2} \mathrm{CH}_{3}\right), 1.60-2.45\left(5 \mathrm{H}, \mathrm{m}\right.$, camphanoyl- $\left.\mathrm{CH}_{2} \times 2 \& 7-\mathrm{OCH}_{2} \mathrm{CH}\left(\mathrm{CH}_{3}\right)_{2}\right), 2.67(2 \mathrm{H}, \mathrm{q}, J$ $\left.=7.5 \mathrm{~Hz}, 2-\mathrm{CH}_{2} \mathrm{CH}_{3}\right), 3.89\left(2 \mathrm{H}, \mathrm{d}, J=6.9 \mathrm{~Hz}, 7-\mathrm{OCH}_{2} \mathrm{CH}\left(\mathrm{CH}_{3}\right)_{2}\right), 5.56(2 \mathrm{H}, \mathrm{t}, J=17.4$ $\left.\mathrm{Hz}, 4^{\prime}-\mathrm{CH}_{2} \mathrm{O}-\right), 6.14(1 \mathrm{H}, \mathrm{s}, 3-\mathrm{H}), 7.0(1 \mathrm{H}, \mathrm{d}, J=9.0 \mathrm{~Hz}, 6-\mathrm{pH}), 8.20(1 \mathrm{H}, \mathrm{d}, J=9.0 \mathrm{~Hz}, 5-$ H). ESI-MS $m / z 457\left(\mathrm{M}^{+}+1\right)$.

6.1.6.8. 2-(1-Bromoethyl)-4'-((-)-camphanoyloxymethyl)-7-isobutoxy-4H-chromen-4one (15): $92 \%$ yield (starting with $23 \mathrm{mg}$ of $\mathbf{4 6 h}$ ): colorless oil. ${ }^{1} \mathrm{H}$ NMR $\delta 0.98,1.05,1.08$ $\left(9 \mathrm{H}\right.$, s, camphanoyl- $\left.\mathrm{CH}_{3} \times 3\right), 1.12\left(6 \mathrm{H}, \mathrm{d}, \mathrm{J}=6.9 \mathrm{~Hz}, 7-\mathrm{OCH}_{2} \mathrm{CH}\left(\mathrm{CH}_{3}\right)_{2}\right), 1.68(3 \mathrm{H}, \mathrm{d}, \mathrm{J}=$ $\left.6.9 \mathrm{~Hz}, 2-\mathrm{CHBrCH}_{3}\right), 1.93-2.48\left(5 \mathrm{H}, \mathrm{m}\right.$, camphanoyl- $\left.\mathrm{CH}_{2} \times 2 \& 7-\mathrm{OCH}_{2} \mathrm{CH}\left(\mathrm{CH}_{3}\right)_{2}\right), 3.91$ $\left(2 \mathrm{H}, \mathrm{d}, J=6.6 \mathrm{~Hz}, 7-\mathrm{OCH}_{2} \mathrm{CH}\left(\mathrm{CH}_{3}\right)_{2}\right), 5.40\left(2 \mathrm{H}, \mathrm{s}, 4^{\prime}-\mathrm{CH}_{2} \mathrm{O}-\right), 5.86(1 \mathrm{H}, \mathrm{q}, J=6.9 \mathrm{~Hz}, 2-$ $\left.\mathrm{CHBrCH}_{3}\right), 6.33(1 \mathrm{H}, \mathrm{s}, 3-\mathrm{H}), 7.02(1 \mathrm{H}, \mathrm{d}, J=9.3 \mathrm{~Hz}, 6-\mathrm{H}), 8.18(1 \mathrm{H}, \mathrm{d}, J=9.3 \mathrm{~Hz}, 5-\mathrm{H})$. ESI-MS $m / z 535\left(\mathrm{M}^{+}+1\right)$.

\subsection{Synthesis of 1'-aryloxy-seco-DCPs (16-28)}

6.2.1. 2-Ethyl-7-(methoxymethoxy)-8-methyl-4H-chromen-4-one (47)-The procedure was the same as that used for the preparation of $39.60 \%$ yield [starting from $3.0 \mathrm{~g}$ of 41, but using DMF $(20 \mathrm{~mL})$ instead of acetone $(60 \mathrm{~mL})]$ : $\mathrm{mp} 93-94{ }^{\circ} \mathrm{C} .{ }^{1} \mathrm{H}$ NMR $\delta 1.33$ $\left(3 \mathrm{H}, \mathrm{d}, J=7.2 \mathrm{~Hz}, 2-\mathrm{CH}_{2} \mathrm{CH}_{3}\right), 2.34\left(3 \mathrm{H}, \mathrm{s}, 8-\mathrm{CH}_{3}\right), 2.68\left(2 \mathrm{H}, \mathrm{q}, J=7.2 \mathrm{~Hz}, 2-\mathrm{CH}_{2} \mathrm{CH}_{3}\right)$, $3.51\left(3 \mathrm{H}, \mathrm{s}, 7-\mathrm{OCH}_{2} \mathrm{OCH}_{3}\right), 5.31\left(2 \mathrm{H}, \mathrm{s}, 7-\mathrm{OCH}_{2} \mathrm{OCH}_{3}\right), 6.13(1 \mathrm{H}, \mathrm{s}, 3-\mathrm{H}), 7.15(1 \mathrm{H}, \mathrm{d}, J=$ $9.0 \mathrm{~Hz}, 6-\mathrm{H}), 8.01(1 \mathrm{H}, \mathrm{d}, J=9.0 \mathrm{~Hz}, 5-\mathrm{H})$. ESI-MS $m / z 203\left(\mathrm{M}^{+}-45\right)$.

\subsubsection{8-(Bromomethyl)-2-ethyl-7-(methoxymethoxy)-4H-chromen-4-one (48)-} The procedure was the same as that used for the preparation of $\mathbf{4 3} .39 \%$ yield (starting from $1.5 \mathrm{~g}$ of 47): $\mathrm{mp} 61-64{ }^{\circ} \mathrm{C} .{ }^{1} \mathrm{H}$ NMR $\delta 1.36\left(3 \mathrm{H}, \mathrm{t}, J=7.5 \mathrm{~Hz}, 2-\mathrm{CH}_{2} \mathrm{CH}_{3}\right), 2.72(2 \mathrm{H}, \mathrm{q}, J=$ $\left.7.5 \mathrm{~Hz}, 2-\mathrm{CH}_{2} \mathrm{CH}_{3}\right), 3.55\left(3 \mathrm{H}, \mathrm{s}, 7-\mathrm{OCH}_{2} \mathrm{OCH}_{3}\right), 4.80\left(2 \mathrm{H}, \mathrm{s}, 8-\mathrm{CH}_{2} \mathrm{Br}\right), 5.39(2 \mathrm{H}, \mathrm{s}, 7-$ $\left.\mathrm{OCH}_{2} \mathrm{OCH}_{3}\right), 6.16(1 \mathrm{H}, \mathrm{s}, 3-\mathrm{H}), 7.18(1 \mathrm{H}, \mathrm{d}, J=9.0 \mathrm{~Hz}, 6-\mathrm{H}), 8.13(1 \mathrm{H}, \mathrm{d}, J=9.0 \mathrm{~Hz}, 5-$ H). ESI-MS $m / z 327\left(\mathrm{M}^{+}+1\right)$.

\subsubsection{2-Ethyl-7-hydroxy-8-(hydroxymethyl)-4H-chromen-4-one (49)-The}

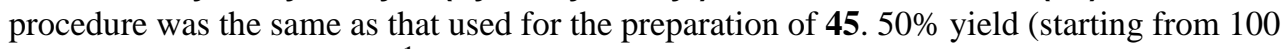
mg of 48): mp $147-148{ }^{\circ} \mathrm{C} .{ }^{1} \mathrm{H}$ NMR $\delta 1.57\left(3 \mathrm{H}, \mathrm{t}, J=7.8 \mathrm{~Hz}, 2-\mathrm{CH}_{2} \mathrm{CH}_{3}\right), 2.98(2 \mathrm{H}, \mathrm{q}, J$ $\left.=7.8 \mathrm{~Hz}, 2-\mathrm{CH}_{2} \mathrm{CH}_{3}\right), 4.86\left(2 \mathrm{H}, \mathrm{s}, 8-\mathrm{CH}_{2} \mathrm{OH}\right), 6.38(1 \mathrm{H}, \mathrm{s}, 3-\mathrm{H}), 7.18(1 \mathrm{H}, \mathrm{d}, J=9.0 \mathrm{~Hz}, 6-$ $\mathrm{H}), 8.14(1 \mathrm{H}, \mathrm{d}, J=9.0 \mathrm{~Hz}, 5-\mathrm{H})$. ESI-MS $m / z 243\left(\mathrm{M}^{+}+\mathrm{Na}\right)$.

\subsubsection{Synthesis of 7-aryloxy-subsituted-8-(hydroxymethyl)-4H-chromen-4-one} $(50 \mathbf{a}-\mathbf{m})$ - The procedure was identical to that used in the preparation of $\mathbf{4 2 a}-\mathbf{b}$.

6.2.4.1. 2-Ethyl-8-(hydroxymethyl)-7-(2-0x0-tetrahydrofuran-3-yloxy)-4H-chromen-4one (50a): $70 \%$ yield (starting from $30 \mathrm{mg}$ of 49): $\mathrm{mp} 210-212{ }^{\circ} \mathrm{C} .{ }^{1} \mathrm{H} \mathrm{NMR}\left(\mathrm{CDCl}_{3}+\right.$ $\left.\mathrm{CD}_{3} \mathrm{OD}\right) \delta 1.33\left(3 \mathrm{H}, \mathrm{t}, J=7.8 \mathrm{~Hz}, 2-\mathrm{CH}_{2} \mathrm{CH}_{3}\right), 2.54\left(2 \mathrm{H}, \mathrm{m}, J=9.0 \mathrm{~Hz}\right.$, furanone $\left.3-\mathrm{H}_{2}\right)$, $2.72\left(2 \mathrm{H}, \mathrm{q}, J=7.8 \mathrm{~Hz}, 2-\mathrm{CH}_{2} \mathrm{CH}_{3}\right), 2.92\left(1 \mathrm{H}, \mathrm{br} \mathrm{s}, 8-\mathrm{OCH}_{2} \mathrm{OH}\right), 4.45,4.62\left(2 \mathrm{H}, \mathrm{m}, J_{1}=9.0\right.$ $\mathrm{Hz}$, furanone 4- $\left.\mathrm{H}_{2}\right), 4.94\left(1 \mathrm{H}, \mathrm{s}, 8-\mathrm{CH}_{2} \mathrm{OH}\right), 5.24(1 \mathrm{H}, \mathrm{t}, J=9.0 \mathrm{~Hz}$, furanone $2-\mathrm{H}), 6.19(1 \mathrm{H}$, 
s, 3-H), $7.17(1 \mathrm{H}, \mathrm{d}, J=9.0 \mathrm{~Hz}, 6-\mathrm{H}), 8.14(1 \mathrm{H}, \mathrm{d}, J=9.0 \mathrm{~Hz}, 5-\mathrm{H})$. ESI-MS $m / z 327$ $\left(\mathrm{M}^{+}+\mathrm{Na}\right)$.

6.2.4.2. 2-Ethyl-8-(hydroxymethyl)-7-(pyridin-2-ylmethoxy)-4H-chromen-4-one (50b): $30 \%$ yield (starting from $38 \mathrm{mg}$ of 49): colorless oil. ${ }^{1} \mathrm{H}$ NMR $\delta 1.36(3 \mathrm{H}, \mathrm{t}, J=7.8 \mathrm{~Hz}, 2$ $\left.\mathrm{CH}_{2} \mathrm{CH}_{3}\right), 2.20\left(1 \mathrm{H}, \mathrm{br} \mathrm{s}, 8-\mathrm{CH}_{2} \mathrm{OH}\right), 2.75\left(2 \mathrm{H}, \mathrm{q}, J=7.8 \mathrm{~Hz}, 2-\mathrm{CH}_{2} \mathrm{CH}_{3}\right), 5.02(2 \mathrm{H}, \mathrm{d}, J=$ $\left.6.9 \mathrm{~Hz}, 8-\mathrm{CH}_{2} \mathrm{OH}\right), 5.39\left(2 \mathrm{H}, \mathrm{s}, 7-\mathrm{OCH}_{2}-\right), 6.17(1 \mathrm{H}, \mathrm{s}, 3-\mathrm{H}), 7.10(1 \mathrm{H}, \mathrm{d}, J=9.0 \mathrm{~Hz}, 6-\mathrm{H})$, $7.37(1 \mathrm{H}, \mathrm{m}, J=7.2 \mathrm{~Hz}$, pyridine $\mathrm{H}), 7.55,7.84(2 \mathrm{H}, \mathrm{d}, J=7.8 \mathrm{~Hz}$, pyridine $\mathrm{H}), 8.10(1 \mathrm{H}$, d, $J=9.0 \mathrm{~Hz}, 5-\mathrm{H}), 8.60\left(1 \mathrm{H}, \mathrm{m}, J=7.8 \mathrm{~Hz}\right.$, pyridine H). ESI-MS m/z $334\left(\mathrm{M}^{+}+\mathrm{Na}\right)$.

6.2.4.3. 2-Ethyl-8-(hydroxymethyl)-7-(pyridin-3-ylmethoxy)-4H-chromen-4-one (50c): $38 \%$ yield (starting from $30 \mathrm{mg}$ of 49 ): $\mathrm{mp} 115-116{ }^{\circ} \mathrm{C} .{ }^{1} \mathrm{H} \mathrm{NMR} \delta 1.33(3 \mathrm{H}, \mathrm{t}, J=7.8 \mathrm{~Hz}$, $\left.2-\mathrm{CH}_{2} \mathrm{CH}_{3}\right), 2.40\left(1 \mathrm{H}, \mathrm{br} \mathrm{s}, 8-\mathrm{CH}_{2} \mathrm{OH}\right), 2.70\left(2 \mathrm{H}, \mathrm{q}, J=7.8 \mathrm{~Hz}, 2-\mathrm{CH}_{2} \mathrm{CH}_{3}\right), 5.00(2 \mathrm{H}, \mathrm{s}, 8-$ $\left.\mathrm{CH}_{2} \mathrm{OH}\right), 5.27\left(2 \mathrm{H}, \mathrm{s}, 7-\mathrm{OCH}_{2}-\right), 6.14(1 \mathrm{H}, \mathrm{s}, 3-\mathrm{H}), 7.07(1 \mathrm{H}, \mathrm{d}, J=9.0 \mathrm{~Hz}, 6-\mathrm{H}), 7.37(1 \mathrm{H}$, q, $J=7.2 \mathrm{~Hz}$, pyridine $\mathrm{H}), 7.81(1 \mathrm{H}, \mathrm{d}, J=7.8 \mathrm{~Hz}$, pyridine $\mathrm{H}), 8.15(1 \mathrm{H}, \mathrm{d}, J=9.0 \mathrm{~Hz}, 5-$ $\mathrm{H}), 8.62(1 \mathrm{H}, \mathrm{d}, J=7.8 \mathrm{~Hz}$, pyridine $\mathrm{H}), 8.72(1 \mathrm{H}, \mathrm{s}$, pyridine $\mathrm{H})$. ESI-MS $m / z 334$ $\left(\mathrm{M}^{+}+\mathrm{Na}\right)$.

6.2.4.4. 2-Ethyl-8-(hydroxymethyl)-7-(pyridin-4-ylmethoxy)-4H-chromen-4-one (50d): $33 \%$ yield (starting from $30 \mathrm{mg}$ of 49 ): $\mathrm{mp} 171-172{ }^{\circ} \mathrm{C} .{ }^{1} \mathrm{H} \mathrm{NMR} \delta 1.33(3 \mathrm{H}, \mathrm{t}, J=7.5 \mathrm{~Hz}$, 2- $\left.\mathrm{CH}_{2} \mathrm{CH}_{3}\right), 2.47\left(1 \mathrm{H}, \mathrm{br} \mathrm{s}, 8-\mathrm{CH}_{2} \mathrm{OH}\right), 2.70\left(2 \mathrm{H}, \mathrm{q}, J=7.5 \mathrm{~Hz}, 2-\mathrm{CH}_{2} \mathrm{CH}_{3}\right), 5.06(2 \mathrm{H}, \mathrm{d}, J$ $\left.=6.3 \mathrm{~Hz}, 8-\mathrm{CH}_{2} \mathrm{OH}\right), 5.28\left(2 \mathrm{H}, \mathrm{s}, 7-\mathrm{OCH}_{2}-\right), 6.14(1 \mathrm{H}, \mathrm{s}, 3-\mathrm{H}), 6.99(1 \mathrm{H}, \mathrm{d}, J=9.0 \mathrm{~Hz}, 6-$ $\mathrm{H}), 7.37(2 \mathrm{H}, \mathrm{d}, J=5.4 \mathrm{~Hz}$, pyridine $\mathrm{H}), 8.14(1 \mathrm{H}, \mathrm{d}, J=9.0 \mathrm{~Hz}, 5-\mathrm{H}), 8.64(2 \mathrm{H}, \mathrm{d}, J=4.8$ $\mathrm{Hz}$, pyridine $\mathrm{H})$. ESI-MS $m / z 312\left(\mathrm{M}^{+}+\mathrm{H}\right)$.

6.2.4.5. 2-Ethyl-8-(hydroxymethyl)-7-(3-(trifluoromethyl)benzyloxy)-4H-chromen-4one (50e): $29 \%$ yield (starting from $22 \mathrm{mg}$ of 49): $\mathrm{mp} 171-172{ }^{\circ} \mathrm{C} .{ }^{1} \mathrm{H}$ NMR $\delta 1.32(3 \mathrm{H}, \mathrm{t}, J$ $\left.=7.5 \mathrm{~Hz}, 2-\mathrm{CH}_{2} \mathrm{CH}_{3}\right), 2.32\left(1 \mathrm{H}\right.$, br s, $\left.8-\mathrm{CH}_{2} \mathrm{OH}\right), 2.69\left(2 \mathrm{H}, \mathrm{q}, J=7.5 \mathrm{~Hz}, 2-\mathrm{CH}_{2} \mathrm{CH}_{3}\right), 5.02$ $\left(2 \mathrm{H}, \mathrm{s}, 8-\mathrm{CH}_{2} \mathrm{OH}\right), 5.30\left(2 \mathrm{H}, \mathrm{s}, 7-\mathrm{OCH}_{2}-\right), 6.13(1 \mathrm{H}, \mathrm{s}, 3-\mathrm{H}), 7.04(1 \mathrm{H}, \mathrm{d}, J=9.0 \mathrm{~Hz}, 6-\mathrm{H})$, 7.53-7.71 (4H, m, aromatic H), $8.14(1 \mathrm{H}, \mathrm{d}, J=9.0 \mathrm{~Hz}, 5-\mathrm{H})$. ESI-MS $m / z 377\left(\mathrm{M}^{+}-\mathrm{H}\right)$.

6.2.4.6. 3-((2-Ethyl-8-(hydroxymethyl)-4-oxo-4H-chromen-7-yloxy)methyl)benzonitrile (50f): $44 \%$ yield (starting from $24 \mathrm{mg}$ of 49): $\mathrm{mp} 201-202{ }^{\circ} \mathrm{C} .{ }^{1} \mathrm{H}$ NMR $\delta 1.35(3 \mathrm{H}, \mathrm{t}, J=$ $\left.7.8 \mathrm{~Hz}, 2-\mathrm{CH}_{2} \mathrm{CH}_{3}\right), 2.74\left(2 \mathrm{H}, \mathrm{q}, J=7.8 \mathrm{~Hz}, 2-\mathrm{CH}_{2} \mathrm{CH}_{3}\right), 5.00\left(2 \mathrm{H}, \mathrm{s}, 8-\mathrm{CH}_{2} \mathrm{OH}\right), 5.31(2 \mathrm{H}$, s, $\left.7-\mathrm{OCH}_{2}-\right), 6.17(1 \mathrm{H}, \mathrm{s}, 3-\mathrm{H}), 7.06(1 \mathrm{H}, \mathrm{d}, J=9.0 \mathrm{~Hz}, 6-\mathrm{H}), 7.56(1 \mathrm{H}, \mathrm{t}, J=7.8 \mathrm{~Hz}$, aromatic $\mathrm{H}), 7.68(1 \mathrm{H}, \mathrm{d}, J=7.8 \mathrm{~Hz}$, aromatic $\mathrm{H}), 7.74(1 \mathrm{H}, \mathrm{d}, J=7.8 \mathrm{~Hz}$, aromatic $\mathrm{H})$, $7.81(1 \mathrm{H}, \mathrm{s}$, aromatic $\mathrm{H}), 8.12(1 \mathrm{H}, \mathrm{d}, J=9.0 \mathrm{~Hz}, 5-\mathrm{H})$. ESI-MS $m / z 334\left(\mathrm{M}^{+}-\mathrm{H}\right)$.

6.2.4.7. 2-Ethyl-8-(hydroxymethyl)-7-(3-methoxybenzyloxy)-4H-chromen-4-one (50g): $34 \%$ yield (starting from $30 \mathrm{mg}$ of 49 ): $\mathrm{mp} 108-110{ }^{\circ} \mathrm{C} .{ }^{1} \mathrm{H} \mathrm{NMR} \delta 1.33(3 \mathrm{H}, \mathrm{t}, J=7.5 \mathrm{~Hz}$, $\left.2-\mathrm{CH}_{2} \mathrm{CH}_{3}\right), 2.38\left(1 \mathrm{H}\right.$, br s, $\left.8-\mathrm{CH}_{2} \mathrm{OH}\right), 2.68\left(2 \mathrm{H}, \mathrm{q}, \mathrm{J}=7.5 \mathrm{~Hz}, 2-\mathrm{CH}_{2} \mathrm{CH}_{3}\right), 3.83(3 \mathrm{H}, \mathrm{s}$, phenyl $\left.\mathrm{OCH}_{3}\right), 5.01\left(2 \mathrm{H}, \mathrm{s}, 8-\mathrm{CH}_{2} \mathrm{OH}\right), 5.23\left(2 \mathrm{H}, \mathrm{s}, 7-\mathrm{OCH}_{2}-\right), 6.13(1 \mathrm{H}, \mathrm{s}, 3-\mathrm{H}), 6.89-7.00$ $(3 \mathrm{H}, \mathrm{m}$, aromatic $\mathrm{H}), 7.05(1 \mathrm{H}, \mathrm{d}, J=9.0 \mathrm{~Hz}, 6-\mathrm{H}), 7.33(1 \mathrm{H}, \mathrm{t}, J=8.1 \mathrm{~Hz}$, aromatic $\mathrm{H})$, $8.12(1 \mathrm{H}, \mathrm{d}, J=9.0 \mathrm{~Hz}, 5-\mathrm{H})$. ESI-MS $m / z 339\left(\mathrm{M}^{+}-\mathrm{H}\right)$.

6.2.4.8. Methyl-3-(2-ethyl-8-(hydroxymethyl)-4-0xo-4H-chromen-7-yloxy)benzoate (50h): $40 \%$ yield (starting from $30 \mathrm{mg}$ of 49): $\mathrm{mp} 153-155^{\circ} \mathrm{C} .{ }^{1} \mathrm{H}$ NMR $\delta 1.32(3 \mathrm{H}, \mathrm{t}, J=$ $\left.7.5 \mathrm{~Hz}, 2-\mathrm{CH}_{2} \mathrm{CH}_{3}\right), 2.33\left(1 \mathrm{H}\right.$, br s, $\left.8-\mathrm{CH}_{2} \mathrm{OH}\right), 2.69\left(2 \mathrm{H}, \mathrm{q}, \mathrm{J}=7.5 \mathrm{~Hz}, 2-\mathrm{CH}_{2} \mathrm{CH}_{3}\right), 3.94$ $\left(3 \mathrm{H}, \mathrm{s}\right.$, phenyl $\left.\mathrm{OCH}_{3}\right), 5.03\left(2 \mathrm{H}, \mathrm{s}, 8-\mathrm{CH}_{2} \mathrm{OH}\right), 5.30\left(2 \mathrm{H}, \mathrm{s}, 7-\mathrm{OCH}_{2}-\right), 6.13(1 \mathrm{H}, \mathrm{s}, 3-\mathrm{H})$, $7.05(1 \mathrm{H}, \mathrm{d}, J=9.0 \mathrm{~Hz}, 6-\mathrm{H}), 7.51(1 \mathrm{H}, \mathrm{t}, J=7.8 \mathrm{~Hz}$, aromatic $\mathrm{H}), 7.65(1 \mathrm{H}, \mathrm{d}, J=7.8 \mathrm{~Hz}$, aromatic $\mathrm{H}), 8.05(1 \mathrm{H}, \mathrm{d}, J=7.8 \mathrm{~Hz}$, aromatic $\mathrm{H}), 8.12(1 \mathrm{H}, \mathrm{s}$, aromatic $\mathrm{H}), 8.14(1 \mathrm{H}, \mathrm{d}, J=$ $9.0 \mathrm{~Hz}, 5-\mathrm{H})$. ESI-MS $m / z, 367\left(\mathrm{M}^{+}-\mathrm{H}\right)$. 
6.2.4.9. 2-Ethyl-8-(hydroxymethyl)-7-(3-methylbenzyloxy)-4H-chromen-4-one (50i): $48 \%$ yield (starting from $30 \mathrm{mg}$ of 49 ): $\mathrm{mp} 147-149^{\circ} \mathrm{C} .{ }^{1} \mathrm{H}$ NMR $\delta 1.32(3 \mathrm{H}, \mathrm{t}, J=7.8 \mathrm{~Hz}$, 2- $\left.\mathrm{CH}_{2} \mathrm{CH}_{3}\right), 2.36\left(1 \mathrm{H}\right.$, br s, $\left.8-\mathrm{CH}_{2} \mathrm{OH}\right), 2.39\left(3 \mathrm{H}, \mathrm{s}\right.$, phenyl $\left.\mathrm{CH}_{3}\right), 2.68(2 \mathrm{H}, \mathrm{q}, J=7.8 \mathrm{~Hz}$, $\left.2-\mathrm{CH}_{2} \mathrm{CH}_{3}\right), 5.00\left(2 \mathrm{H}, \mathrm{br} \mathrm{s}, 8-\mathrm{CH}_{2} \mathrm{OH}\right), 5.22\left(2 \mathrm{H}, \mathrm{s}, 7-\mathrm{OCH}_{2}-\right), 6.13(1 \mathrm{H}, \mathrm{s}, 3-\mathrm{H}), 7.07(1 \mathrm{H}$, $\mathrm{d}, J=9.0 \mathrm{~Hz}, 6-\mathrm{H}), 7.12-7.34(4 \mathrm{H}, \mathrm{m}$, aromatic $\mathrm{H}), 8.14(1 \mathrm{H}, \mathrm{d}, J=9.0 \mathrm{~Hz}, 5-\mathrm{H})$. ESI-MS $m / z 323\left(\mathbf{M}^{+}-\mathrm{H}\right)$.

6.2.4.10. 7-(3,5-Dimethoxybenzyloxy)-2-ethyl-8-(hydroxymethyl)-4H-chromen-4-one (50j): $44 \%$ yield (starting from $30 \mathrm{mg}$ of 49): $\mathrm{mp} 154-155^{\circ} \mathrm{C} .{ }^{1} \mathrm{H}$ NMR $\delta 1.32(3 \mathrm{H}, \mathrm{t}, J=$ $\left.7.8 \mathrm{~Hz}, 2-\mathrm{CH}_{2} \mathrm{CH}_{3}\right), 2.37\left(1 \mathrm{H}, \mathrm{t}, J=6.9 \mathrm{~Hz}, 8-\mathrm{CH}_{2} \mathrm{OH}\right), 2.68(2 \mathrm{H}, \mathrm{q}, J=7.8 \mathrm{~Hz}, 2-$ $\left.\mathrm{CH}_{2} \mathrm{CH}_{3}\right), 3.81\left(6 \mathrm{H}, \mathrm{s}, 2 \times \mathrm{OCH}_{3}\right), 5.01\left(2 \mathrm{H}, \mathrm{d}, \mathrm{J}=6.9 \mathrm{~Hz}, 8-\mathrm{CH}_{2} \mathrm{OH}\right), 5.20(2 \mathrm{H}, \mathrm{s}, 7-$ $\left.\mathrm{OCH}_{2^{-}}\right), 6.13(1 \mathrm{H}, \mathrm{s}, 3-\mathrm{H}), 6.44(1 \mathrm{H}, \mathrm{t}, J=2.4 \mathrm{~Hz}$, aromatic $\mathrm{H}), 6.57(2 \mathrm{H}, \mathrm{d}, J=2.4 \mathrm{~Hz}$, aromatic H), $7.04(1 \mathrm{H}, \mathrm{d}, J=9.0 \mathrm{~Hz}, 6-\mathrm{H}), 8.13(1 \mathrm{H}, \mathrm{d}, J=9.0 \mathrm{~Hz}, 5-\mathrm{H})$. ESI-MS $m / z, 369$ $\left(\mathrm{M}^{+}-\mathrm{H}\right)$.

6.2.4.11. 2-Ethyl-8-(hydroxymethyl)-7-((3-trifluoromethoxy)benzyloxy)-4H-chromen-4one (50k): $73 \%$ yield (starting from $30 \mathrm{mg}$ of 49): $\mathrm{mp} 109-110{ }^{\circ} \mathrm{C} .{ }^{1} \mathrm{H}$ NMR $\delta 1.33$ (3H, t, $J$ $\left.=7.5 \mathrm{~Hz}, 2-\mathrm{CH}_{2} \mathrm{CH}_{3}\right), 2.29\left(1 \mathrm{H}, \mathrm{t}, J=6.6 \mathrm{~Hz}, 8-\mathrm{CH}_{2} \mathrm{OH}\right), 2.69(2 \mathrm{H}, \mathrm{q}, J=7.5 \mathrm{~Hz}, 2-$ $\left.\mathrm{CH}_{2} \mathrm{CH}_{3}\right), 5.02\left(2 \mathrm{H}, \mathrm{d}, \mathrm{J}=6.6 \mathrm{~Hz}, 8-\mathrm{CH}_{2} \mathrm{OH}\right), 5.27\left(2 \mathrm{H}, \mathrm{s}, 7-\mathrm{OCH}_{2}-\right), 6.14(1 \mathrm{H}, \mathrm{s}, 3-\mathrm{H})$, $7.03(1 \mathrm{H}, \mathrm{d}, J=9.0 \mathrm{~Hz}, 6-\mathrm{H}), 7.23(1 \mathrm{H}, \mathrm{d}, J=7.8 \mathrm{~Hz}$, aromatic $\mathrm{H}), 7.31(1 \mathrm{H}, \mathrm{s}$, aromatic $\mathrm{H}), 7.38(1 \mathrm{H}, \mathrm{d}, J=7.8 \mathrm{~Hz}$, aromatic H), $7.46(1 \mathrm{H}, \mathrm{t}, J=7.8 \mathrm{~Hz}$, aromatic H), $8.15(1 \mathrm{H}, \mathrm{d}, J$ $=9.0 \mathrm{~Hz}, 5-\mathrm{H})$. ESI-MS m/z $393\left(\mathrm{M}^{+}-\mathrm{H}\right)$.

6.2.4.12. 7-(2-Bromo-5-methoxybenzyloxy)-2-ethyl-8-(hydroxymethyl)-4H-chromen-4one (501): $39 \%$ yield (starting from $30 \mathrm{mg}$ of 49): $\mathrm{mp} 132-134{ }^{\circ} \mathrm{C} .{ }^{1} \mathrm{H}$ NMR $\delta 1.32(3 \mathrm{H}, \mathrm{t}, J$ $\left.=7.8 \mathrm{~Hz}, 2-\mathrm{CH}_{2} \mathrm{CH}_{3}\right), 1.83\left(1 \mathrm{H}, \mathrm{br} \mathrm{s}, 8-\mathrm{CH}_{2} \mathrm{OH}\right), 2.69\left(2 \mathrm{H}, \mathrm{q}, J=7.8 \mathrm{~Hz}, 2-\mathrm{CH}_{2} \mathrm{CH}_{3}\right), 3.81$ $\left(3 \mathrm{H}, \mathrm{s}, \mathrm{OCH}_{3}\right), 5.02\left(2 \mathrm{H}, \mathrm{s}, 8-\mathrm{CH}_{2} \mathrm{OH}\right), 5.26\left(2 \mathrm{H}, \mathrm{s}, 7-\mathrm{OCH}_{2}-\right), 6.13(1 \mathrm{H}, \mathrm{s}, 3-\mathrm{H}), 6.80(1 \mathrm{H}$, $\mathrm{dd}, J_{l}=9.0 \mathrm{~Hz}, J_{2}=3.3 \mathrm{~Hz}$, aromatic H), $7.04(1 \mathrm{H}, \mathrm{s}$, aromatic $\mathrm{H}), 7.07(1 \mathrm{H}, \mathrm{d}, J=9.0 \mathrm{~Hz}$, aromatic H), $7.51(1 \mathrm{H}, \mathrm{d}, J=8.7 \mathrm{~Hz}, 6-\mathrm{H}), 8.14(1 \mathrm{H}, \mathrm{d}, J=8.7 \mathrm{~Hz}, 5-\mathrm{H})$. ESI-MS $m / z, 441$ $\left(\mathrm{M}^{+}+\mathrm{Na}\right)$.

6.2.4.13. 7-(4,5-Dimethoxy-2-nitrobenzyloxy)-2-ethyl-8-(hydroxymethyl)-4Hchromen-4-one (50m): $76 \%$ yield (starting from $30 \mathrm{mg}$ of 49): $\mathrm{mp} 222-224{ }^{\circ} \mathrm{C} .{ }^{1} \mathrm{H}$ NMR $\delta$ $1.34\left(3 \mathrm{H}, \mathrm{t}, J=7.8 \mathrm{~Hz}, 2-\mathrm{CH}_{2} \mathrm{CH}_{3}\right), 2.18\left(1 \mathrm{H}, \mathrm{t}, J=6.0 \mathrm{~Hz}, 8-\mathrm{CH}_{2} \mathrm{OH}\right), 2.70(2 \mathrm{H}, \mathrm{q}, J=$ $\left.7.8 \mathrm{~Hz}, 2-\mathrm{CH}_{2} \mathrm{CH}_{3}\right), 3.99\left(6 \mathrm{H}, \mathrm{s}, 2 \times \mathrm{OCH}_{3}\right), 5.07\left(2 \mathrm{H}, \mathrm{d}, J=6.0 \mathrm{~Hz}, 8-\mathrm{CH}_{2} \mathrm{OH}\right), 5.68(2 \mathrm{H}$, s, 7- $\left.\mathrm{OCH}_{2^{-}}\right), 6.15(1 \mathrm{H}, \mathrm{s}, 3-\mathrm{H}), 7.07(1 \mathrm{H}, \mathrm{d}, J=8.7 \mathrm{~Hz}, 6-\mathrm{H}), 7.37(1 \mathrm{H}, \mathrm{s}$, aromatic $\mathrm{H}), 7.80$ $(1 \mathrm{H}, \mathrm{s}$, aromatic $\mathrm{H}), 8.16(1 \mathrm{H}, \mathrm{d}, J=8.7 \mathrm{~Hz}, 5-\mathrm{H})$. ESI-MS $m / z 438\left(\mathrm{M}^{+}+\mathrm{Na}\right)$.

6.2.5. Synthesis of 1 '-aryloxy-subsituted-seco-DCPs (16-28)-The procedure was the same as that used for the preparation of $8-\mathbf{1 5}$.

6.2.5.1. 4'-((-)-Camphanoyloxymethyl)-2-ethyl-7-(2-oxo-tetrahydrofuran-3-yloxy)-4Hchromen-4-one (16): $37 \%$ yield, white solid (starting from $29 \mathrm{mg}$ of 50a): $\mathrm{mp}$ 211-212 ${ }^{\circ} \mathrm{C} .{ }^{1} \mathrm{H}$ NMR $\delta 0.88,0.99,1.07\left(9 \mathrm{H}, \mathrm{s}\right.$, camphanoyl- $\left.\mathrm{CH}_{3} \times 3\right), 1.32(3 \mathrm{H}, \mathrm{t}, J=7.8 \mathrm{~Hz}, 2-$ $\left.\mathrm{CH}_{2} \mathrm{CH}_{3}\right), 1.68,1.90,2.00,2.39\left(4 \mathrm{H}, \mathrm{m}\right.$, camphanoyl- $\left.\mathrm{CH}_{2} \times 2\right), 2.68(2 \mathrm{H}, \mathrm{q}, J=7.8 \mathrm{~Hz}, 2-$ $\left.\mathrm{CH}_{2} \mathrm{CH}_{3}\right), 2.83\left(2 \mathrm{H}\right.$, m, furanone $\left.3-\mathrm{H}_{2}\right) ; 4.42,4.58\left(2 \mathrm{H}, \mathrm{m}, J_{l}=6.6 \mathrm{~Hz}, J_{2}=1.5 \mathrm{~Hz}\right.$, furanone $\left.4-\mathrm{H}_{2}\right), 5.19(1 \mathrm{H}, \mathrm{t}, J=7.8 \mathrm{~Hz}$, furanone $2-\mathrm{H}), 5.58\left(2 \mathrm{H}, \mathrm{m}, J=7.5 \mathrm{~Hz}, 4^{\prime}-\mathrm{CH}_{2}-\right), 6.16(1 \mathrm{H}$, s, 3-H), $7.21\left(1 \mathrm{H}, \mathrm{dd}, J_{l}=9.0 \mathrm{~Hz}, J_{2}=3.3 \mathrm{~Hz}, 6-\mathrm{H}\right), 8.22(1 \mathrm{H}, \mathrm{d}, J=9.0 \mathrm{~Hz}, 5-\mathrm{H})$. ESI-MS $m /$ z $507\left(\mathrm{M}^{+}+\mathrm{Na}\right)$.

6.2.5.2. 4'-((-)-Camphanoyloxymethyl)-2-ethyl-7-(pyridin-2-ylmethoxy)-4Hchromen-4-one (17): 44\% yield, white solid (starting from $16 \mathrm{mg}$ of 50b): $\mathrm{mp} 169-170$ 
${ }^{\circ} \mathrm{C} .{ }^{1} \mathrm{H}$ NMR $\delta$ 0.86, 0.97, $1.08\left(9 \mathrm{H}, \mathrm{s}\right.$, camphanoyl- $\left.\mathrm{CH}_{3} \times 3\right), 1.32(3 \mathrm{H}, \mathrm{t}, J=7.5 \mathrm{~Hz}, 2-$ $\left.\mathrm{CH}_{2} \mathrm{CH}_{3}\right), 1.66,1.87,2.01,2.34\left(4 \mathrm{H}, \mathrm{m}\right.$, camphanoyl- $\left.\mathrm{CH}_{2} \times 2\right), 2.68(2 \mathrm{H}, \mathrm{q}, J=7.5 \mathrm{~Hz}, 2-$ $\left.\mathrm{CH}_{2} \mathrm{CH}_{3}\right), 5.39\left(2 \mathrm{H}, \mathrm{s}, 7-\mathrm{OCH}_{2}-\right), 5.66\left(2 \mathrm{H}, \mathrm{s}, 4^{\prime}-\mathrm{CH}_{2}-\right), 6.15(1 \mathrm{H}, \mathrm{s}, 3-\mathrm{H}), 7.05(1 \mathrm{H}, \mathrm{d}, J=$ $9.0 \mathrm{~Hz}, 6-\mathrm{H}), 7.26,7.55(2 \mathrm{H}, \mathrm{m}, J=7.8 \mathrm{~Hz}$, pyridine $\mathrm{H}), 7.78\left(1 \mathrm{H}, \mathrm{m}, J_{l}=7.8 \mathrm{~Hz}, J_{2}=1.8\right.$ $\mathrm{Hz}$, pyridine $\mathrm{H}), 8.18(1 \mathrm{H}, \mathrm{d}, J=9.0 \mathrm{~Hz}, 5-\mathrm{H}), 8.61(1 \mathrm{H}, \mathrm{m}, J=7.8 \mathrm{~Hz}$, pyridine H). ESIMS $m / z 514\left(\mathrm{M}^{+}+\mathrm{Na}\right)$.

6.2.5.3. 4'-((-)-Camphanoyloxymethyl)-2-ethyl-7-(pyridin-3-ylmethoxy)-4Hchromen-4-one (18): $83 \%$ yield, white solid (starting from $16 \mathrm{mg}$ of 50c): $\mathrm{mp} 166-167$ ${ }^{\circ} \mathrm{C} .{ }^{1} \mathrm{H}$ NMR $\delta 0.81,0.95,1.08\left(9 \mathrm{H}, \mathrm{s}\right.$, camphanoyl- $\left.\mathrm{CH}_{3} \times 3\right), 1.32(3 \mathrm{H}, \mathrm{t}, J=7.5 \mathrm{~Hz}, 2-$ $\left.\mathrm{CH}_{2} \mathrm{CH}_{3}\right), 1.66,1.87,2.01,2.34\left(4 \mathrm{H}, \mathrm{m}\right.$, camphanoyl- $\left.\mathrm{CH}_{2} \times 2\right), 2.67(2 \mathrm{H}, \mathrm{q}, J=7.5 \mathrm{~Hz}, 2-$ $\left.\mathrm{CH}_{2} \mathrm{CH}_{3}\right), 5.27\left(2 \mathrm{H}, \mathrm{s}, 7-\mathrm{OCH}_{2}\right), 5.57\left(2 \mathrm{H}, \mathrm{q}, J=11.4 \mathrm{~Hz}, 4^{\prime}-\mathrm{CH}_{2}-\right), 6.16(1 \mathrm{H}, \mathrm{s}, 3-\mathrm{H})$, $7.08(1 \mathrm{H}, \mathrm{d}, J=8.7 \mathrm{~Hz}, 6-\mathrm{H}), 7.39\left(1 \mathrm{H}, \mathrm{dd}, J_{l}=7.8 \mathrm{~Hz}, J_{2}=4.8 \mathrm{~Hz}\right.$, pyridine $\left.\mathrm{H}\right), 7.84(1 \mathrm{H}, \mathrm{d}$, $J=7.8 \mathrm{~Hz}$, pyridine $\mathrm{H}), 8.23(1 \mathrm{H}, \mathrm{d}, J=8.7 \mathrm{~Hz}, 5-\mathrm{H}), 7.78\left(1 \mathrm{H}, \mathrm{dd}, J_{l}=6.3 \mathrm{~Hz}, J_{2}=1.8 \mathrm{~Hz}\right.$, pyridine $\mathrm{H}), 8.69(1 \mathrm{H}, \mathrm{d}, J=1.2 \mathrm{~Hz}$, pyridine $\mathrm{H})$. ESI-MS $m / z 492\left(\mathrm{M}^{+}+\mathrm{H}\right)$.

6.2.5.4. 4'-((-)-Camphanoyloxymethyl)-2-ethyl-7-(pyridin-4-ylmethoxy)-4Hchromen-4-one (19): $90 \%$ yield, white solid (starting from $14 \mathrm{mg}$ of 50d): $\mathrm{mp} 162-163$ ${ }^{\circ} \mathrm{C} .{ }^{1} \mathrm{H}$ NMR $\delta 0.84,0.97,1.08\left(9 \mathrm{H}, \mathrm{s}\right.$, camphanoyl- $\left.\mathrm{CH}_{3} \times 3\right), 1.33(3 \mathrm{H}, \mathrm{t}, J=7.5 \mathrm{~Hz}, 2-$ $\left.\mathrm{CH}_{2} \mathrm{CH}_{3}\right), 1.66,1.87,2.01,2.39\left(4 \mathrm{H}, \mathrm{m}\right.$, camphanoyl- $\left.\mathrm{CH}_{2} \times 2\right), 2.68(2 \mathrm{H}, \mathrm{q}, J=7.5 \mathrm{~Hz}, 2-$ $\left.\mathrm{CH}_{2} \mathrm{CH}_{3}\right), 5.28\left(2 \mathrm{H}, \mathrm{s}, 7-\mathrm{OCH}_{2}-\right), 5.64\left(2 \mathrm{H}, \mathrm{q}, J=11.4 \mathrm{~Hz}, 4^{\prime}-\mathrm{CH}_{2}-\right), 6.16(1 \mathrm{H}, \mathrm{s}, 3-\mathrm{H})$, $7.00(1 \mathrm{H}, \mathrm{d}, J=9.0 \mathrm{~Hz}, 6-\mathrm{H}), 7.38(2 \mathrm{H}, \mathrm{d}, J=6.0 \mathrm{~Hz}$, pyridine $\mathrm{H}), 8.21(1 \mathrm{H}, \mathrm{d}, J=9.0 \mathrm{~Hz}$, $5-\mathrm{H}), 8.65\left(2 \mathrm{H}, \mathrm{d}, J=6.0 \mathrm{~Hz}\right.$, pyridine H). ESI-MS $m / z, 492\left(\mathrm{M}^{+}+\mathrm{H}\right)$.

6.2.5.5. 4'-((-)-Camphanoyloxymethyl)-2-ethyl-7-(3-(trifluoromethyl)benzyloxy)-4Hchromen-4-one (20): $74 \%$ yield, white solid (starting from $11 \mathrm{mg}$ of 50e): $\mathrm{mp}$ 156-157 ${ }^{\circ} \mathrm{C} .{ }^{1} \mathrm{H}$ NMR $\delta 0.81,0.94,1.07\left(9 \mathrm{H}, \mathrm{s}\right.$, camphanoyl- $\left.\mathrm{CH}_{3} \times 3\right), 1.32(3 \mathrm{H}, \mathrm{t}, J=7.8 \mathrm{~Hz}, 2$ $\left.\mathrm{CH}_{2} \mathrm{CH}_{3}\right), 1.66,1.86,1.98,2.35\left(4 \mathrm{H}, \mathrm{m}\right.$, camphanoyl- $\left.\mathrm{CH}_{2} \times 2\right), 2.70(2 \mathrm{H}, \mathrm{q}, J=7.8 \mathrm{~Hz}, 2-$ $\left.\mathrm{CH}_{2} \mathrm{CH}_{3}\right), 5.29\left(2 \mathrm{H}, \mathrm{s}, 7-\mathrm{OCH}_{2}-\right), 5.60\left(2 \mathrm{H}, \mathrm{q}, J=11.4 \mathrm{~Hz}, 4^{\prime}-\mathrm{CH}_{2}-\right), 6.16(1 \mathrm{H}, \mathrm{s}, 3-\mathrm{H})$, $7.05(1 \mathrm{H}, \mathrm{d}, J=9.0 \mathrm{~Hz}, 6-\mathrm{H}), 7.54-7.69(4 \mathrm{H}, \mathrm{m}$, aromatic $\mathrm{H}), 8.22(1 \mathrm{H}, \mathrm{d}, J=9.0 \mathrm{~Hz}, 5-\mathrm{H})$. ESI-MS $m / z 559\left(\mathrm{M}^{+}+\mathrm{H}\right)$.

6.2.5.6. 4'-((-)-Camphanoyloxymethyl)-7-(3-cyanobenzyloxy)-2-ethyl-4H-chromen-4one (21): $65 \%$ yield, white solid (starting from $16 \mathrm{mg}$ of 50f): $\mathrm{mp} 175-176{ }^{\circ} \mathrm{C} .{ }^{1} \mathrm{H}$ NMR $\delta$ $0.84,0.98,1.08\left(9 \mathrm{H}, \mathrm{s}\right.$, camphanoyl- $\left.\mathrm{CH}_{3} \times 3\right), 1.32\left(3 \mathrm{H}, \mathrm{t}, J=7.5 \mathrm{~Hz}, 2-\mathrm{CH}_{2} \mathrm{CH}_{3}\right), 1.67$, $1.90,1.99,2.40\left(4 \mathrm{H}, \mathrm{m}\right.$, camphanoyl- $\left.\mathrm{CH}_{2} \times 2\right), 2.70\left(2 \mathrm{H}, \mathrm{q}, J=7.5 \mathrm{~Hz}, 2-\mathrm{CH}_{2} \mathrm{CH}_{3}\right), 5.28$ $\left(2 \mathrm{H}, \mathrm{s}, 7-\mathrm{OCH}_{2}-\right), 5.61\left(2 \mathrm{H}, \mathrm{q}, J=11.4 \mathrm{~Hz}, 4^{\prime}-\mathrm{CH}_{2}-\right), 6.16(1 \mathrm{H}, \mathrm{s}, 3-\mathrm{H}), 7.02(1 \mathrm{H}, \mathrm{d}, J=9.0$ $\mathrm{Hz}, 6-\mathrm{H}), 7.54-7.75(4 \mathrm{H}, \mathrm{m}$, aromatic H), $8.22(1 \mathrm{H}, \mathrm{d}, J=9.0 \mathrm{~Hz}, 5-\mathrm{H})$. ESI-MS m/z 516 $\left(\mathrm{M}^{+}+\mathrm{H}\right)$.

6.2.5.7. 4'-((-)-Camphanoyloxymethyl)-2-ethyl-7-(3-methoxybenzyloxy)-4Hchromen-4-one (22): 57\% yield, white solid (starting from $16 \mathrm{mg}$ of 50g): $\mathrm{mp} 126-127$ ${ }^{\circ} \mathrm{C} .{ }^{1} \mathrm{H}$ NMR $\delta 0.83,0.94,1.07\left(9 \mathrm{H}, \mathrm{s}\right.$, camphanoyl- $\left.\mathrm{CH}_{3} \times 3\right), 1.32(3 \mathrm{H}, \mathrm{t}, J=7.5 \mathrm{~Hz}, 2$ $\left.\mathrm{CH}_{2} \mathrm{CH}_{3}\right), 1.67,1.87,1.98,2.37\left(4 \mathrm{H}, \mathrm{m}\right.$, camphanoyl- $\left.\mathrm{CH}_{2} \times 2\right), 2.69(2 \mathrm{H}, \mathrm{q}, J=7.5 \mathrm{~Hz}, 2-$ $\left.\mathrm{CH}_{2} \mathrm{CH}_{3}\right), 5.23\left(2 \mathrm{H}, \mathrm{s}, 7-\mathrm{OCH}_{2}\right), 3.82\left(3 \mathrm{H}, \mathrm{s}, \mathrm{OCH}_{3}\right), 5.60\left(2 \mathrm{H}, \mathrm{q}, J=11.4 \mathrm{~Hz}, 4^{\prime}-\mathrm{CH}_{2}-\right)$, $6.14(1 \mathrm{H}, \mathrm{s}, 3-\mathrm{H}), 6.87,6.97\left(2 \mathrm{H}, \mathrm{dd}, J_{l}=8.1 \mathrm{~Hz}, J_{2}=2.1 \mathrm{~Hz}\right.$, aromatic $\left.\mathrm{H}\right), 7.00(1 \mathrm{H}, \mathrm{s}$, aromatic $\mathrm{H}), 7.05(1 \mathrm{H}, \mathrm{d}, J=9.0 \mathrm{~Hz}, 6-\mathrm{H}), 7.31(1 \mathrm{H}, \mathrm{t}, J=8.1 \mathrm{~Hz}$, aromatic $\mathrm{H}), 8.18(1 \mathrm{H}$, d, $J=9.0 \mathrm{~Hz}, 5-\mathrm{H})$. ESI-MS $m / z, 543\left(\mathrm{M}^{+}+\mathrm{Na}\right)$.

6.2.5.8. 4'-((-)-Camphanoyloxymethyl)-2-ethyl-7-(3-methoxycarbonyl)benzyloxy)-4Hchromen-4-one (23): $97 \%$ yield, white solid (starting from $20 \mathrm{mg}$ of 50h): $\mathrm{mp}$ 190-191 ${ }^{\circ} \mathrm{C} .{ }^{1} \mathrm{H}$ NMR $\delta 0.82,0.94,1.07\left(9 \mathrm{H}, \mathrm{s}\right.$, camphanoyl- $\left.\mathrm{CH}_{3} \times 3\right), 1.31(3 \mathrm{H}, \mathrm{t}, J=7.8 \mathrm{~Hz}, 2-$ $\left.\mathrm{CH}_{2} \mathrm{CH}_{3}\right), 1.66,1.87,1.99,2.37\left(4 \mathrm{H}, \mathrm{m}\right.$, camphanoyl- $\left.\mathrm{CH}_{2} \times 2\right), 2.67(2 \mathrm{H}, \mathrm{q}, J=7.8 \mathrm{~Hz}, 2-$ 
$\left.\mathrm{CH}_{2} \mathrm{CH}_{3}\right), 3.94\left(3 \mathrm{H}, \mathrm{s},-\mathrm{OCOCH}_{3}\right), 5.29\left(2 \mathrm{H}, \mathrm{s}, 7-\mathrm{OCH}_{2}-\right), 5.60\left(2 \mathrm{H}, \mathrm{q}, J=11.7 \mathrm{~Hz}, 4^{\prime}-\right.$ $\left.\mathrm{CH}_{2} \mathrm{O}-\right), 6.15(1 \mathrm{H}, \mathrm{s}, 3-\mathrm{H}), 7.05(1 \mathrm{H}, \mathrm{d}, J=9.0 \mathrm{~Hz}, 6-\mathrm{H}), 7.51,7.67,8.03(3 \mathrm{H}, \mathrm{d}, J=7.8 \mathrm{~Hz}$, aromatic $\mathrm{H}), 8.09(1 \mathrm{H}, \mathrm{s}$, aromatic $\mathrm{H}), 8.21(1 \mathrm{H}, \mathrm{d}, J=9.0 \mathrm{~Hz}, 5-\mathrm{H})$. ESI-MS $m / z 571$ $\left(\mathrm{M}^{+}+\mathrm{Na}\right)$.

6.2.5.9. 4'-((-)-Camphanoyloxymethyl)-2-ethyl-7-(3-methylbenzyloxy)-4H-chromen-4one (24): $64 \%$ yield, white solid (starting from $21 \mathrm{mg}$ of 50i): $\mathrm{mp} 172-173{ }^{\circ} \mathrm{C} .{ }^{1} \mathrm{H}$ NMR $\delta$ $0.83,0.94,1.07\left(9 \mathrm{H}, \mathrm{s}\right.$, camphanoyl- $\left.\mathrm{CH}_{3} \times 3\right), 1.31\left(3 \mathrm{H}, \mathrm{t}, J=7.8 \mathrm{~Hz}, 2-\mathrm{CH}_{2} \mathrm{CH}_{3}\right), 1.66$, 1.87, 1.98, $2.37\left(4 \mathrm{H}, \mathrm{m}\right.$, camphanoyl- $\left.\mathrm{CH}_{2} \times 2\right), 2.37\left(3 \mathrm{H}, \mathrm{s}, \mathrm{CH}_{3}\right.$ on phenyl), $2.67(2 \mathrm{H}, \mathrm{q}, J$ $\left.=7.8 \mathrm{~Hz}, 2-\mathrm{CH}_{2} \mathrm{CH}_{3}\right), 5.22\left(2 \mathrm{H}, \mathrm{s}, 7-\mathrm{OCH}_{2}-\right), 5.59\left(2 \mathrm{H}, \mathrm{q}, J=11.1 \mathrm{~Hz}, 4^{\prime}-\mathrm{CH}_{2} \mathrm{O}-\right), 6.14$ $(1 \mathrm{H}, \mathrm{s}, 3-\mathrm{H}), 7.06(1 \mathrm{H}, \mathrm{d}, J=9.0 \mathrm{~Hz}, 6-\mathrm{H}), 7.14-7.31(4 \mathrm{H}, \mathrm{m}$, aromatic $\mathrm{H}), 8.19(1 \mathrm{H}, \mathrm{d}, J=$ $9.0 \mathrm{~Hz}, 5-\mathrm{H})$. ESI-MS m/z $527\left(\mathrm{M}^{+}+\mathrm{Na}\right)$.

6.2.5.10. 4'-((-)-Camphanoyloxymethyl)-7-(3,5-dimethoxybenzyloxy)-2-ethyl-4Hchromen-4-one (25): 65\% yield, white solid (starting from $30 \mathrm{mg}$ of 50j): $\mathrm{mp}$ 159-160 ${ }^{\circ} \mathrm{C} .{ }^{1} \mathrm{H}$ NMR $\delta 0.84,0.95,1.07\left(9 \mathrm{H}, \mathrm{s}\right.$, camphanoyl- $\left.\mathrm{CH}_{3} \times 3\right), 1.31(3 \mathrm{H}, \mathrm{t}, J=7.5 \mathrm{~Hz}, 2-$ $\left.\mathrm{CH}_{2} \mathrm{CH}_{3}\right), 1.66,1.87,1.99,2.37$ (4H, m, camphanoyl- $\left.\mathrm{CH}_{2} \times 2\right), 2.67(2 \mathrm{H}, \mathrm{q}, J=7.5 \mathrm{~Hz}, 2-$ $\left.\mathrm{CH}_{2} \mathrm{CH}_{3}\right), 3.80\left(6 \mathrm{H}, \mathrm{s}, 2 \times \mathrm{CH}_{3}\right.$ on phenyl), $5.19\left(2 \mathrm{H}, \mathrm{s}, 7-\mathrm{OCH}_{2}-\right), 5.60(2 \mathrm{H}, \mathrm{q}, J=11.4$ $\left.\mathrm{Hz}, 4^{\prime}-\mathrm{CH}_{2} \mathrm{O}-\right), 6.15(1 \mathrm{H}, \mathrm{s}, 3-\mathrm{H}), 6.42(1 \mathrm{H}, \mathrm{d}, J=2.4 \mathrm{~Hz}$, aromatic $\mathrm{H}), 6.56(2 \mathrm{H}, \mathrm{d}, J=8.4$ $\mathrm{Hz}$, aromatic H), $7.04(1 \mathrm{H}, \mathrm{d}, J=9.0 \mathrm{~Hz}, 6-\mathrm{H}), 8.18(1 \mathrm{H}, \mathrm{d}, J=9.0 \mathrm{~Hz}, 5-\mathrm{H})$. ESI-MS $m / z$ $573\left(\mathrm{M}^{+}+\mathrm{Na}\right)$.

6.2.5.11. 4'-((-)-Camphanoyloxymethyl)-2-ethyl-7-(3-trifluoromethoxybenzyloxy)-4Hchromen-4-one (26): $79 \%$ yield, white solid (starting from $39 \mathrm{mg}$ of 50k): $\mathrm{mp} \mathrm{133-134}$ ${ }^{\circ} \mathrm{C} .{ }^{1} \mathrm{H}$ NMR $\delta 0.82,0.95,1.07\left(9 \mathrm{H}, \mathrm{s}\right.$, camphanoyl- $\left.\mathrm{CH}_{3} \times 3\right), 1.32(3 \mathrm{H}, \mathrm{t}, J=7.5 \mathrm{~Hz}, 2$ $\left.\mathrm{CH}_{2} \mathrm{CH}_{3}\right), 1.66,1.87,1.99,2.37\left(4 \mathrm{H}, \mathrm{m}\right.$, camphanoyl- $\left.\mathrm{CH}_{2} \times 2\right), 2.67(2 \mathrm{H}, \mathrm{q}, J=7.5 \mathrm{~Hz}, 2-$ $\left.\mathrm{CH}_{2} \mathrm{CH}_{3}\right), 5.26\left(2 \mathrm{H}, \mathrm{s}, 7-\mathrm{OCH}_{2}-\right), 5.60\left(2 \mathrm{H}, \mathrm{q}, J=11.1 \mathrm{~Hz}, 4^{\prime}-\mathrm{CH}_{2} \mathrm{O}-\right), 6.15(1 \mathrm{H}, \mathrm{s}, 3-\mathrm{H})$, $7.04(1 \mathrm{H}, \mathrm{d}, J=9.0 \mathrm{~Hz}, 6-\mathrm{H}), 7.22,7.39(2 \mathrm{H}, \mathrm{d}, J=7.8 \mathrm{~Hz}$, aromatic $\mathrm{H}), 7.29(1 \mathrm{H}, \mathrm{s}$, aromatic $\mathrm{H}), 7.46(1 \mathrm{H}, \mathrm{t}, J=7.8 \mathrm{~Hz}$, aromatic $\mathrm{H}), 8.21(1 \mathrm{H}, \mathrm{d}, J=9.0 \mathrm{~Hz}, 5-\mathrm{H})$. ESI-MS $m /$ z $597\left(\mathrm{M}^{+}+\mathrm{Na}\right)$.

6.2.5.12. 7-(2-Bromo-5-methoxybenzyloxy)-4'-((-)-camphanoyloxymethyl)-2-ethyl-4Hchromen-4-one (27): 54\% yield, white solid (starting from $22 \mathrm{mg}$ of 50l): $\mathrm{mp}$ 158-159 ${ }^{\circ} \mathrm{C} .{ }^{1} \mathrm{H}$ NMR $\delta 0.85,0.95,1.07\left(9 \mathrm{H}, \mathrm{s}\right.$, camphanoyl- $\left.\mathrm{CH}_{3} \times 3\right), 1.32(3 \mathrm{H}, \mathrm{t}, J=7.5 \mathrm{~Hz}, 2-$ $\left.\mathrm{CH}_{2} \mathrm{CH}_{3}\right), 1.66,1.87,1.99,2.37\left(4 \mathrm{H}, \mathrm{m}\right.$, camphanoyl- $\left.\mathrm{CH}_{2} \times 2\right), 2.67(2 \mathrm{H}, \mathrm{q}, J=7.5 \mathrm{~Hz}, 2-$ $\left.\mathrm{CH}_{2} \mathrm{CH}_{3}\right), 3.80\left(3 \mathrm{H}, \mathrm{s}, \mathrm{CH}_{3}\right.$ on phenyl), $5.25\left(2 \mathrm{H}, \mathrm{s}, 7-\mathrm{OCH}_{2}-\right), 5.63\left(2 \mathrm{H}, \mathrm{q}, J=11.7 \mathrm{~Hz}, 4^{\prime}-\right.$ $\left.\mathrm{CH}_{2} \mathrm{O}-\right), 6.16(1 \mathrm{H}, \mathrm{s}, 3-\mathrm{H}), 6.77\left(1 \mathrm{H}, \mathrm{dd}, J_{l}=8.7 \mathrm{~Hz}, J_{2}=3.0 \mathrm{~Hz}\right.$, aromatic $\left.\mathrm{H}\right), 7.05(1 \mathrm{H}, \mathrm{d}, J$ $=9.0 \mathrm{~Hz}, 6-\mathrm{H}), 7.08(1 \mathrm{H}, \mathrm{d}, J=3.0 \mathrm{~Hz}$, aromatic $\mathrm{H}), 7.48(1 \mathrm{H}, \mathrm{d}, J=8.7 \mathrm{~Hz}$, aromatic $\mathrm{H})$, $8.22(1 \mathrm{H}, \mathrm{d}, J=9.0 \mathrm{~Hz}, 5-\mathrm{H})$. ESI-MS $m / z 623\left(\mathrm{M}^{+}+\mathrm{Na}\right)$.

6.2.5.13. 4'-((-)-Camphanoyloxymethyl)-7-(4,5-dimethoxy-2-nitrobenzyloxy)-2ethyl-4H-chromen-4-one (28): $79 \%$ yield, light yellow solid (starting from $43 \mathrm{mg}$ of $\mathbf{5 0 m}$ ): $\mathrm{mp} 211-212{ }^{\circ} \mathrm{C} .{ }^{1} \mathrm{H}$ NMR $\delta 0.81,0.94,1.06\left(9 \mathrm{H}, \mathrm{s}\right.$, camphanoyl- $\left.\mathrm{CH}_{3} \times 3\right), 1.34(3 \mathrm{H}, \mathrm{t}, J=$ $\left.7.5 \mathrm{~Hz}, 2-\mathrm{CH}_{2} \mathrm{CH}_{3}\right), 1.66,1.87,1.96,2.37\left(4 \mathrm{H}, \mathrm{m}\right.$, camphanoyl- $\left.\mathrm{CH}_{2} \times 2\right), 2.69(2 \mathrm{H}, \mathrm{q}, J=$ $\left.7.5 \mathrm{~Hz}, 2-\mathrm{CH}_{2} \mathrm{CH}_{3}\right), 4.00\left(6 \mathrm{H}, \mathrm{s}, 2 \times \mathrm{OCH}_{3}\right), 5.66\left(4 \mathrm{H}, \mathrm{s}, 7-\mathrm{OCH}_{2}-\& 4^{\prime}-\mathrm{CH}_{2} \mathrm{O}-\right), 6.17(1 \mathrm{H}$, s, 3-H), $7.09(1 \mathrm{H}, \mathrm{d}, J=9.0 \mathrm{~Hz}, 6-\mathrm{H}), 7.37(1 \mathrm{H}, \mathrm{s}$, aromatic $\mathrm{H}), 7.81(1 \mathrm{H}, \mathrm{s}$, aromatic $\mathrm{H})$, $8.24(1 \mathrm{H}, \mathrm{d}, J=9.0 \mathrm{~Hz}, 5-\mathrm{H})$. ESI-MS $m / z 618\left(\mathrm{M}^{+}+\mathrm{Na}\right)$.

\subsection{Synthesis of 4'-camphanol-seco-DCPs (29-31)}

A mixture of 43a-c (1 equiv), camphanol (1.2 equiv), and $\mathrm{NaH}$ ( 6 equiv) in toluene ( $6 \mathrm{~mL}$ ) was stirred for $4 \mathrm{~h}$ at room temperature and monitored by TLC $\left(\mathrm{CH}_{2} \mathrm{Cl}_{2} / \mathrm{MeOH} 20: 1\right)$. Icewater $(10 \mathrm{~mL})$ was then added to stop the reaction. Following extraction with EtOAc (10 
$\mathrm{mL} \times 3$ ), the organic layer was dried over $\mathrm{Na}_{2} \mathrm{SO}_{4}$. After removal of solvent in vacuo, the residue was purified by PTLC (eluent: $\mathrm{CH}_{2} \mathrm{Cl}_{2} / \mathrm{MeOH} 40: 1$ and 20:1) to give 29-31.

\subsubsection{2-Ethyl-7-methoxy-8-((4,7,7-trimethyl-3-oxo-2-} oxabicyclo[2.2.1] heptan-1-yl)methoxy)methyl)-4H-chromen-4-one (29)-12\% yield, white solid (starting from $50 \mathrm{mg}$ of 43a): $\mathrm{mp} 127-128{ }^{\circ} \mathrm{C} .{ }^{1} \mathrm{H}$ NMR $\delta 0.87(6 \mathrm{H}, \mathrm{s}$, camphanol- $\left.\mathrm{CH}_{3} \times 2\right), 1.07\left(3 \mathrm{H}\right.$, s, camphanol- $\left.\mathrm{CH}_{3}\right), 1.32\left(3 \mathrm{H}, \mathrm{t}, J=7.5 \mathrm{~Hz}, 2-\mathrm{CH}_{2} \mathrm{CH}_{3}\right)$, $1.58-2.10\left(4 \mathrm{H}, \mathrm{m}\right.$, camphanol- $\left.\mathrm{CH}_{2} \times 2\right), 2.68\left(2 \mathrm{H}, \mathrm{q}, J=7.5 \mathrm{~Hz}, 2-\mathrm{CH}_{2} \mathrm{CH}_{3}\right), 3.84(2 \mathrm{H}, \mathrm{q}, J$ $=11.4 \mathrm{~Hz}$, camphanol- $\left.\mathrm{CH}_{2}\right), 3.97\left(3 \mathrm{H}, \mathrm{s}, 7-\mathrm{OCH}_{3}\right), 4.86\left(2 \mathrm{H}, \mathrm{q}, J_{l}=11.4 \mathrm{~Hz}, J_{2}=13.8 \mathrm{~Hz}\right.$, 4'- $\left.\mathrm{CH}_{2} \mathrm{O}-\right), 6.14(1 \mathrm{H}, \mathrm{s}, 3-\mathrm{H}), 7.02(1 \mathrm{H}, \mathrm{d}, J=9.0 \mathrm{~Hz}, 6-\mathrm{H}), 8.18(1 \mathrm{H}, \mathrm{d}, J=9.0 \mathrm{~Hz}, 5-\mathrm{H})$. ESI-MS $m / z, 423\left(\mathrm{M}^{+}+\mathrm{Na}\right)$.

6.3.2. 2-Ethyl-7-ethoxy-8-(((4,7,7-trimethyl-3-oxo-2-oxabicyclo[2.2.1]heptan-1yl)methoxy)methyl)-4H-chro men-4-one (30)-9\% yield, white solid (starting from $100 \mathrm{mg}$ of 43b): $\mathrm{mp} 60-62{ }^{\circ} \mathrm{C} .{ }^{1} \mathrm{H}$ NMR $\delta 0.87\left(6 \mathrm{H}, \mathrm{s}\right.$, camphanol- $\left.\mathrm{CH}_{3} \times 2\right), 1.07(3 \mathrm{H}, \mathrm{s}$, camphanol- $\left.\mathrm{CH}_{3}\right), 1.32\left(3 \mathrm{H}, \mathrm{t}, J=7.5 \mathrm{~Hz}, 2-\mathrm{CH}_{2} \mathrm{CH}_{3}\right), 1.48(3 \mathrm{H}, \mathrm{t}, J=6.9 \mathrm{~Hz}, 7-$ $\left.\mathrm{OCH}_{2} \mathrm{CH}_{3}\right), 1.61-2.04\left(4 \mathrm{H}, \mathrm{m}\right.$, camphanol- $\left.\mathrm{CH}_{2} \times 2\right), 2.67\left(2 \mathrm{H}, \mathrm{q}, J=7.5 \mathrm{~Hz}, 2-\mathrm{CH}_{2} \mathrm{CH}_{3}\right)$, $3.80\left(2 \mathrm{H}, \mathrm{q}, J=13.8 \mathrm{~Hz}\right.$, camphanol- $\left.\mathrm{CH}_{2}\right), 4.20\left(2 \mathrm{H}, \mathrm{q}, J=6.9 \mathrm{~Hz}, 7-\mathrm{OCH}_{2} \mathrm{CH}_{3}\right), 4.87$ $\left(2 \mathrm{H}, \mathrm{q}, J_{l}=10.5 \mathrm{~Hz}, J_{2}=24 \mathrm{~Hz}, 4^{\prime}-\mathrm{CH}_{2} \mathrm{O}-\right), 6.13(1 \mathrm{H}, \mathrm{s}, 3-\mathrm{H}), 6.99(1 \mathrm{H}, \mathrm{d}, J=9.0 \mathrm{~Hz}, 6-\mathrm{H})$, $8.16(1 \mathrm{H}, \mathrm{d}, J=9.0 \mathrm{~Hz}, 5-\mathrm{H})$. ESI-MS $m / z, 437\left(\mathrm{M}^{+}+\mathrm{Na}\right)$.

\subsubsection{2-Ethyl-7-isopropoxy-8-(((4,7,7-trimethyl-3-oxo-2-} oxabicyclo[2.2.1]heptan-1-yl)methoxy)methyl)-4H-c hromen-4-one (31)-5\% yield, colorless oil (starting from $200 \mathrm{mg}$ of 43c). ${ }^{1} \mathrm{H}$ NMR $\delta 0.87\left(6 \mathrm{H}\right.$, s, camphanol- $\mathrm{CH}_{3} \times$ 2), $1.06\left(3 \mathrm{H}, \mathrm{s}\right.$, camphanol- $\left.\mathrm{CH}_{3}\right), 1.32\left(3 \mathrm{H}, \mathrm{t}, J=7.2 \mathrm{~Hz}, 2-\mathrm{CH}_{2} \mathrm{CH}_{3}\right), 1.40(6 \mathrm{H}, \mathrm{d}, J=6.0$ $\left.\mathrm{Hz}, 7-\mathrm{OCH}\left(\mathrm{CH}_{3}\right)_{2}\right), 1.57-2.03\left(4 \mathrm{H}, \mathrm{m}\right.$, camphanol- $\left.\mathrm{CH}_{2} \times 2\right), 2.67(2 \mathrm{H}, \mathrm{q}, J=7.2 \mathrm{~Hz}, 2-$ $\left.\mathrm{CH}_{2} \mathrm{CH}_{3}\right), 3.78\left(2 \mathrm{H}, \mathrm{q}, J=14.4 \mathrm{~Hz}\right.$, camphanol- $\left.\mathrm{CH}_{2}\right), 4.74(1 \mathrm{H}, \mathrm{m}, J=6.0 \mathrm{~Hz}, 7-$ $\left.\mathrm{OCH}\left(\mathrm{CH}_{3}\right)_{2}\right), 4.84\left(2 \mathrm{H}, \mathrm{q}, J_{1}=11.4 \mathrm{~Hz}, J_{2}=10.8 \mathrm{~Hz}, 4^{\prime}-\mathrm{CH}_{2} \mathrm{O}-\right), 6.13(1 \mathrm{H}, \mathrm{s}, 3-\mathrm{H}), 7.0(1 \mathrm{H}$, $\mathrm{d}, J=9.0 \mathrm{~Hz}, 6-\mathrm{H}), 8.13(1 \mathrm{H}, \mathrm{d}, J=9.0 \mathrm{~Hz}, 5-\mathrm{H})$. ESI-MS $m / z 429\left(\mathrm{M}^{+}+1\right)$.

6.4. Synthesis of 4'-piperidinyl oxalamide-seco-DCPs (34-37) -A mixture of 43b ( 1 equiv), piperidinyl oxalamide (1.2 equiv), and DMAP ( 2.5 equiv) in THF $(5 \mathrm{~mL}$ ) was stirred for $24 \mathrm{~h}$ at room temperature and monitored by $\mathrm{TLC}\left(\mathrm{CH}_{2} \mathrm{Cl}_{2} / \mathrm{MeOH} 20: 1\right)$. After removal of solvent in vacuo, the residue was purified by column chromatography (eluent: $\mathrm{CH}_{2} \mathrm{Cl}_{2} / \mathrm{MeOH}$ 99:1) to give 34-37.

\subsubsection{7-Ethoxy-2-ethyl-8-((4-(2-oxo-2-(2-thienyl)acetyl)piperazin-1-} yl)methyl)-4H-chromen-4-one (34)-27\% yield, white solid (starting from $50 \mathrm{mg}$ of 43b): $\mathrm{mp} 62-64{ }^{\circ} \mathrm{C} .{ }^{1} \mathrm{H}$ NMR $\delta 1.31\left(3 \mathrm{H}, \mathrm{t}, J=7.5 \mathrm{~Hz}, 2-\mathrm{CH}_{2} \mathrm{CH}_{3}\right), 1.46(3 \mathrm{H}, \mathrm{t}, J=6.9 \mathrm{~Hz}$, 7- $\left.\mathrm{OCH}_{2} \mathrm{CH}_{3}\right), 2.58\left(2 \mathrm{H}, \mathrm{t}, J=5.1 \mathrm{~Hz}\right.$, piperazine $\left.\mathrm{H}_{2}\right), 2.66\left(4 \mathrm{H}, \mathrm{m}, 2-\mathrm{CH}_{2} \mathrm{CH}_{3}\right.$ \& piperazine $\left.\mathrm{H}_{2}\right), 3.44,3.72\left(4 \mathrm{H}, \mathrm{t}, J=5.1 \mathrm{~Hz}\right.$, piperazine $\left.\mathrm{H}_{2} \times 2\right), 3.87\left(2 \mathrm{H}, \mathrm{s}, 8-\mathrm{CH}_{2}-\right), 4.17(2 \mathrm{H}, \mathrm{q}, J=$ $\left.6.9 \mathrm{~Hz}, 7-\mathrm{OCH}_{2} \mathrm{CH}_{3}\right), 6.12(1 \mathrm{H}, \mathrm{s}, 3-\mathrm{H}), 6.98(1 \mathrm{H}, \mathrm{d}, J=9.0 \mathrm{~Hz}, 6-\mathrm{H}), 7.18,7.80(3 \mathrm{H}, \mathrm{d}, J$ $=3.9 \mathrm{~Hz}$, thiophene $\mathrm{H}), 8.12(1 \mathrm{H}, \mathrm{d}, J=9.0 \mathrm{~Hz}, 5-\mathrm{H})$. ESI-MS $m / z 455\left(\mathrm{M}^{+}+1\right)$.

\subsubsection{7-Ethoxy-2-ethyl-8-((4-(2-oxo-2-phenylacetyl)piperazin-1-yl)methyl)-4H-} chromen-4-one (35)-11\% yield, white solid (starting from $50 \mathrm{mg}$ of 43b): $\mathrm{mp}$ 61-62 ${ }^{\circ} \mathrm{C} .{ }^{1} \mathrm{H}$ NMR $\delta 1.31\left(3 \mathrm{H}, \mathrm{t}, J=7.5 \mathrm{~Hz}, 2-\mathrm{CH}_{2} \mathrm{CH}_{3}\right), 1.45\left(3 \mathrm{H}, \mathrm{t}, J=7.2 \mathrm{~Hz}, 7-\mathrm{OCH}_{2} \mathrm{CH}_{3}\right)$, $2.53\left(2 \mathrm{H}, \mathrm{t}, J=5.1 \mathrm{~Hz}\right.$, piperazine $\left.\mathrm{H}_{2}\right), 2.64\left(2 \mathrm{H}, \mathrm{q}, J=7.5 \mathrm{~Hz}, 2-\mathrm{CH}_{2} \mathrm{CH}_{3}\right), 2.68,3.33$, $3.75\left(6 \mathrm{H}, \mathrm{t}, J=5.1 \mathrm{~Hz}\right.$, piperazine $\left.\mathrm{H}_{2} \times 3\right), 3.87\left(2 \mathrm{H}, \mathrm{s}, 8-\mathrm{CH}_{2}-\right), 4.17(2 \mathrm{H}, \mathrm{q}, J=7.2 \mathrm{~Hz}, 7-$ $\left.\mathrm{OCH}_{2} \mathrm{CH}_{3}\right), 6.12(1 \mathrm{H}, \mathrm{s}, 3-\mathrm{H}), 6.98(1 \mathrm{H}, \mathrm{d}, J=9.0 \mathrm{~Hz}, 6-\mathrm{H}), 7.51(2 \mathrm{H}, \mathrm{t}, J=7.8 \mathrm{~Hz}$, aromatic $\mathrm{H}), 7.65(1 \mathrm{H}, \mathrm{t}, J=6.6 \mathrm{~Hz}$, aromatic $\mathrm{H}), 7.94(1 \mathrm{H}, \mathrm{d}, J=7.4 \mathrm{~Hz}$, aromatic $\mathrm{H}), 8.13$ $(1 \mathrm{H}, \mathrm{d}, J=9.0 \mathrm{~Hz}, 5-\mathrm{H})$. ESI-MS $m / z 449\left(\mathrm{M}^{+}+1\right)$. 


\subsubsection{7-Ethoxy-2-ethyl-8-((4-(2-oxo-3-phenylpropanoyl)piperazin-1-} yl)methyl)-4H-chromen-4-one (36)-10\% yield, white solid (starting from $50 \mathrm{mg}$ of 43b): $\mathrm{mp} 54-56{ }^{\circ} \mathrm{C} .{ }^{1} \mathrm{H}$ NMR $\delta 1.30\left(3 \mathrm{H}, \mathrm{t}, J=7.2 \mathrm{~Hz}, 2-\mathrm{CH}_{2} \mathrm{CH}_{3}\right), 1.45(3 \mathrm{H}, \mathrm{t}, J=6.9 \mathrm{~Hz}$, $\left.7-\mathrm{OCH}_{2} \mathrm{CH}_{3}\right), 2.06,2.44,3.08,3.52\left(8 \mathrm{H}, \mathrm{t}, J=5.1 \mathrm{~Hz}\right.$, piperazine $\left.\mathrm{H}_{2} \times 4\right), 2.63(2 \mathrm{H}, \mathrm{q}, J=$ $\left.7.2 \mathrm{~Hz}, 2-\mathrm{CH}_{2} \mathrm{CH}_{3}\right), 3.78\left(2 \mathrm{H}, \mathrm{s}, 8-\mathrm{CH}_{2}-\right), 4.02\left(2 \mathrm{H}, \mathrm{s},-\mathrm{CH}_{2}-\mathrm{C}_{6} \mathrm{H}_{5}\right), 4.16(2 \mathrm{H}, \mathrm{q}, J=6.9 \mathrm{~Hz}$, $\left.7-\mathrm{OCH}_{2} \mathrm{CH}_{3}\right), 6.13(1 \mathrm{H}, \mathrm{s}, 3-\mathrm{H}), 6.97(1 \mathrm{H}, \mathrm{d}, J=9.0 \mathrm{~Hz}, 6-\mathrm{H}), 7.17-7.27\left(1 \mathrm{H} \times 5, \mathrm{~m}, J_{1}=\right.$ $7.2 \mathrm{~Hz}, J_{2}=6.6 \mathrm{~Hz}$, aromatic $\left.\mathrm{H}\right), 8.13(1 \mathrm{H}, \mathrm{d}, J=9.0 \mathrm{~Hz}, 5-\mathrm{H})$. ESI-MS $m / z 463\left(\mathrm{M}^{+}+\mathrm{H}\right)$.

\subsubsection{4'-((4-(2-(1H-Indol-3-yl)-2-oxoacetyl)piperazin-1-yl)methyl)-2-ethyl-7-} ethoxy-4H-chromen-4-one (37)—29\% yield, white solid (starting from $50 \mathrm{mg}$ of $\mathbf{4 3 b}$ ): mp 122-124 ${ }^{\circ} \mathrm{C} .{ }^{1} \mathrm{H}$ NMR $\delta 1.30\left(3 \mathrm{H}, \mathrm{t}, J=7.5 \mathrm{~Hz}, 2-\mathrm{CH}_{2} \mathrm{CH}_{3}\right), 1.44(3 \mathrm{H}, \mathrm{t}, J=6.9 \mathrm{~Hz}, 7-$ $\left.\mathrm{OCH}_{2} \mathrm{CH}_{3}\right), 2.53,2.66,3.48,3.73\left(8 \mathrm{H}, \mathrm{t}, J=5.1 \mathrm{~Hz}\right.$, piperazine $\left.\mathrm{H}_{2} \times 4\right), 2.64(2 \mathrm{H}, \mathrm{q}, J=$ $\left.7.5 \mathrm{~Hz}, 2-\mathrm{CH}_{2} \mathrm{CH}_{3}\right), 3.90\left(2 \mathrm{H}, \mathrm{s}, 8-\mathrm{CH}_{2}-\right), 4.15\left(2 \mathrm{H}, \mathrm{q}, J=6.9 \mathrm{~Hz}, 7-\mathrm{OCH}_{2} \mathrm{CH}_{3}\right), 6.12(1 \mathrm{H}$, s, 3-H), $6.97(1 \mathrm{H}, \mathrm{d}, J=9.0 \mathrm{~Hz}, 6-\mathrm{H}), 7.24-7.41(3 \mathrm{H}, \mathrm{m}$, aromatic $\mathrm{H}), 7.85(1 \mathrm{H}$, br s, aromatic $\mathrm{H}), 8.13(1 \mathrm{H}, \mathrm{d}, J=9.0 \mathrm{~Hz}, 5-\mathrm{H}), 8.31(1 \mathrm{H}$, br s, pyrrole $\mathrm{H}), 10.09(1 \mathrm{H}, \mathrm{br} \mathrm{s}$, pyrrole NH). ESI-MS $m / z 488\left(\mathrm{M}^{+}+\mathrm{H}\right)$.

\subsection{Synthesis of 1'-thia -seco-DCK (32)}

6.5.1. 7-Hydroxy-4-methyl-2-oxo-2H-chromene-8-carbaldehyde (52)—A reaction mixture of $51(20.0 \mathrm{~g}, 114 \mathrm{mmol})$ and hexamethylenetetramine $(40.0 \mathrm{~g}, 285 \mathrm{mmol})$ in HOAc $(150 \mathrm{~mL})$ was stirred for $5.5 \mathrm{~h}$ at $80-90{ }^{\circ} \mathrm{C}$. Aq. $\mathrm{HCl}\left(300 \mathrm{~mL}\right.$, conc. $\mathrm{HCl} / \mathrm{H}_{2} \mathrm{O} 84: 100$, v/v) was then added, and the reaction mixture was stirred for $0.5 \mathrm{~h}$ at $70{ }^{\circ} \mathrm{C}$. After cooling, the reaction mixture was poured into ice-water $(1.5 \mathrm{~L})$ and extracted with EtOAc $(500 \mathrm{~mL} \times 3)$. The combined organic fraction was dried over $\mathrm{Na}_{2} \mathrm{SO}_{4}$, and the solvent was removed in vacuo. The residue was recrystallized from EtOAc to provide $\mathbf{5 2}$ as a light yellow solid (2.4 $\mathrm{g}, 11 \%$ yield): $\mathrm{mp} 120-122{ }^{\circ} \mathrm{C}$.

\subsubsection{8-(1,3-Dioxolan-2-yl)-7-hydroxy-4-methyl-2H-chromene-2-one (53)—A}

mixture of $52(2.13 \mathrm{~g}, 10.4 \mathrm{mmol})$, ethane-1,2-diol (3.0 mL) and $p$-toluenesulfonic acid (120 $\mathrm{mg}$ ) in toluene $(25 \mathrm{~mL})$ was refluxed for $2 \mathrm{~h}$ with removal of water by a water separator. After removing solvent in vacuo, the residue was dissolved in $\mathrm{CH}_{2} \mathrm{Cl}_{2}$ and filtered. The filtrate was washed with saturated $\mathrm{NaHCO}_{3}$, and the organic layer was dried over anhydrous $\mathrm{Na}_{2} \mathrm{SO}_{4}$ and concentrated under reduced pressure to afford $\mathbf{5 3}$ as a yellow solid (1.96 g, 76\% yield): mp $215-217^{\circ} \mathrm{C} .{ }^{1} \mathrm{H}$ NMR $\delta 2.39\left(3 \mathrm{H}, \mathrm{s}, 4-\mathrm{CH}_{3}\right), 4.11-4.61\left(4 \mathrm{H}, \mathrm{m}, 2 \times \mathrm{CH}_{2}\right.$ of $1,3-$ dioxolane), $6.12(1 \mathrm{H}, \mathrm{s}, 3-\mathrm{H}), 6.39(1 \mathrm{H}, \mathrm{s}, 8-\mathrm{CH}-), 6.84(1 \mathrm{H}, \mathrm{d}, J=9.1 \mathrm{~Hz}, 6-\mathrm{H}), 7.50(1 \mathrm{H}$, $\mathrm{d}, J=9.1 \mathrm{~Hz}, 5-\mathrm{H})$.

\subsubsection{O-(8-(1,3-Dioxolan-2-yl)-4-methyl-2-oxo-2H-chromen-7-yl)- $\mathrm{N}, \mathrm{N}$ - dimethylcarbamothioate (54)-Compound 53 (1.50 g, 6.05 mmol) and $\mathrm{KOH}(2.0 \mathrm{~g}, 36$ $\mathrm{mmol})$ were dissolved in $\mathrm{MeOH}(30 \mathrm{~mL})$ and reacted with dimethylthiocarbamoyl chloride $(2.5 \mathrm{~g}, 20 \mathrm{mmol})$ for $3 \mathrm{~h}$ at $\mathrm{rt}$. The mixture was poured into saturated $\mathrm{NH}_{4} \mathrm{Cl}(150 \mathrm{~mL})$ and filtered to afford crude product, which was purified by column chromatography (eluent: petroleum ether/EtOAc 4:1) to give $\mathbf{5 4}$ as a white solid (667 mg, 33\% yield): $\mathrm{mp} \mathrm{190-192}$ ${ }^{\circ} \mathrm{C} .{ }^{1} \mathrm{H}$ NMR $\delta 2.36\left(3 \mathrm{H}, \mathrm{s}, 4-\mathrm{CH}_{3}\right), 3.38,3.47\left(6 \mathrm{H}, \mathrm{s},-\mathrm{N}\left(\mathrm{CH}_{3}\right)_{2}\right), 4.05-4.40\left(4 \mathrm{H}, \mathrm{m}, 2 \times \mathrm{CH}_{2}\right.$ of 1,3-dioxolane), $6.27(2 \mathrm{H}, \mathrm{s}, 3-\mathrm{H} \& 8-\mathrm{CH}-), 7.02(1 \mathrm{H}, \mathrm{d}, J=8.6 \mathrm{~Hz}, 6-\mathrm{H}), 7.62(1 \mathrm{H}, \mathrm{d}, J$ $=8.6 \mathrm{~Hz}, 5-\mathrm{H})$. ESI-MS $\mathrm{m} / \mathrm{z} 336(\mathrm{M}+\mathrm{H})$.}

\subsubsection{S-(8-(1,3-Dioxolan-2-yl)-4-methyl-2-oxo-2H-chromen-7-yl)- $\mathrm{N}, \mathrm{N}$ - dimethylcarbamothioate (55)—Compound 54 (1.50 g, $5.70 \mathrm{mmol})$ was heated to 200 ${ }^{\circ} \mathrm{C}$ with stirring for $1 \mathrm{~h}$. The crude product was purified by column chromatography (eluent: petroleum ether/EtOAc 4:1) to give $\mathbf{5 5}$ as light yellow crystals ( $235 \mathrm{mg}$, $47 \%$ yield): $\mathrm{mp}$ 138-140 ${ }^{\circ} \mathrm{C} .{ }^{1} \mathrm{H}$ NMR $\delta 2.42\left(3 \mathrm{H}, \mathrm{s}, 4-\mathrm{CH}_{3}\right), 3.08\left(6 \mathrm{H}, \mathrm{s},-\mathrm{N}\left(\mathrm{CH}_{3}\right)_{2}\right), 4.05-4.48(4 \mathrm{H}, \mathrm{m}$,}


$2 \times \mathrm{CH}_{2}$ of 1,3-dioxolane), $6.36(1 \mathrm{H}, \mathrm{s}, 3-\mathrm{H}), 6.65(1 \mathrm{H}, \mathrm{s}, 8-\mathrm{CH}-), 7.46(1 \mathrm{H}, \mathrm{d}, J=8.29 \mathrm{~Hz}$, 6-H), $7.59(1 \mathrm{H}, \mathrm{d}, J=8.29 \mathrm{~Hz}, 5-\mathrm{H})$. ESI-MS $m / z 336(\mathrm{M}+\mathrm{H})$.

6.5.5. 7-(Isopropylthio)-4-methyl-2-oxo-2H-chromene-8-carbaldehyde (58)Under nitrogen and in the dark, compound $\mathbf{5 5}(200 \mathrm{mg}, 0.6 \mathrm{mmol})$ was hydrolyzed in the presence of $\mathrm{KOH}(500 \mathrm{mg})$ in $\mathrm{MeOH}(20 \mathrm{~mL})$ for $2 \mathrm{~h}$ at reflux temperature. At completion, 2-bromopropane $(2.0 \mathrm{~mL})$ was added, and the reaction continued for another $30 \mathrm{~min}$. The reaction solution was then poured into cool $1 \mathrm{~N} \mathrm{HCl}(100 \mathrm{~mL})$ and filtered to give $\mathbf{5 8}$ as a light yellow solid (12 mg, 8\% yield): $\mathrm{mp} 159-162{ }^{\circ} \mathrm{C} .{ }^{1} \mathrm{H}$ NMR $\delta 1.44(6 \mathrm{H}, \mathrm{d}, J=6.7 \mathrm{~Hz}, 7-$ $\left.\mathrm{SCH}\left(\mathrm{CH}_{3}\right)_{2}\right), 2.45\left(3 \mathrm{H}, \mathrm{s}, 4-\mathrm{CH}_{3}\right), 3.62\left(1 \mathrm{H}, \mathrm{m}, J=6.7 \mathrm{~Hz}, 7-\mathrm{SCH}\left(\mathrm{CH}_{3}\right)_{2}\right), 6.15(1 \mathrm{H}, \mathrm{s}, 3-$ $\mathrm{H}), 7.30(1 \mathrm{H}, \mathrm{d}, J=9.0 \mathrm{~Hz}, 6-\mathrm{H}), 7.67(1 \mathrm{H}, \mathrm{d}, J=9.0 \mathrm{~Hz}, 5-\mathrm{H}), 10.84(1 \mathrm{H}, \mathrm{s}, 8-\mathrm{CHO})$. ESIMS $m / z, 263(\mathrm{M}+\mathrm{H})$.

\subsubsection{4'-((-)-Camphanoyloxymethyl)-7-(isopropylthio)-4-methyl-2H-}

chromen-2-one (32)-A mixture of $\mathbf{5 8}$ (9 mg, $0.034 \mathrm{mmol})$ and $\mathrm{NaBH}_{4}(3 \mathrm{mg})$ in $\mathrm{MeOH}$ $(2 \mathrm{~mL})$ was stirred for $1 \mathrm{~h}$ at room temperature, then acidified to $\mathrm{pH} 3-4$ with $1 \mathrm{~N} \mathrm{HCl}$ and extracted with $\mathrm{CH}_{2} \mathrm{Cl}_{2}(10 \mathrm{~mL} \times 3)$. The organic layer was dried over anhydrous $\mathrm{Na}_{2} \mathrm{SO}_{4}$, and most of the solvent was removed under reduced pressure to give crude 59. Then, 32 was synthesized following the same synthetic procedure as for $\mathbf{1 6} \mathbf{2 8}$, but starting from $\mathbf{5 9}$. 52\% yield, White solid: $\mathrm{mp} 146-147^{\circ} \mathrm{C} .{ }^{1} \mathrm{H}$ NMR $\left.\delta \times 3\right), 1.34(6 \mathrm{H}, \mathrm{d}, J=6.71 .00,1.05,1.09$ (9H, s, camphanoyl- $\left.\mathrm{CH}_{3} \mathrm{~Hz}, 7-\mathrm{SCH}\left(\mathrm{CH}_{3}\right)_{2}\right), 1.67-2.46\left(4 \mathrm{H}, \mathrm{m}\right.$, camphanoyl- $\left.\mathrm{CH}_{2} \times 2\right), 2.47$ $\left(3 \mathrm{H}, \mathrm{s}, 4-\mathrm{CH}_{3}\right), 3.57\left(1 \mathrm{H}, \mathrm{m}, J=6.7 \mathrm{~Hz}, 7-\mathrm{SCH}\left(\mathrm{CH}_{3}\right)_{2}\right), 5.65\left(2 \mathrm{H}, \mathrm{s}, 4^{\prime}-\mathrm{CH}_{2} \mathrm{O}-\right), 6.27(1 \mathrm{H}$, $\mathrm{s}, 3-\mathrm{H}), 7.36(1 \mathrm{H}, \mathrm{d}, J=8.4 \mathrm{~Hz}, 6-\mathrm{H}), 7.57(1 \mathrm{H}, \mathrm{d}, J=8.4 \mathrm{~Hz}, 5-\mathrm{H})$. ESI-MS $m / z, 445(\mathrm{M}$ $+\mathrm{H})$.

\subsection{Synthesis of 1 '-thia-seco-DCP (33)}

6.6.1. 2-Ethyl-7-hydroxy-4H-chromen-4-one (64)-The procedure was the same as that used for the preparation of $\mathbf{4 1 . 5 2 \%}$ yield, white crystals (starting from $10 \mathrm{~g}$ of $\mathbf{6 0}$ ): $\mathrm{mp}$ $188-189^{\circ} \mathrm{C}$.

6.6.2. 2-Ethyl-7-hydroxy-4-oxo-4H-chromen-8-carbaldehyde (65)-The procedure was the same as that used for the preparation of $\mathbf{5 2 . 4 4 \%}$ yield, white crystals (starting from $650 \mathrm{mg}$ of 64): $\mathrm{mp} 179-181^{\circ} \mathrm{C}$.

\subsubsection{O-(8-(1,3-Dioxolan-2-yl)-2-ethyl-4-oxo-4H-chromen-7-yl)- $N, N$ -}

dimethylcarbamothioate (67) - Compound 66 was prepared by the same procedure as used for the preparation of $\mathbf{5 2}$. However, due to its instability, $\mathbf{6 6}$ was not purified, but was reacted directly with dimethylthiocarbamoyl chloride $(1.0 \mathrm{~g}, 8.09 \mathrm{mmol})$ to give compound $\mathbf{6 7}$ following the same method used for the synthesis of 54. 31\% yield, white solid (starting from $600 \mathrm{mg}$ of 66): $\mathrm{mp} 132-134{ }^{\circ} \mathrm{C} .{ }^{1} \mathrm{H}$ NMR $\delta 1.31\left(3 \mathrm{H}, \mathrm{t}, J=7.43 \mathrm{~Hz}, 2-\mathrm{CH}_{2} \mathrm{CH}_{3}\right), 2.66$ $\left(2 \mathrm{H}, \mathrm{q}, J=7.43 \mathrm{~Hz}, 2-\mathrm{CH}_{2} \mathrm{CH}_{3}\right), 3.43\left(6 \mathrm{H}, \mathrm{s},-\mathrm{N}\left(\mathrm{CH}_{3}\right)_{2}\right), 4.08,4.24\left(4 \mathrm{H}, \mathrm{m}, 2 \times \mathrm{CH}_{2}\right.$ of $1,3-$ dioxolane), $6.19(1 \mathrm{H}, \mathrm{s}, 3-\mathrm{H}), 6.35(1 \mathrm{H}, \mathrm{s}, 8-\mathrm{CH}-), 7.06(2 \mathrm{H}, \mathrm{d}, J=8.6 \mathrm{~Hz}, 6-\mathrm{H}), 8.22(2 \mathrm{H}$, d, $J=8.6 \mathrm{~Hz}, 5-\mathrm{H})$. ESI-MS $\mathrm{m} / \mathrm{z} 350(\mathrm{M}+\mathrm{H})$

\subsubsection{S-(8-(1,3-Dioxolan-2-yl)-2-ethyl-4-oxo-4H-chromen-7-yl)- $\mathrm{N}, \mathrm{N}-$ dimethylcarbamothioate (68)-The procedure was the same as that used for the preparation of 55. 34\% yield, light yellow solid (starting from $450 \mathrm{mg}$ of 67): $\mathrm{mp} 132-135$ ${ }^{\circ} \mathrm{C} .{ }^{1} \mathrm{H}$ NMR $\delta 1.32\left(3 \mathrm{H}, \mathrm{t}, J=7.4 \mathrm{~Hz}, 2-\mathrm{CH}_{2} \mathrm{CH}_{3}\right), 2.66\left(2 \mathrm{H}, \mathrm{q}, J=7.4 \mathrm{~Hz}, 2-\mathrm{CH}_{2} \mathrm{CH}_{3}\right)$, $3.13\left(6 \mathrm{H}, \mathrm{s},-\mathrm{N}\left(\mathrm{CH}_{3}\right)_{2}\right), 4.08,4.27\left(4 \mathrm{H}, \mathrm{m}, 2 \times \mathrm{CH}_{2}\right.$ of 1,3-dioxolane $), 6.21(1 \mathrm{H}, \mathrm{s}, 3-\mathrm{H}), 6.59$ $(1 \mathrm{H}, \mathrm{s}, 8-\mathrm{CH}-), 7.52(1 \mathrm{H}, \mathrm{d}, J=8.6 \mathrm{~Hz}, 6-\mathrm{H}), 8.20(2 \mathrm{H}, \mathrm{d}, J=8.6 \mathrm{~Hz}, 5-\mathrm{H})$. ESI-MS $m / z$ $350(\mathrm{M}+\mathrm{H})$.}


6.6.5. 2-Ethyl-7-(isopropylthio)-4-oxo-4H-chromene-8-carbaldehyde (71)—The

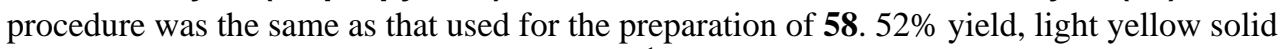
(starting from $70 \mathrm{mg}$ of 68$)$ : $\mathrm{mp} 152-154{ }^{\circ} \mathrm{C} .{ }^{1} \mathrm{H}$ NMR $\delta 1.32(3 \mathrm{H}, \mathrm{t}, J=7.3 \mathrm{~Hz}, 2-$ $\left.\mathrm{CH}_{2} \mathrm{CH}_{3}\right), 1.45\left(6 \mathrm{H}, \mathrm{d}, J=6.7 \mathrm{~Hz}, 7-\mathrm{SCH}\left(\mathrm{CH}_{3}\right)_{2}\right), 2.72\left(2 \mathrm{H}, \mathrm{q}, J=7.3 \mathrm{~Hz}, 2-\mathrm{CH}_{2} \mathrm{CH}_{3}\right)$, $3.67\left(1 \mathrm{H}, \mathrm{m}, J=6.7 \mathrm{~Hz}, 7-\mathrm{SCH}\left(\mathrm{CH}_{3}\right)_{2}\right), 6.23(1 \mathrm{H}, \mathrm{s}, 3-\mathrm{CH}), 7.40(1 \mathrm{H}, \mathrm{d}, J=9.0 \mathrm{~Hz}, 6-\mathrm{H})$, $8.24(1 \mathrm{H}, \mathrm{d}, J=9.0 \mathrm{~Hz}, 5-\mathrm{H}), 10.81(1 \mathrm{H}, \mathrm{s}, 8-\mathrm{CHO})$. ESI-MS m/z $277(\mathrm{M}+\mathrm{H})$.

6.6.6. 4'-((-)-Camphanoyloxymethyl)-7-(isopropylthio)-2-ethyl-4H-chromene-2one (33)-The procedure was the same as that used for the preparation of $32.48 \%$ yield, white solid (starting from $27 \mathrm{mg}$ of 71): $\mathrm{mp} 92-94{ }^{\circ} \mathrm{C} .{ }^{1} \mathrm{H}$ NMR $\delta 0.95,1.05,1.00,1.09(9 \mathrm{H}$, s, camphanoyl- $\left.\mathrm{CH}_{3} \times 3\right), 1.31\left(3 \mathrm{H}, \mathrm{t}, J=7.3 \mathrm{~Hz}, 2-\mathrm{CH}_{2} \mathrm{CH}_{3}\right), 1.35(6 \mathrm{H}, \mathrm{d}, J=6.7 \mathrm{~Hz}, 7-$ $\left.\mathrm{SCH}\left(\mathrm{CH}_{3}\right)_{2}\right), 1.89-2.40\left(4 \mathrm{H}, \mathrm{m}\right.$, camphanoyl- $\left.\mathrm{CH}_{2} \times 2\right), 2.67(2 \mathrm{H}, \mathrm{q}, J=7.3 \mathrm{~Hz}, 2-$ $\left.\mathrm{CH}_{2} \mathrm{CH}_{3}\right), 3.62\left(1 \mathrm{H}, \mathrm{m}, \mathrm{J}=6.7 \mathrm{~Hz}, 7-\mathrm{SCH}\left(\mathrm{CH}_{3}\right)_{2}\right), 5.66\left(2 \mathrm{H}, \mathrm{s}, 4^{\prime}-\mathrm{CH}_{2} \mathrm{O}-\right), 6.18(1 \mathrm{H}, \mathrm{s}, 3-$ H), $7.42(1 \mathrm{H}, \mathrm{d}, J=8.6 \mathrm{~Hz}, 6-\mathrm{H}), 8.14(1 \mathrm{H}, \mathrm{d}, J=8.6 \mathrm{~Hz}, 5-\mathrm{H})$. ESI-MS $m / z .459(\mathrm{M}+\mathrm{H})$.

\subsection{HIV-1 infectivity assay}

Anti-HIV-1 activity was measured as reductions in Luc reporter gene expression after a single round of virus infection of TZM-bl cells. HIV-1 at 200 TCID $_{50}$ and various dilutions of test samples (eight dilutions, fourfold stepwise) were mixed in a total volume of $100 \mu \mathrm{L}$ growth medium in 96-well black solid plates (Corning-Costar). After 48-h incubation, culture medium was removed from each well and $100 \mu \mathrm{L}$ of Bright Glo luciferase reagent was added to each culture well. The luciferase activity in the assay wells was measured using a Victor 2 luminometer. The 50\% inhibitory dose $\left(\mathrm{EC}_{50}\right)$ was defined as the sample concentration that caused a 50\% reduction in Relative Luminescence Units (RLU) compared to virus control wells after subtraction of background RLU.

\subsection{Cytotoxicity assay}

Compounds were tested for cytotoxicity against TZM-bl cells. The cells at $1 \times 10^{5}$ cells $/ \mathrm{mL}$ were added to each well in a 96-well plate in the presence of various concentrations of the tested compounds for an indicated period parallel to the antiviral assays. Cell viability was determined by using a Promega cytotoxicity assay kit, CellTiter-Glo® Luminescent Cell Viability Assay, following the manufacturer's instruction. The drug concentration that resulted in a $50 \%$ decrease in viable cells was defined as the $\mathrm{IC}_{50}$ of the compound.

\subsection{Chemical stability analysis}

Each tested compound $(1 \mathrm{mg})$ was dissolved in $\mathrm{MeOH}(0.5 \mathrm{~mL})$ in centrifuge tubes. After adding $1 \% \mathrm{HCl}(0.2 \mathrm{~mL})$ into the tubes, each mixture was shaken at room temperature. The amount of compound in acidic solution was measured by HPLC (Column: Hypersil ODS2 $5 \mu \mathrm{m}, 4.6 \mathrm{~mm} \mathrm{G} 250 \mathrm{~mm}$; a mobile phase of $30 \%$ water and $70 \% \mathrm{MeOH}$ ) at $1 \mathrm{~min}$ and 30 $\min$.

\section{Supplementary Material}

Refer to Web version on PubMed Central for supplementary material.

\section{Acknowledgments}

This research was supported by the grants from the National Natural Science Foundation of China awarded to P.X. (No. 20272010) and Y.C. (No. 30200348 and 30873164, respectively), and Grant AI-33066 from the National Institute of Allergies and Infectious Diseases awarded to K.H.L. Thanks are also due to the National Drug Innovative Program (Grant No. 2009ZX09301-011) for partial support. 


\section{References}

1. Kilmarx PH. Curr Opin HIV AIDS. 2009; 4:240-246. [PubMed: 19532059]

2. Huang L, Kashiwada Y, Cosentino LM, Fan S, Chen CH, McPhail AT, Fujioka T, Mihashi K, Lee KH. J Med Chem. 1994; 37:3947-3955. [PubMed: 7525962]

3. Xie L, Takeuchi Y, Cosentino LM, Lee KH. J Med Chem. 1999; 42:2662-2672. [PubMed: 10411486]

4. Yang ZY, Xia Y, Xia P, Brossi A, Cosentino LM, Lee KH. Bioorg Med Chem Lett. 2000; 10:10031005. [PubMed: 10843202]

5. Chen Y, Zhang Q, Zhang B, Xia P, Xia Y, Yang ZY, Kilgore N, Wild C, Morris-Natschke SL, Lee KH. Bioorg Med Chem. 2004; 12:6383-6387. [PubMed: 15556756]

6. Xia P, Yin ZJ, Chen Y, Zhang Q, Zhang B, Xia Y, Yang ZY, Kilgore N, Wild C, Morris-Natschke SL, Lee KH. Bioorg Med Chem Lett. 2004; 14:3341-3343. [PubMed: 15149703]

7. Xie L, Yu D, Wild C, Allaway G, Turpin J, Smith PC, Lee KH. J Med Chem. 2004; 47:756-760. [PubMed: 14736256]

8. Zhang Q, Chen Y, Xia P, Xia Y, Yang ZY, Yu D, Morris-Natschke SL, Lee KH. Bioorg Med Chem Lett. 2004; 14:5855-5857. [PubMed: 15501055]

9. Wang Y, Huang SX, Xia P, Xia Y, Yang ZY, Kilgore N, Morris-Natschke SL, Lee KH. Bioorg Med Chem Lett. 2007; 17:4316-4319. [PubMed: 17533128]

10. Xu SQ, Yan X, Chen Y, Xia P, Qian K, Yu D, Xia Y, Yang ZY, Morris-Natschke SL, Lee KH. Bioorg Med Chem. 2010; 18:7203-7211. [PubMed: 20846868]

11. Yu D, Brossi A, Kilgore N, Wild C, Allaway G, Lee KH. Bioorg Med Chem Lett. 2003; 13:15751576. [PubMed: 12699758]

12. Zhou T, Shi Q, Chen CH, Zhu H, Huang L, Ho P, Lee KH. Bioorg Med Chem. 2010; 18:66786689. [PubMed: 20728367]

13. Tang J, Qian K, Zhang BN, Chen Y, Xia P, Yu D, Xia Y, Yang ZY, Chen CH, Morris-Natschke SL, Lee KH. Bioorg Med Chem. 2010; 18:4363-4373. [PubMed: 20537902] 


\section{Research Highlights}

- Thirty 2',3'-seco-3'-nor DCP and DCK analogs (8-37) were designed and synthesized.

- Several seco-compounds showed potent anti-HIV activity against HIV-1 $1_{\text {NL4-3 }}$ and RTMDR strains.

- $\quad 1^{\prime}$-O-Isopropoxy-2', $3^{\prime}$-seco-3'-nor-DCP (12) showed the greatest potency among the newly synthesized compounds.

- The seco-analogues exhibited better chemical stability in acidic conditions than DCP/DCK compounds.

- Seco-DCP analogues may be favorable for development as novel anti-HIV candidates. 


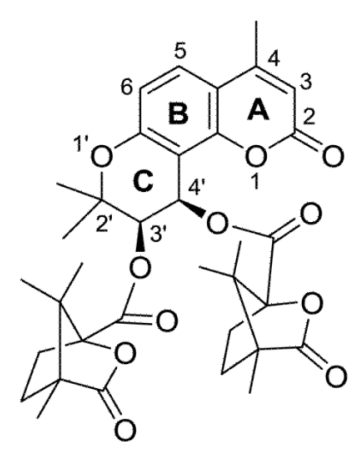

1. $D C K R=H$

2. 4-Methyl DCK $\mathrm{R}=\mathrm{CH}_{3}$

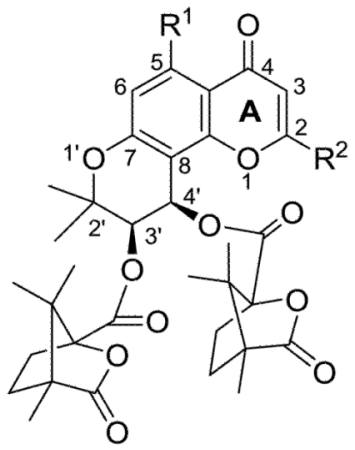

3. $D C P R^{1}=R^{2}=H$

4. 2-Ethyl DCP $\mathrm{R}^{1}=\mathrm{H}, \mathrm{R}^{2}=\mathrm{CH}_{2} \mathrm{CH}_{3}$

5. 2-Ethyl-5-methyl DCP R ${ }^{1}=\mathrm{CH}_{3}, \mathrm{R}^{2}=\mathrm{CH}_{2} \mathrm{CH}_{3}$

6. 2,5-Dimethyl DCP R $\mathrm{R}^{1}=\mathrm{R}^{2}=\mathrm{CH}_{3}$

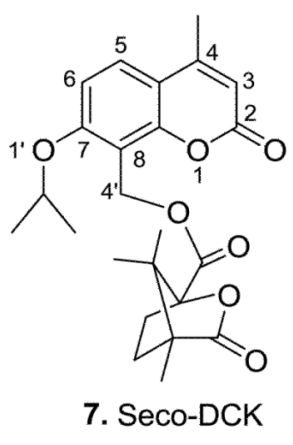

7. Seco-DCK

Figure 1.

DCK \& DCP analogues and seco-DCK 
<smiles>[R]Oc1ccc2c(=O)cc(C([R2])C)oc2c1COC(=O)C12OC(=O)C(C)(CC1(C)C)C2(C)C</smiles>

8. $\mathrm{R}^{1}=\mathrm{CH}_{3}, \mathrm{R}^{2}=\mathrm{H}$

9. $\mathrm{R}^{1}=\mathrm{CH}_{3}, \mathrm{R}^{2}=\mathrm{Br}$

10. $\mathrm{R}^{1}=\mathrm{CH}_{2} \mathrm{CH}_{3}, \mathrm{R}^{2}=\mathrm{H}$

11. $\mathrm{R}^{1}=\mathrm{CH}_{2} \mathrm{CH}_{3}, \mathrm{R}^{2}=\mathrm{Br}$

12. $\mathrm{R}^{1}=\mathrm{CH}\left(\mathrm{CH}_{3}\right)_{2}, \mathrm{R}^{2}=\mathrm{H}$

13. $\mathrm{R}^{1}=\mathrm{CH}\left(\mathrm{CH}_{3}\right)_{2}, \mathrm{R}^{2}=\mathrm{Br}$

14. $R^{1}=$ isobutyl, $R^{2}=H$

15. $R^{1}=$ isobutyl, $R^{2}=B r$

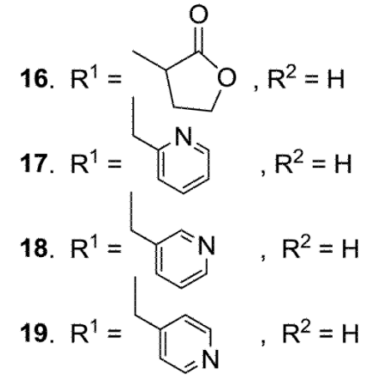<smiles>[R]c1cc(COc2ccc3c(=O)cc(CC)oc3c2COC(=O)C2(C)OC(=O)C3(C)CC2(C)C3(C)C)c([R4])c([R])c1[R]</smiles>

20. $R^{1}=C F_{3}, R^{2}=R^{3}=R^{4}=H$

21. $R^{1}=C N, R^{2}=R^{3}=R^{4}=H$

22. $R^{1}=\mathrm{OCH}_{3}, \mathrm{R}^{2}=\mathrm{R}^{3}=\mathrm{R}^{4}=\mathrm{H}$

23. $R^{1}=\mathrm{CO}_{2} \mathrm{CH}_{3}, \mathrm{R}^{2}=\mathrm{R}^{3}=\mathrm{R}^{4}=\mathrm{H}$

24. $R^{1}=\mathrm{CH}_{3}, \mathrm{R}^{2}=\mathrm{R}^{3}=\mathrm{R}^{4}=\mathrm{H}$

25. $R^{1}=R^{3}=O^{2} H_{3}, R^{2}=R^{4}=H$

26. $R^{1}=\mathrm{OCF}_{3}, \mathrm{R}^{2}=\mathrm{R}^{3}=\mathrm{R}^{4}=\mathrm{H}$

27. $R^{1}=\mathrm{OCH}_{3}, R^{2}=R^{3}=H, R^{4}=B r$

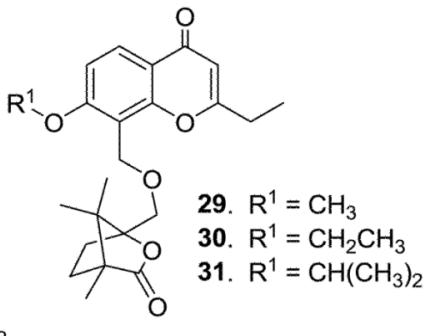

Figure 2.

Newly designed $1^{\prime}$ - $O$-substituted $2{ }^{\prime}, 3^{\prime}$-seco-3'-nor-DCP analogues (8-31) 


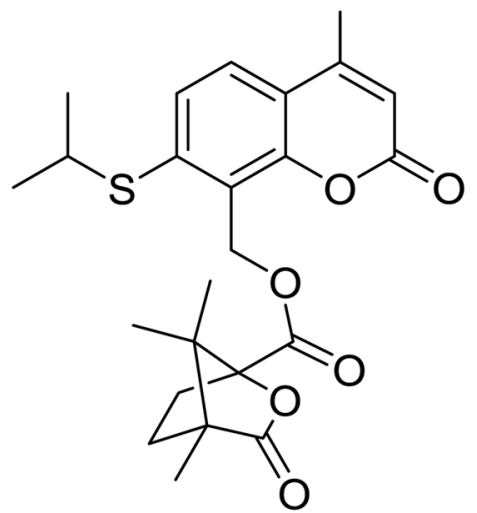

32

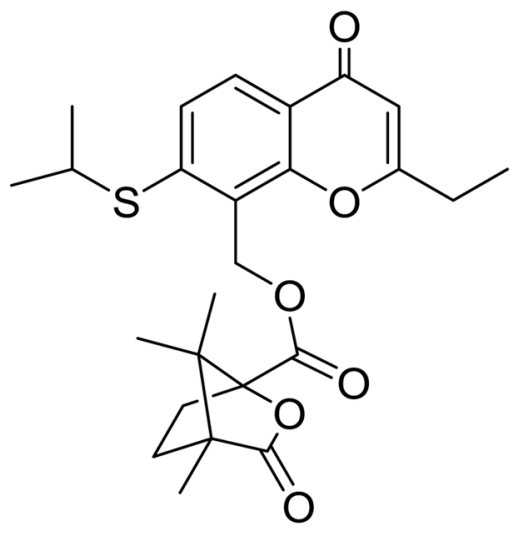

33

Figure 3.

Newly designed 1'-thia-2', 3'-seco-3'-nor-DCK (32) and -DCP (33) analogues 


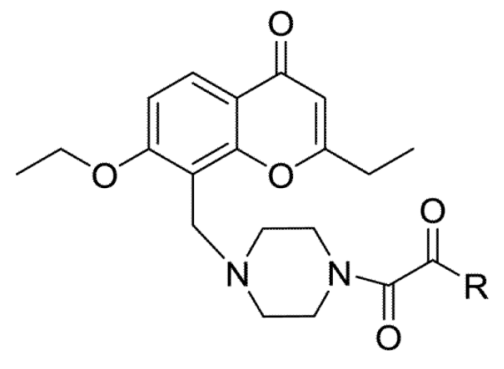

34. $R=-\left.\right|_{S}$

35. $\mathrm{R}=$<smiles>Cc1ccccc1</smiles>

36. $R=$<smiles>CCc1ccccc1</smiles>

37. $\mathrm{R}=$<smiles>[R]C#Cc1c[nH]c2ccccc12</smiles>

Figure 4.

Newly designed 4'-( $N^{\prime}$-substituted piperidin-1-yl)-2',3'-seco-3'-nor-DCP analogues (34-37) 


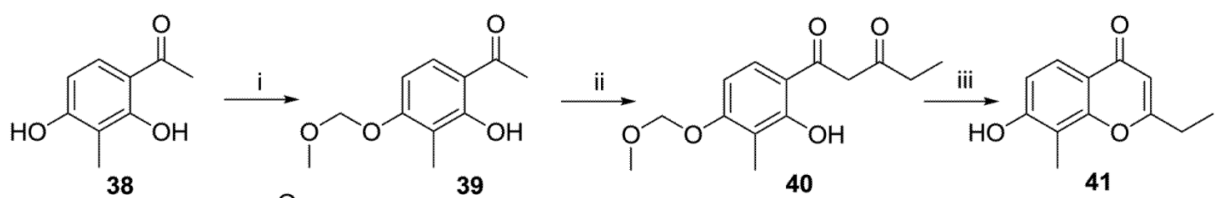

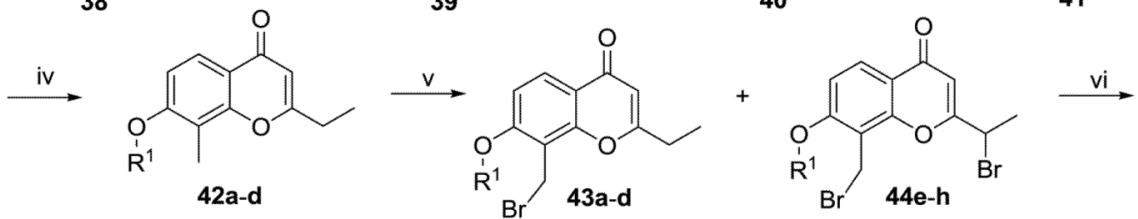

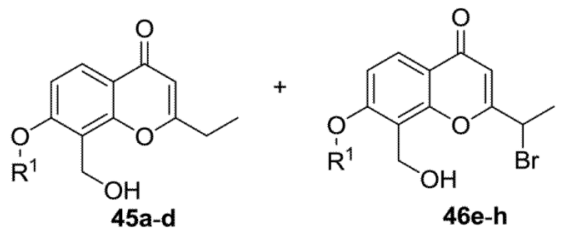

a,e. $R^{1}=\mathrm{CH}_{3}$; b,f. $\mathbf{R}^{1}=\mathrm{CH}_{2} \mathrm{CH}_{3}$;

c,g. $\mathbf{R}^{1}=\mathrm{CH}\left(\mathrm{CH}_{3}\right)_{2} ;$ d,h. $\mathrm{R}^{1}=\mathrm{CH}_{2} \mathrm{CH}\left(\mathrm{CH}_{3}\right)_{2}$

8. $\mathrm{R}^{1}=\mathrm{CH}_{3}, \mathrm{R}^{2}=\mathrm{H}$ 9. $\mathrm{R}^{1}=\mathrm{CH}_{3}, \mathrm{R}^{2}=\mathrm{Br}$ 10. $\mathrm{R}^{1}=\mathrm{CH}_{2} \mathrm{CH}_{3}, \mathrm{R}^{2}=\mathrm{H}$ 11. $\mathrm{R}^{1}=\mathrm{CH}_{2} \mathrm{CH}_{3}, \mathrm{R}^{2}=\mathrm{Br}$ 12. $\mathrm{R}^{1}=\mathrm{CH}\left(\mathrm{CH}_{3}\right)_{2}, \mathrm{R}^{2}=\mathrm{H}$ 13. $\mathrm{R}^{1}=\mathrm{CH}\left(\mathrm{CH}_{3}\right)_{2}, \mathrm{R}^{2}=\mathrm{Br}$ 14. $R^{1}=$ isobutyl, $R^{2}=H$
15. $R^{1}=$ isobutyl, $R^{2}=B r$

Scheme 1.

The synthetic routes to $1^{\prime}-O$-alkyl-2', $3^{\prime}$-seco-3'-nor-DCPs (8-15). Reagents and conditions: (i). chloromethyl methyl ether/ $\mathrm{K}_{2} \mathrm{CO}_{3} /$ acetone/rt; (ii). ethyl propionate/NaH/THF/reflux; (iii). conc. $\mathrm{HCl} / \mathrm{EtOH} / \mathrm{refux}$; (iv). variable bromides/ $\mathrm{K}_{2} \mathrm{CO}_{3} / \mathrm{DMF}$; (v). 1.2 equiv. NBS/ $\mathrm{CCl}_{4} /$ reflux; (vi). a. $\mathrm{NaOAc} / \mathrm{Ac}_{2} \mathrm{O} /$ reflux; b. $2 \mathrm{~N} \mathrm{HCl} / \mathrm{EtOH} / \mathrm{reflux}$; (vii). camphanoyl chloride/DMAP/ $\mathrm{CH}_{2} \mathrm{Cl}_{2} / \mathrm{rt}$. 


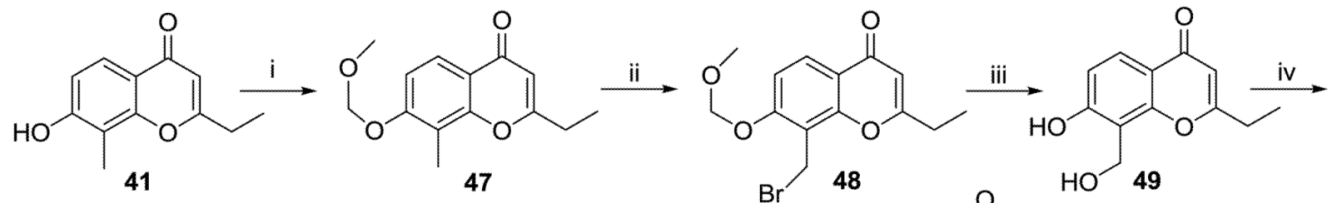<smiles>[R]Oc1ccc2c(=O)cc(CCC(C)C)oc2c1CO</smiles>

16. $\mathrm{R}^{1}=\mathrm{O}, \mathrm{R}^{2}=\mathrm{H}$<smiles>[R]Oc1ccc2c(=O)cc(C([R])C)oc2c1COC(=O)C1(C)OC(=O)C2(C)CC1(C)C2</smiles>
50a-m<smiles>[R]c1cc(COc2ccc3c(=O)cc(CC)oc3c2COC(=O)C23OC(=O)C(C)(CC2(C)C)C3(C)C)c([R])c([R])c1[R]</smiles>

18. $R^{1}=N, R^{2}=H$

19. $R^{1}=R_{N}^{2}=H$

20. $\mathrm{R}^{1}=\mathrm{CF}_{3}, \mathrm{R}^{2}=\mathrm{R}^{3}=\mathrm{R}^{4}=\mathrm{H}$

21. $R^{1}=C N, R^{2}=R^{3}=R^{4}=H$

22. $R^{1}=O_{C} H_{3}, R^{2}=R^{3}=R^{4}=H$

23. $R^{1}=\mathrm{CO}_{2} \mathrm{CH}_{3}, \mathrm{R}^{2}=\mathrm{R}^{3}=\mathrm{R}^{4}=\mathrm{H}$

24. $R^{1}=\mathrm{CH}_{3}, \mathrm{R}^{2}=\mathrm{R}^{3}=\mathrm{R}^{4}=\mathrm{H}$

25. $R^{1}=R^{3}=O_{C H}, R^{2}=R^{4}=H$

26. $R^{1}=\mathrm{OCF}_{3}, \mathrm{R}^{2}=\mathrm{R}^{3}=\mathrm{R}^{4}=\mathrm{H}$

27. $R^{1}=\mathrm{OCH}_{3}, \mathrm{R}^{2}=\mathrm{R}^{3}=\mathrm{H}, \mathrm{R}^{4}=\mathrm{Br}$

28. $R^{1}=R^{2}=O_{C H}, R^{3}=H, R^{4}=N_{2}$

\section{Scheme 2.}

The synthesis of 1'-O-aryl or heterocyclic substituted 2',3'-seco-3'-nor-2-ethyl-DCPs (1628). Reaction Conditions: (i). chloromethyl methyl ether/ $\mathrm{K}_{2} \mathrm{CO}_{3} / \mathrm{DMF} / \mathrm{rt}$; (ii). 1.2 equiv. $\mathrm{NBS} / \mathrm{CCl}_{4} /$ reflux; (iii). a. $\mathrm{NaOAc} / \mathrm{Ac}_{2} \mathrm{O} /$ reflux; b. 2N HCl/EtOH/reflux; (iv). variable bromides/ $\mathrm{K}_{2} \mathrm{CO}_{3} / \mathrm{DMF} / \mathrm{rt}$; (v). camphanoyl chloride/DMAP/CH $\mathrm{Cl}_{2} / \mathrm{rt}$. 
<smiles>[R]Oc1ccc2c(=O)cc(CC)oc2c1CBr</smiles><smiles>[R]Oc1ccc2c(=O)cc(CC)oc2c1CO</smiles><smiles>[R]C(=O)C(=O)N1CCN(Cc2c(OCC)ccc3c(=O)cc(CC)oc23)CC1</smiles><smiles>[14CH3]c1cccs1</smiles><smiles>[R5]C#Cc1ccccc1</smiles>

36.

29. $\mathrm{R}^{1}=\mathrm{CH}_{3}$

30. $\mathrm{R}^{1}=\mathrm{CH}_{2} \mathrm{CH}_{3}$

$\mathrm{O}$ 31. $\mathrm{R}^{1}=\mathrm{CH}\left(\mathrm{CH}_{3}\right)_{2}$

Scheme 3.

The synthetic routes to $4^{\prime}$-camphanol ethers of $2^{\prime}, 3^{\prime}$-seco-3'-nor-2-ethyl-DCPs (29-31) and $4^{\prime}$-(N'-substituted piperidin-1-yl)-2',3'-seco-3'-nor=DCP analogues (36-39). Reaction Conditions: (i). camphanol/NaH/toluene/rt; (ii). variable $\mathrm{N}^{\prime}$-substituted piperidines/DMAP/ $\mathrm{THF} / \mathrm{rt}$. 
<smiles>Cc1cc(=O)oc2c(C(O)C(C)(C)C)c(O)ccc12</smiles>

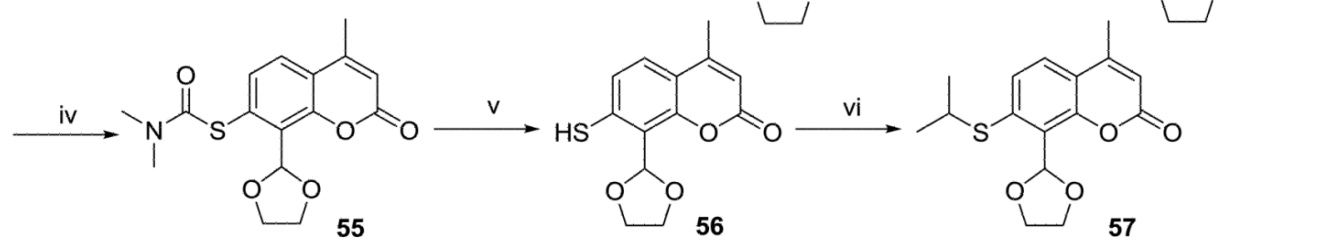

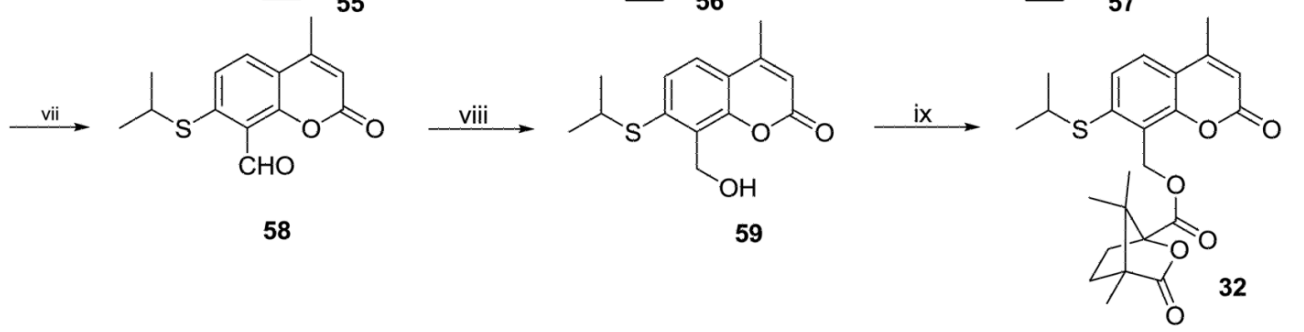

Scheme 4.

The synthetic route to 1'-thia-2',3'-seco-3'-nor-4-methyl-DCK (32). Reaction Conditions: (i). hexamethylenamine/HOAc; (ii). $\mathrm{HOCH}_{2} \mathrm{CH}_{2} \mathrm{OH} / \mathrm{p}$-TSA/benzene/reflux; (iii).

dimethylthiocarbamoyl chloride/DMF/ $\mathrm{K}_{2} \mathrm{CO}_{3}$; (iv). heat at $195-205{ }^{\circ} \mathrm{C}$; (v). $\mathrm{KOH} / \mathrm{MeOH}$; (vi). isopropyl bromide/KOH/DMF; (vii). $1 \mathrm{~N} \mathrm{HCl}$; (viii). $\mathrm{NaBH}_{4} / \mathrm{MeOH}$; (ix). camphanoyl chloride/DMAP/ $\mathrm{CH}_{2} \mathrm{Cl}_{2}$ 


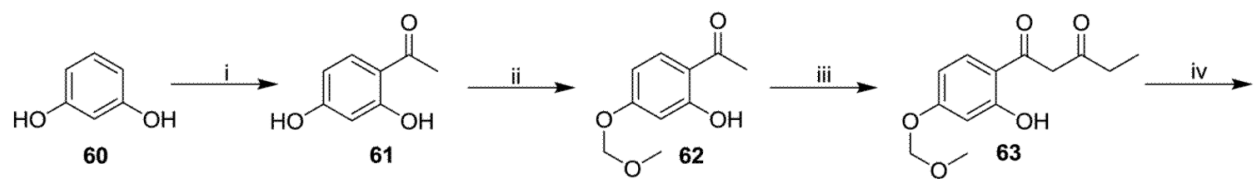

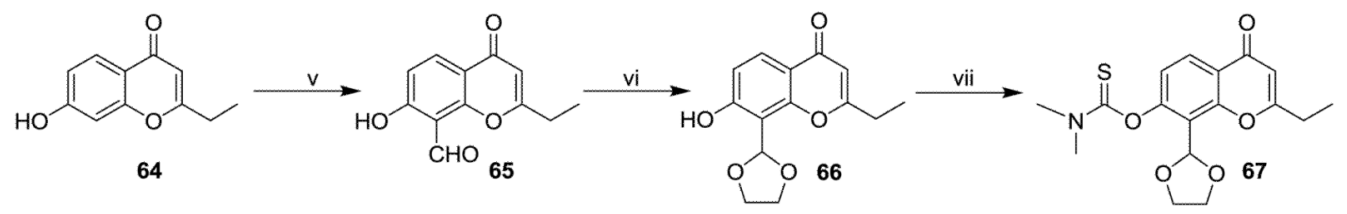

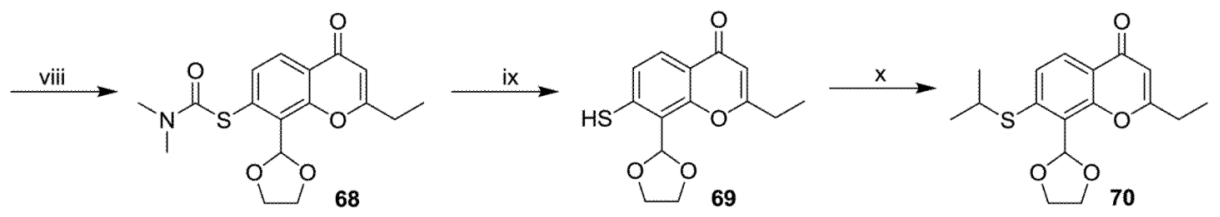

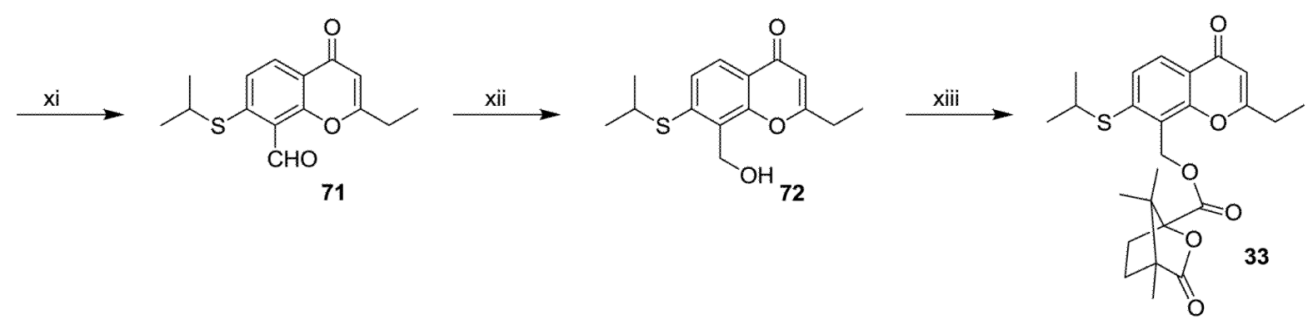

Scheme 5.

The synthesis of 1'-thia-2',3'-seco-3'-nor-2-ethyl-DCP (33). Reaction Conditions: (i). HOAc/ $\mathrm{ZnCl}_{2}$ /reflux; (ii). chloromethyl methyl ether $/ \mathrm{K}_{2} \mathrm{CO}_{3}$ /acetone/ice-water bath; (iii). ethyl propionate/NaH/THF/reflux; (iv). conc. $\mathrm{HCl} / \mathrm{EtOH} /$ reflux; (v). a. urotropin/HOAc/reflux; b. $\mathrm{HCl} /$ reflux; (vi). ethylene glycol/benzene/p-TSA- $\mathrm{H}_{2} \mathrm{O} /$ reflux; (vii). dimethylthiocarbamoyl chloride $/ \mathrm{K}_{2} \mathrm{CO}_{3} / \mathrm{MeOH}$; (viii). $\mathrm{N}_{2} / 220^{\circ} \mathrm{C}$; (ix). $\mathrm{K}_{2} \mathrm{CO}_{3} / \mathrm{MeOH} / \mathrm{reflux}$; (x). 2-bromopropane; (xi). $1 \mathrm{~N} \mathrm{HCl}$; (xii). $\mathrm{NaBH}_{4} / \mathrm{MeOH}$; (xiii). camphanoyl chloride/DMAP/CH $\mathrm{Cl}_{2}$. 


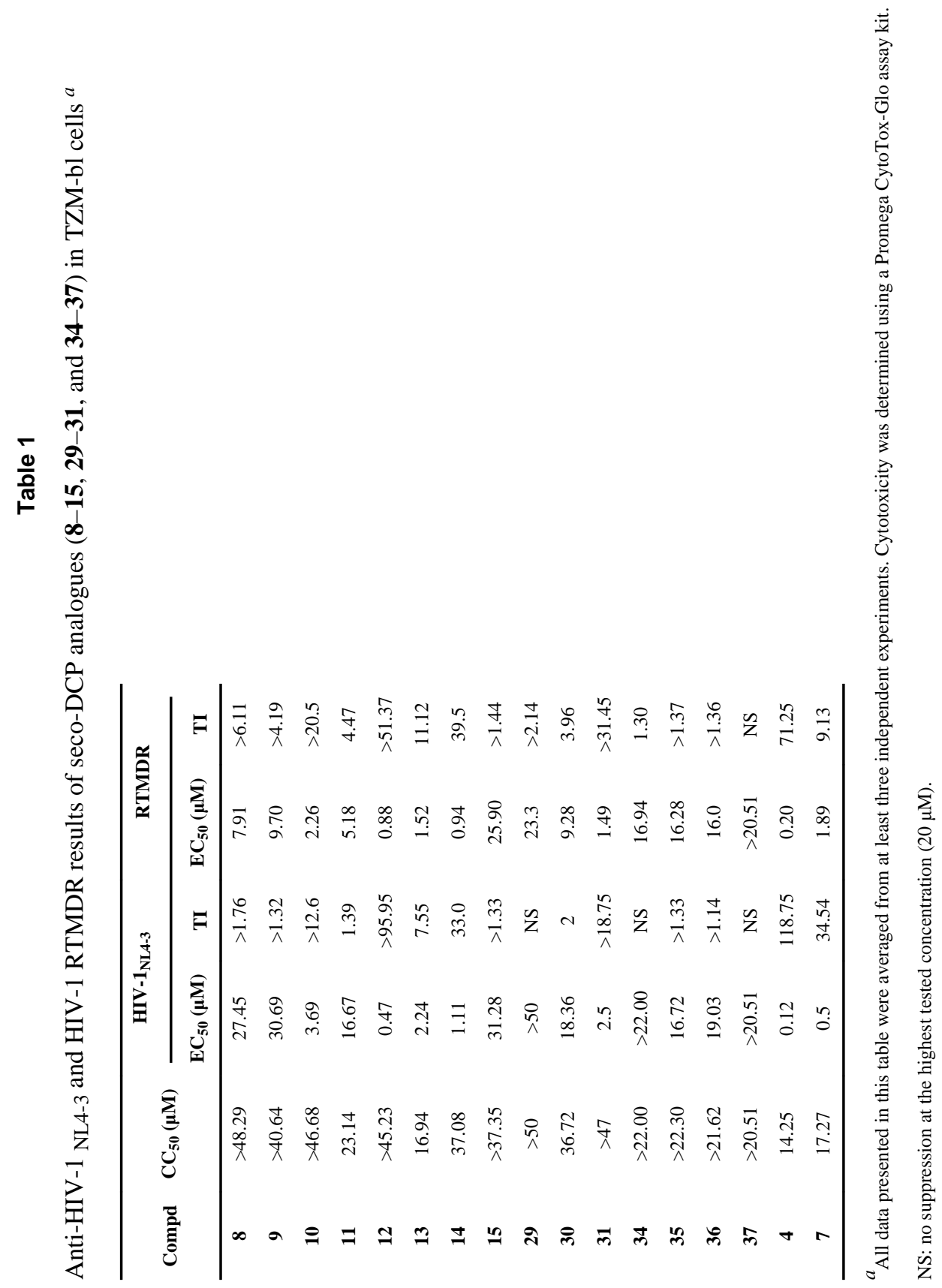

Eur J Med Chem. Author manuscript; available in PMC 2012 October 1. 
Table 2

Anti-HIV-1 NL4-3 data of seco-DCP and -DCK analogues (16-28, 32, and 33) in TZM-bl cells ${ }^{a}$

\begin{tabular}{|c|c|c|c|}
\hline \multirow{2}{*}{ Compd } & \multirow{2}{*}{$\mathrm{CC}_{50}(\mu \mathrm{M})$} & \multicolumn{2}{|c|}{ HIV-1 $1_{\text {NLA-3 }}$} \\
\hline & & $\mathrm{EC}_{50}(\mu \mathrm{M})$ & TI \\
\hline 16 & - & - & NS \\
\hline 17 & $>40.69$ & 11.00 & 3.70 \\
\hline 18 & $>40.69$ & 1.26 & 32.29 \\
\hline 19 & $>40.69$ & 1.93 & 21.08 \\
\hline 20 & & & NS \\
\hline 21 & $>38.79$ & 2.41 & $>16.09$ \\
\hline 22 & $>38.42$ & 1.63 & 23.57 \\
\hline 23 & $>36.46$ & 0.93 & 39.20 \\
\hline 24 & $>39.64$ & 1.92 & 20.65 \\
\hline 25 & $>36.32$ & 22.18 & 1.64 \\
\hline 26 & $>34.81$ & 18.45 & 1.87 \\
\hline 27 & - & - & NS \\
\hline 28 & - & - & NS \\
\hline 32 & 32.62 & 1.53 & 21.32 \\
\hline 33 & 6.3 & 0.56 & 11.25 \\
\hline 4 & 14.25 & 0.12 & 118.75 \\
\hline 7 & 17.27 & 0.5 & 34.54 \\
\hline
\end{tabular}

${ }^{a}$ All data presented in this table were averaged from at least three independent experiments. Cytotoxicity was determined using a Promega CytoTox-Glo ${ }^{\mathrm{TM}}$ assay kit. NS: no suppression at the highest tested concentration $(20 \mu \mathrm{M})$. 


\section{Table 3}

Chemical stability of 4-Me-DCK (2), seco-DCK (7), 1'-thia-seco-DCK (32), 2-ethyl-DCP (4), and seco-DCP (12) in acidic conditions ${ }^{a}$

\begin{tabular}{ccc}
\hline & \multicolumn{2}{c}{ Purity $($ area \%) } \\
\cline { 2 - 3 } & Reaction Time = 1 $\mathbf{~ m i n}$ & Reaction Time = $\mathbf{3 0}$ min \\
\hline $\mathbf{2}$ & $100 \%$ & $64 \%$ \\
$\mathbf{7}$ & $100 \%$ & $77 \%$ \\
$\mathbf{3 2}$ & $100 \%$ & $96 \%$ \\
$\mathbf{4}$ & $100 \%$ & $91 \%$ \\
$\mathbf{1 2}$ & $100 \%$ & $100 \%$ \\
\hline
\end{tabular}

${ }^{a}$ Condition: $1 \% \mathrm{HCl} / \mathrm{MeOH} / \mathrm{rt}$; Compound purity: peak area percentage by HPLC determination. 